\title{
HYDROLOGIC MODELING OF THE SAN JOAQUIN VALLEY WATERSHED FOR PURPOSES OF NITRATE ANALYSIS
}

\author{
A Thesis \\ presented to \\ the Faculty of California Polytechnic State University \\ San Luis Obispo
}

\author{
In Partial Fulfillment \\ of the Requirements for the Degree
}

Master of Science in Civil and Environmental Engineering

By

Stephen Clayton

March 2013 
(C)2012

Stephen Carl Clayton

\section{ALL RIGHTS RESERVED}




\section{COMMITTEE MEMBERSHIP}

TITLE

AUTHOR:

DATE SUBMITTED:

COMMITTEE CHAIR:

COMMITTEE MEMBER:

COMMITTEE MEMBER:
Hydrologic Modeling of the San Joaquin Valley Watershed for Purposes of Nitrate Analysis

Stephen Carl Clayton

February 2013
Misgana Muleta, Ph.D., Assistant Professor Civil and Environmental Engineering Department Cal Poly, San Luis Obispo

Tryg Lundquist, Ph.D., Associate Professor Civil and Environmental Engineering Department Cal Poly, San Luis Obispo

Shikha Rahman, Ph.D., Associate Professor Civil and Environmental Engineering Department Cal Poly, San Luis Obispo 


\author{
ABSTRACT \\ Hydrologic Modeling of the San Joaquin Valley \\ Watershed for Purposes of Nitrate Analysis
}

Stephen Clayton

The San Joaquin Valley is regarded as one of the most productive agricultural regions in the world. This extensive agriculture has, however, caused extensive pollution of both ground water and surface water. This thesis develops a hydrologic model of the surface and ground waters of the San Joaquin Valley. Such modeling is useful in the development and implementation of water quality regulations such as Total Maximum Daily Loads (TMDLs). A properly validated watershed simulation model can supplement data collection and can account for watershed characteristics including topography, soils, climate, land cover, anthropogenic activities, as well as simulate watershed responses including streamflow and contaminant concentration at detailed spatial and temporal scales. Models can be used as a decision support tool to manage complex agricultural watersheds such as the San Joaquin Valley. Once developed, such watershed simulation models can be used to identify contaminant source areas, locate hot-spot areas that have high pollution risk, identify optimal monitoring sites, and determine best management practices to cost-effectively reduce pollution. As a step towards developing a model as a decision making tool, the objective of this study is to appraise effectiveness of a widely used watershed simulation model known as Soil and Water Assessment Tool (SWAT) to simulate hydrology of the San Joaquin Valley watershed. For this thesis SWAT was successfully calibrated for streamflow at several locations in the watershed, thus demonstrating the capability of the model to represent the complex, snow-driven hydrology of the San Joaquin Valley watershed including dams and reservoirs located in the mountains, and agricultural activities and flow diversion systems in the valleys. Calibration of sediment and nitrate loadings in the surface waters were also attempted; the results were, however, less than convincing compared to stream flow calibration. Future studies are recommended to improve accuracy of the water quality predictions and to evaluate long-term effectiveness of various watershed management policies in improving surface water and groundwater quality in the San Joaquin Valley. The hydrology model developed in this study can be used as a foundation for future studies that focus on water quality. 


\section{ACKNOWLEDGEMENTS}

I'd like to thank Nigel Quinn and Darren Ficklin for their input and assistance with this thesis. I appreciate the time and effort they took in answering my questions. I'd like to thank Dr. Muleta for being the head of my Thesis committee and guiding me throughout the development of the Thesis and encouraging me throughout the calibration process. I would also like to thank Dr. Shikha Rahman and Dr. Tryg Lundquist for being on my Thesis Committee.

Lastly, for their constant support and encouragement which helped me more than they know, I thank my family. 


\section{TABLE OF CONTENTS}

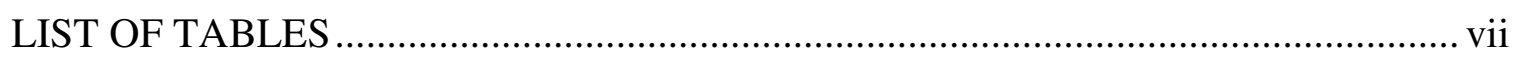

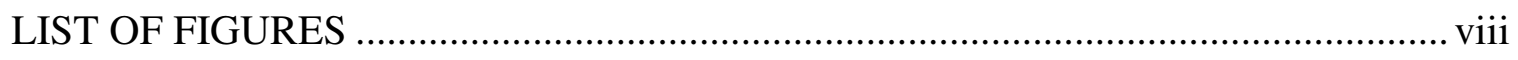

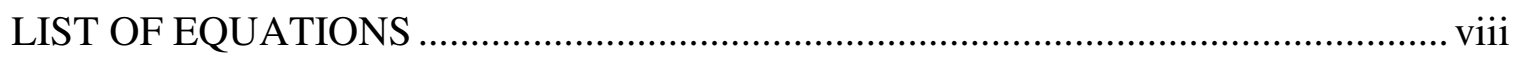

LIST OF COMMONLY USED ACRONYMS ....................................................... ix

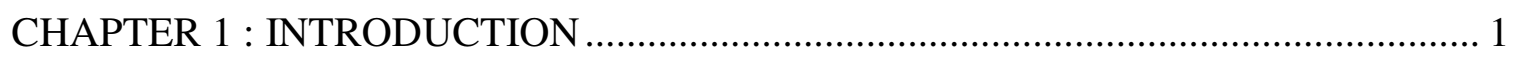

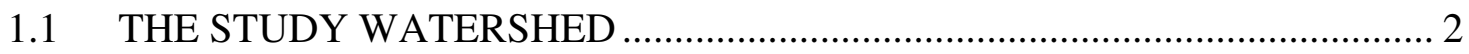

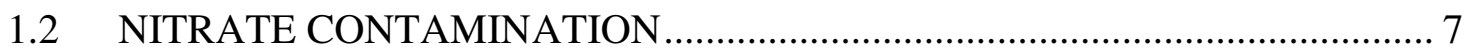

1.3 THE SOIL AND WATER ASSESSMENT TOOL (SWAT) …………….......... 9

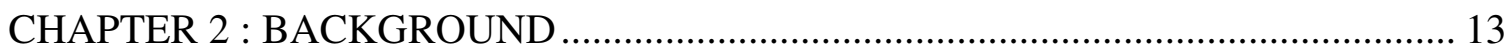

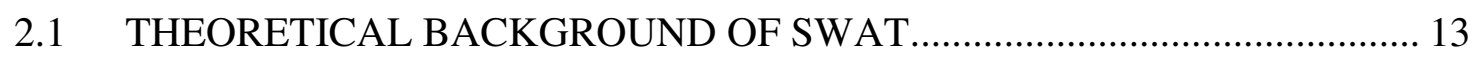

2.2 SAN JOAQUIN VALLEY WATERSHED ………........................................ 17

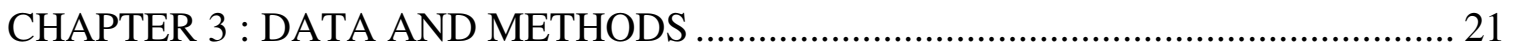

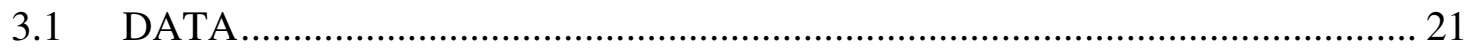

3.2 SENSITIVITY ANALYSIS AND MODEL CALIBRATION METHODS ..... 31

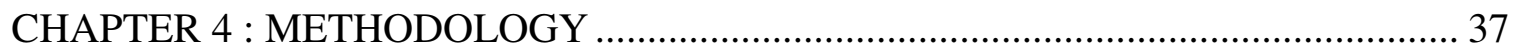

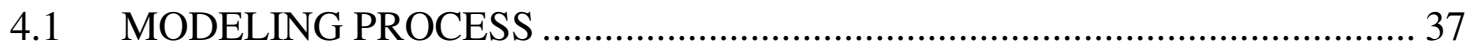

4.2 MODEL EVALUATION METHODS ....................................................... 41

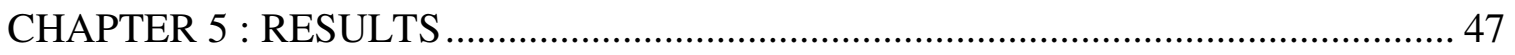

5.1 SUBBASINS AND HYDROLOGIC RESPONSE UNITS (HRUs) …............. 47

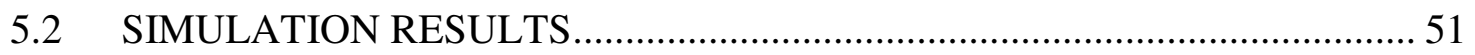

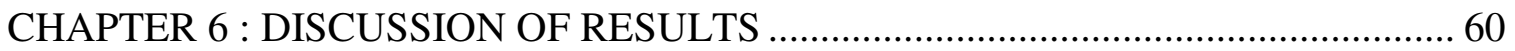

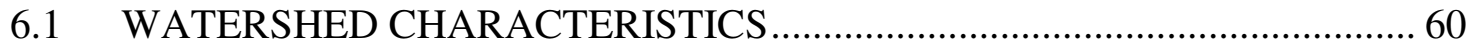

6.2 DISCUSSION OF MODEL EVALUATION RESULTS .................................. 62

CHAPTER 7 : CONCLUSIONS \& RECOMMENDATIONS …………………............ 70

CHAPTER 8 : BIBLIOGRAPHY \& ACKNOWLEDGEMENTS ................................... 75

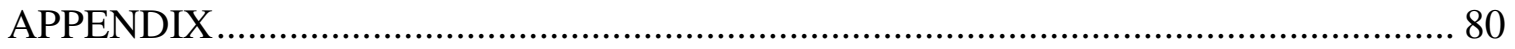




\section{LIST OF TABLES}

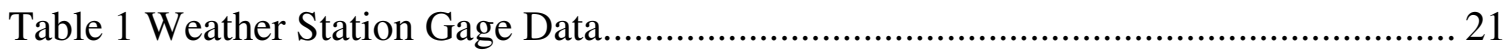

Table 2 Agriculture Layer Subdivision................................................................... 25

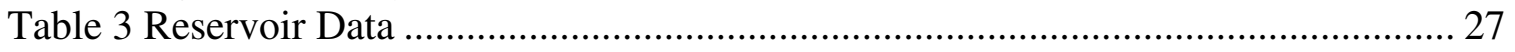

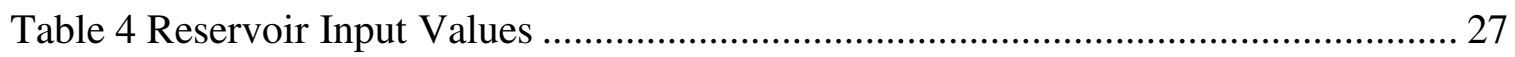

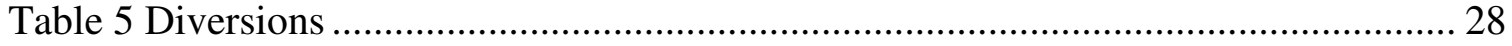

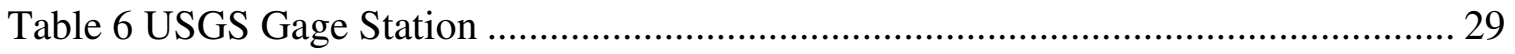

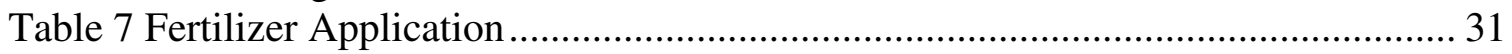

Table 8 Schedule of Sensitivity / Calibration / Validation ............................................ 46

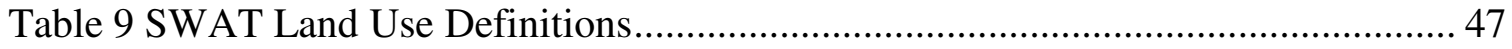

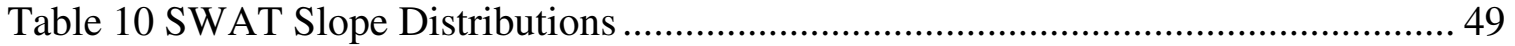

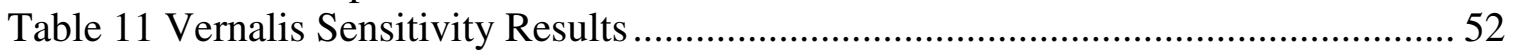

Table 12 Calibration Parameter Results ........................................................................ 54

Table 13 Calibration/Validation Efficiency Values: Results........................................ 56

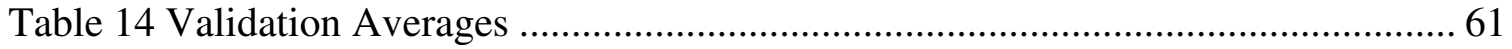

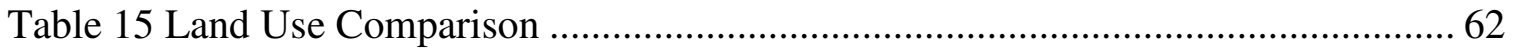

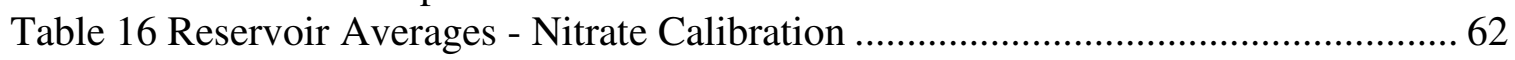

Table 17 Monthly Diversion Values .......................................................................... 80

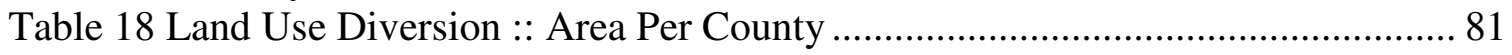

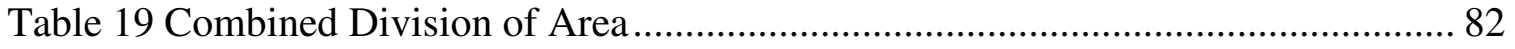

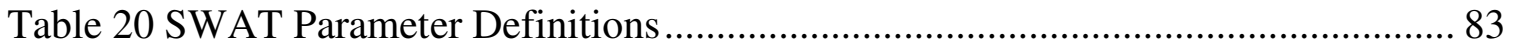

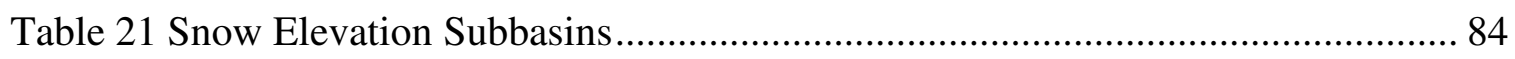




\section{LIST OF FIGURES}

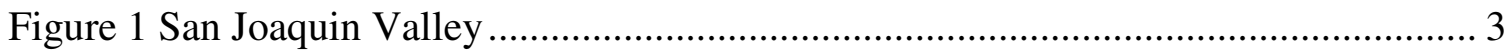

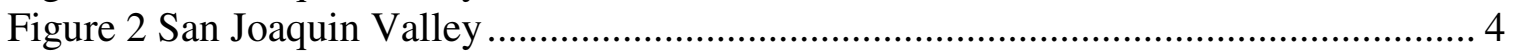

Figure 3 California Watersheds ........................................................................ 4

Figure 4 Schematic of Water Management in SWAT (Neitsch 2005a) ......................... 15

Figure 5 San Joaquin Watershed Station Data........................................................ 23

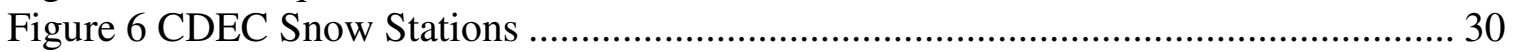

Figure 7 Upper Toulumne River Mask ................................................................ 42

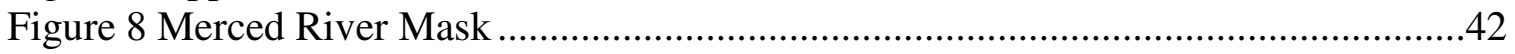

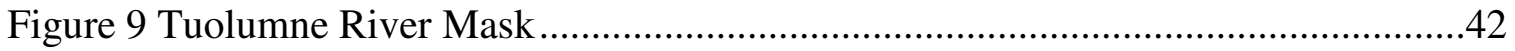

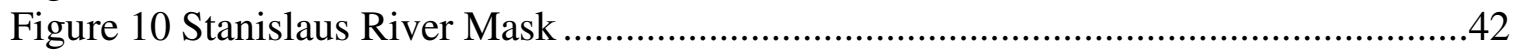

Figure 11 Orestimba River Mask.......................................................................42

Figure 12 Vernalis Outlet Model (no masks) ..............................................................42

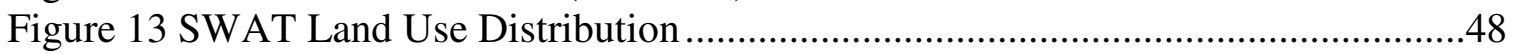

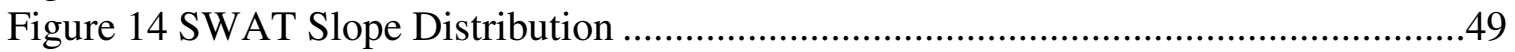

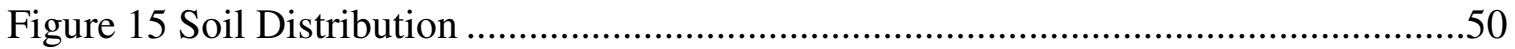

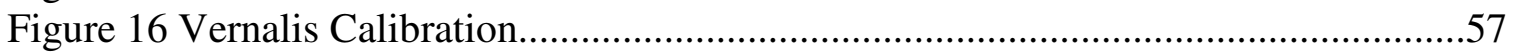

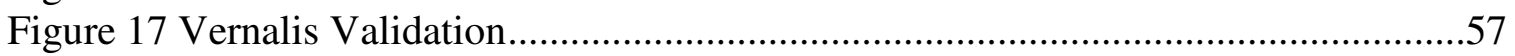

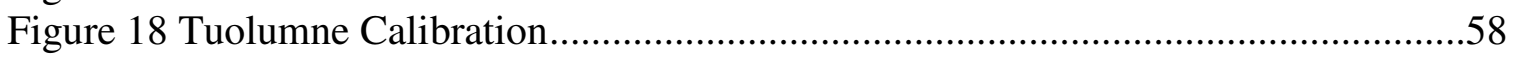

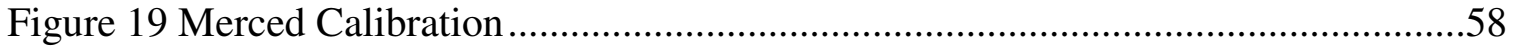

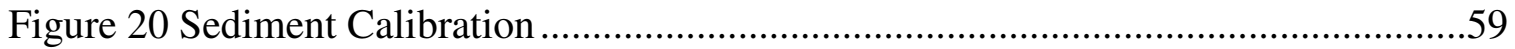

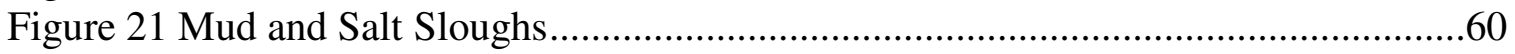




\section{LIST OF EQUATIONS}

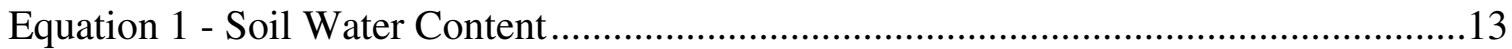

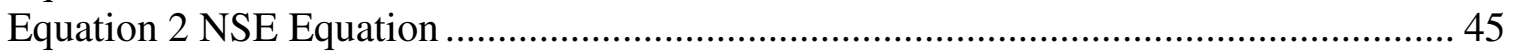




\section{LIST OF COMMONLY USED ACRONYMS}

ASABE

AWC

BMP

CVRWQCB

CDEC

CDHP

CIMIS

CVSC

DEM

DWR

EC

EPA

HRU

LH

NAD27

NAD88

NLCD

NPDES

NRCS

OAT

RDTC

RWQCB

SCE-UA

SJ

SJV

SJR

STATSGO

SWAT

SWE

SWRCB

TMDL

USDA

USGS
American Society of Agricultural and Biological Engineers

Available Water Capacity

Best Management Practice

Central Valley Regional Water Quality Control Board

California Data Exchange Center

California Department of Public Health

California Irrigation Management Information System

Central Valley Salinity Coalition

Digital Elevation Model

Department of Water Resources

Electroconductivity

Environmental Protection Agency

Hydrologic Response Units

Latin-Hypercube method

North American Datum 1927

North American Datum 1988

National Land Cover Dataset

National Pollutant Discharge Elimination System

Natural Resources Conservation Service

One-factor-At-a-Time

River Discharge Technical Committee

Regional Water Quality Control Board

Shuffled Complex Evolution Algorithm

San Joaquin

San Joaquin Valley

San Joaquin River

State Soil Geographic (database)

Soil and Water Assessment Tool

Snow Water Equivalent

State Water Resources Control Board

Total Maximum Daily Load

US Department of Agriculture

US Geological Survey 


\section{CHAPTER 1 : INTRODUCTION}

Engineering models are meant to provide a better understanding of natural phenomena and may provide predictions in a deterministic or probabilistic sense (Ritter 2001). Models simplify real life scenarios and situations. If used correctly, with the proper understanding of the utility as well as the flaws of modeling, they can sufficiently represent reality to justify decisions and formulate policies. In particular, hydrologic models try to represent hydrologic conditions through the use of physical laws and mechanistic approaches. Such models have been developed for research, management, and regulation for water resources engineering purposes.

Interest groups like the California Water and Environmental Modeling Forum (CWEMF) insist that the success of California's complex water system depends on how well the water community develops and uses data and models to address water management problems (CWEMF 2005). CWEMF also asserts that California's water problems have evolved over the recent decades because of greater and more diverse demands on California's water system. Even with the recent dry year, water disputes have arisen over reservoir water release, as shown in a recent news article concerning the Merced Irrigation District (Smith 2012). California water problems have also increased complexity based on more intricate water management, increased technical complexity of California's water management, and increasing demands and expectations for technical analysis (CWEMF 2005). Based on these emerging water problems, complex water modeling is also emerging as a tool to develop plans that corroborate between stakeholders, such as the basin plans developed by the CVRWQCB which partner with 
organizations. Consequently, continued investment in California's water system infrastructure means continued investment in Water Resource models.

\subsection{THE STUDY WATERSHED}

The San Joaquin Valley (SJV) is one of the world's most important agricultural areas, with more than 250 crops cultivated (Ritter 2001, Umbach 2002, Cowan 2005). In a 2005 San Joaquin (SJ) report, over 42\% of the market value of crops in California came from the SJV (Cowan 2005). The Agriculture industry in the San Joaquin Valley also takes a part in shaping policy issues such as labor, immigration, the environment, water supply, and land use (Cowan 2005).

It is important to distinguish between the San Joaquin Valley (SJV) from the San Joaquin River (SJR) basin. The SJV is a region in the California valley extending 250 miles from Stockton, in the north, to Bakersfield, in the south, and includes large sections of two major California watersheds: the Tulare Lake basin and San Joaquin River basin (Figure 1). Most statistical reports on the SJV are primarily derived from the eight main counties which comprise the SJV (Figure 2), counties from both the SJR and Tulare Lake Basins (Figure 3) (Umbach 2002, Cowan 2005, Baker 2005). The surface runoff of the San Joaquin River basin drains into the San Joaquin River and, eventually, the Sacramento Delta (Figure 2). The watershed study area of this thesis focuses on the San Joaquin River watershed and includes the non-agricultural Sierra Nevada mountainous region.

Agriculture plays an important role in the San Joaquin Valley. Land area in farms range from 45\% to $90 \%$ for SJ valley counties (Umbach 2002), and although farm land is continually encroached on by developing urban areas, agriculture will likely remain a central pillar of the economy for the foreseeable future (Cowan 2005). The SJ produces a 
range of agricultural crop types including citrus, field, truck, berry, and vineyard crops. Major crops include rice, fruits and nuts, tomatoes, sugar beets, corn, alfalfa, and wheat (Saleh 2007). Many stakeholders and shareholders have investments in the agriculture produced in the San Joaquin, including the San Joaquin Farm Bureau (http://www.sjfb.org/).

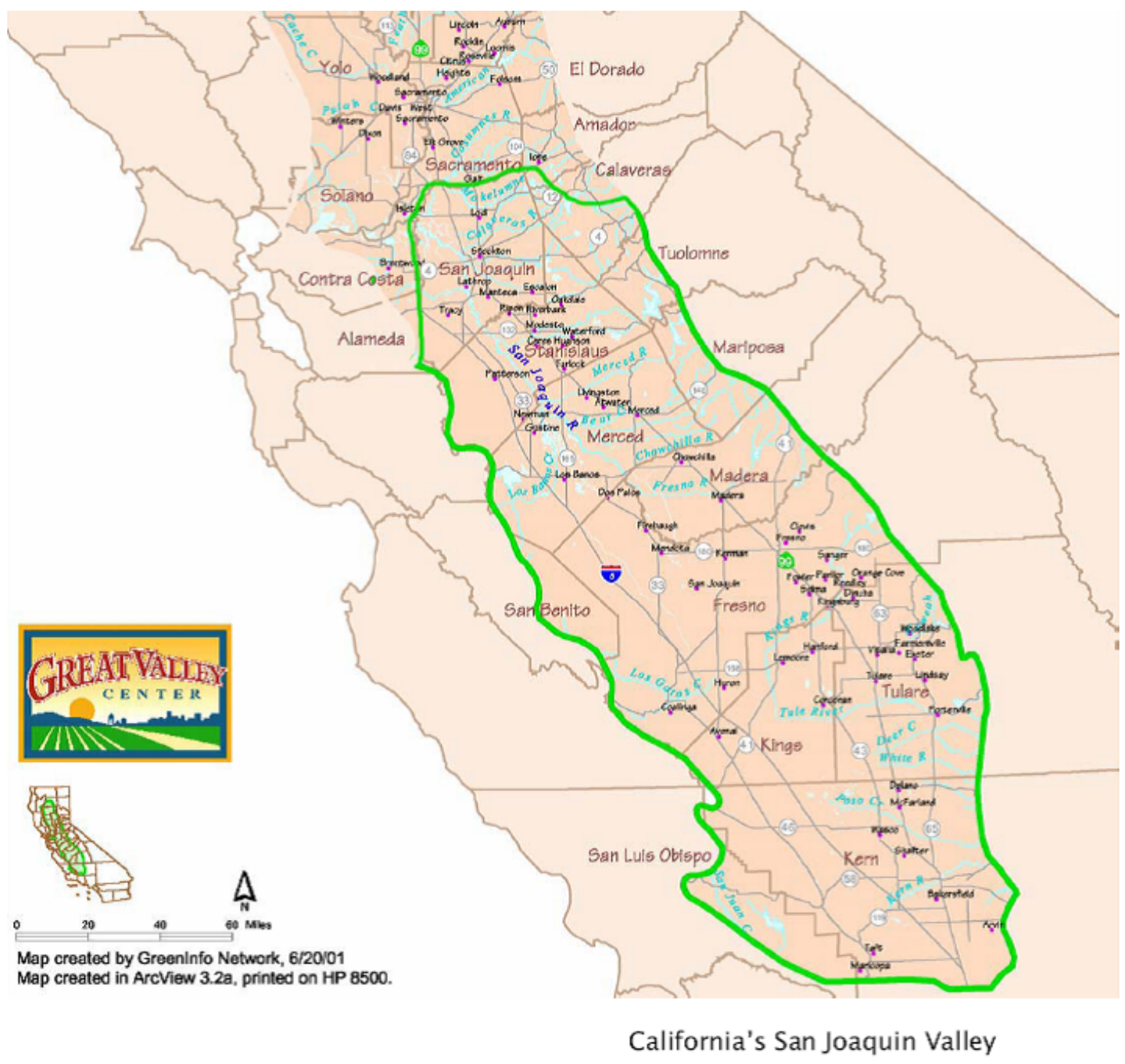

Figure 1 San Joaquin Valley 


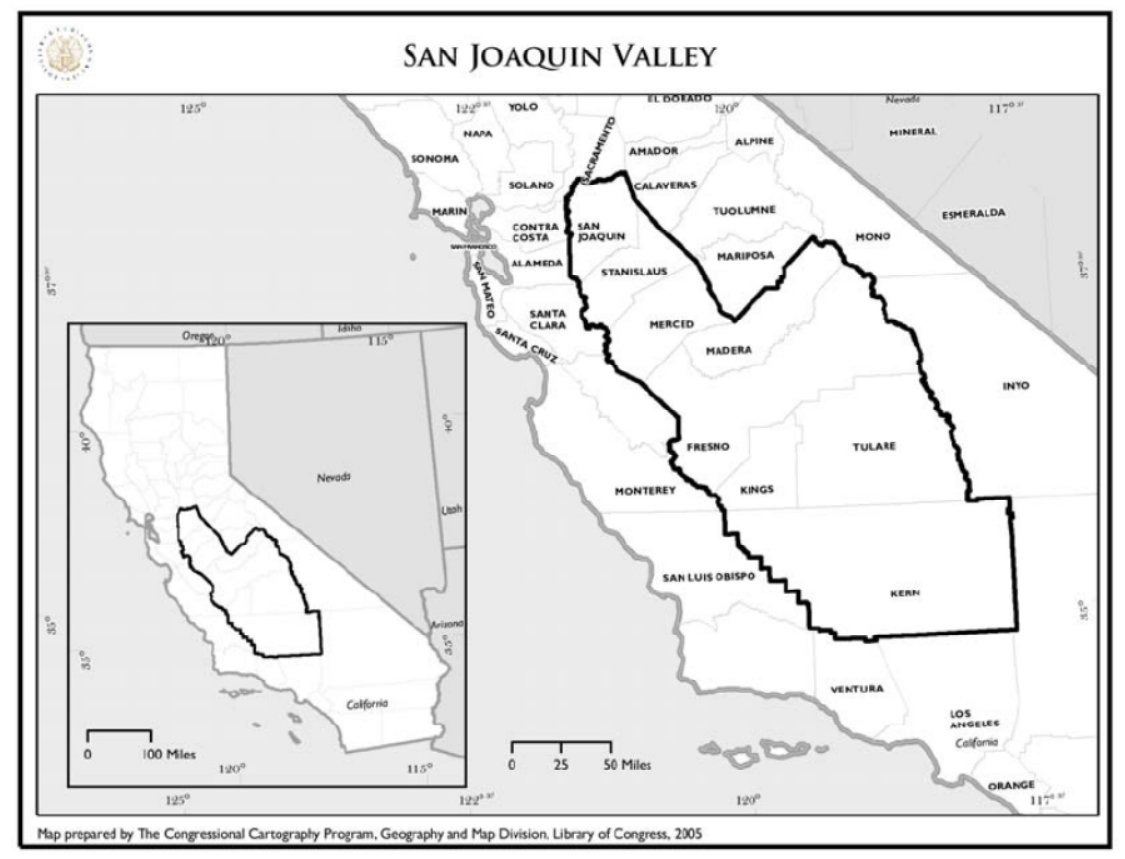

Figure 2 San Joaquin Valley

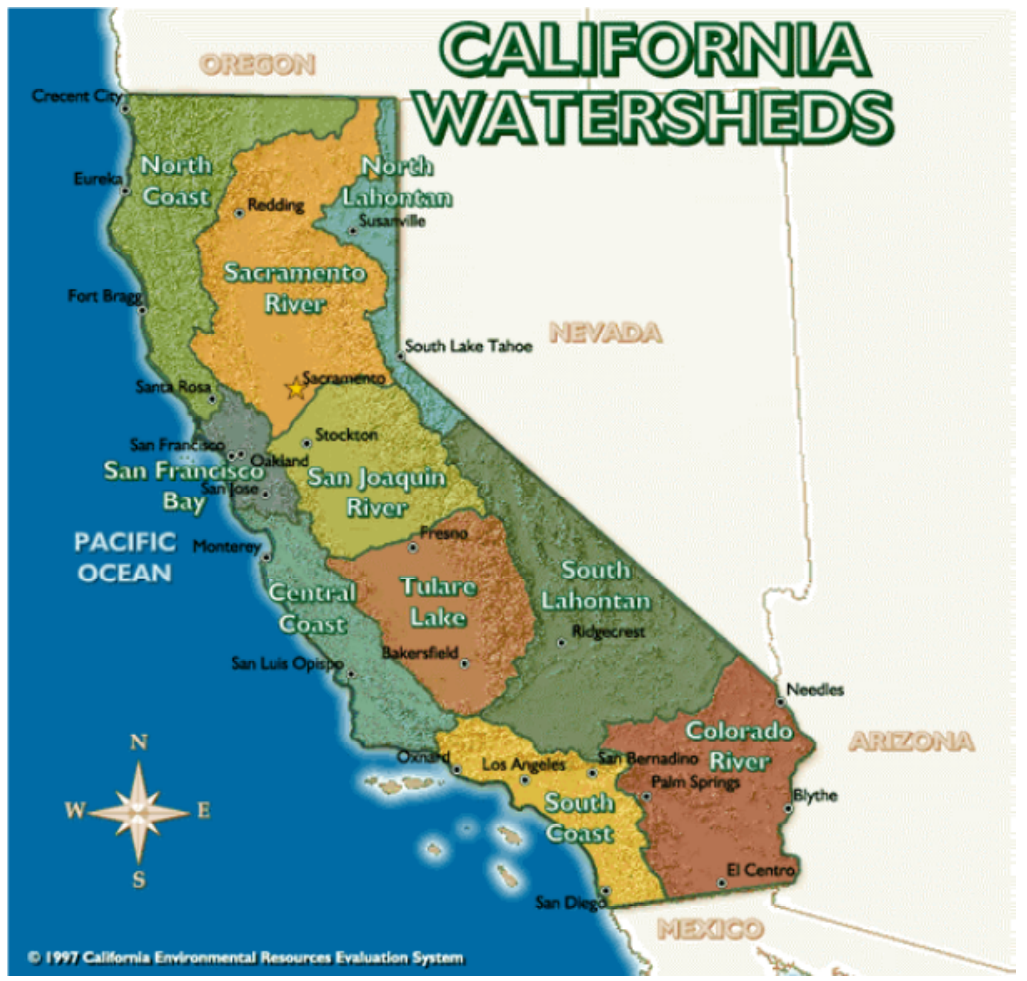

Figure 3 California Watersheds 
Without irrigation the commercial agriculture of the San Joaquin Valley (SJV), with its arid climate, would not be economical (RDTC 1999). In 2005, over $80 \%$ of the farms in the SJV were irrigated (Cowan 2005). Not only has this created water use/water rights issues, it has also garnered attention to runoff water quality.

For the entire valley region, several water quality concerns have emerged. Increased salinity in the lower San Joaquin River has been identified as one of the most serious water quality issues, with agricultural return flows from farmlands west of the San Joaquin River. Several state agencies and programs, like the San Joaquin Valley Drainage Program (SJVDP) and the Central Valley Salinity Coalition (CVSC), have been formed to address drainage issues. Another water quality problem, associated with lack of proper drainage in certain valley areas, has been accumulation of trace elements identified in waterfowl and aquatic organisms, including selenium and mercury, as well as elevated concentrations of arsenic, boron, molybdenum, and chromium in the valley region. This was especially poignant in the case of the 1981 Kesterson reservoir, where improper drainage led to the closure of the facility after adverse effects of selenium on wildlife was observed (SWRCB 1999). Increased pesticide contamination of both ground and surface water has also been detected by the United States Geological Survey (USGS), with some concentrations high enough to adversely affect aquatic life. Reduced concentrations of dissolved oxygen in the San Joaquin River and, subsequently, the Sacramento Delta, has also caused concern, prompting several Delta programs and Best Management Practices (BMP) efforts to increase the Dissolved Oxygen (DO) in the Sacramento channel, such as the CALFED Bay-Delta Program. Increased nitrate concentration in the groundwater is also a key concern for the long term sustainability of 
water quality in the SJ, which stems from fertilizers, manure, and septic systems. High nitrate levels violated drinking water standards in $25 \%$ of residential wells tested by the USGS (Cowan 2005).

Several public and private organizations have responsed to these water quality concerns for SJV and SJR. The California Department Water Resources (DWR) utilizes many organizations to implement various plans and policies for water monitoring and management. The Basin Plan developed for the SJ and Sacramento Rivers by the Water Board in 1975 is an ongoing effort to protect Central Valley water quality, incorporating 22 amendments since 1994 to meet clean water goals (CVRWQCB 2005). Parts of the Basin Plan include the National Pollutant Discharge Elimination System (NPDES) and Total Maximum Daily Loads (TMDLs). The NPDES is devoted to regulating municipal and industrial wastewater. TMDLs are loading restrictions on potentially harmful water quality constituents.

Several external stakeholders also assist in addressing water discharge quality issues. The SJR Real Time Water Quality Program from the DWR uses several monitoring stations to try to meet Vernalis Electroconductivity (EC) objectives by facilitating the control and timing of wetland and agricultural drainage. The Central Valley Salts Coalition (CVSC) and the Central Valley Clean Water Association are also examples of interested stakeholders in water quality of central valley water.

Stakeholders often use various models or programs studies on the SJV and SJR. These include the Watershed Analysis Risk Management Framework (WARMF) model by CVSC, the SWAT model, Quinn's Diversion model (Quinn 2002), and ESTIMATOR 
by the U.S. EPA (Saleh, 2007). The present thesis seeks to expand on these previous studies, particularly for the emerging issue of increasing nitrate concentrations.

\subsection{NITRATE CONTAMINATION}

Nitrogen is essential to plant nutrient uptake, for photosynthesis and synthesis of enzymes and proteins, and undergoes various processes in the soil, plants, and the atmosphere (Ritter 2001). Nitrogen is a highly reactive element, occurring in both mineral and organic compounds, forming within several oxidation states including the two mineral forms that are modeled in the SWAT program, nitrates (NO3) and nitrites (NO2). Nitrate is the most uptaken form of nitrogen by plant roots, and is therefore often applied as fertilizer to maximize crop yield. In the soil, the various processes of nitrogen are complex, as the nitrogen interacts with the soil, plants, water within the soil, microorganisms, and the atmosphere. The nitrogen cycle is the transformation between the various nitrogen forms within the soil, including the processes of nitrification, denitrification, volatization, mineralization, immobilization, and plant uptake.

Nitrate nitrogen is a water quality constituent that is a concern for agriculture. A recent 2011 Basin Plan summary includes efforts undertaken to control nitrates and salts by the Central Valley Water Board in conjunction with the Central Valley Salts Coalition (Creedon 2011). A 2012 study on groundwater in the Tulare Lake Basin stated that nitrate contamination is an urgent policy issue for California (Harter 2012).

Nitrogen is considered a water pollutant when in excess and is therefore regulated by the California Department of Public Health (CDHP) with a municipal supply well drinking standard of $45 \mathrm{mg} / \mathrm{L}$ as Nitrate, equal to the U.S. EPA Maximum Contaminant Level (MCL) of $10 \mathrm{mg} / \mathrm{L}$ as Nitrogen (Eldridge 2011). A high nitrate level in drinking water is particularly unsafe for infants, the elderly, and young animals in which the 
nitrate converts to nitrite in the digestive tract. Nitrite interferes with the oxygen carrying capacity of the blood, causing methemoglobinemia (also known as blue baby syndrome) (Ng et al. 2000). Nitrate intake is also linked to chronic conditions such as miscarriages, lymphoma, gastric cancer, hypertension, and thyroid disorder. Unsafe nitrate levels can also reduce livestock growth and reproduction, and affects fish reproduction (Eldrige 2011).

Nitrogen deposition can occur from various point and non-point sources, including animal manure, sewage and industrial point sources, soil organic matter, application of fertilizers, and even from atmospheric deposition. Point sources such as waste treatment facilities, power generation and manufacturing sites, or pipeline discharge, are sources of contaminants that can be readily identified with a site. Nonpoint sources like agricultural nutrient runoff due to fertilizers and pesticide, or urban runoff, cannot be traced back to a single source. Nonpoint source pollution depends on climatic factors, soil type, land management, and topography; consequently, these are the databases used by hydrologic models to model runoff quality (Ritter 2001). The Total Maximum Daily Load (TMDL) programs and the National Pollutant Discharge Elimination System (NPDES) program have been implemented by RWQCBs or by the U.S. EPA in order to target water contaminants from point sources and non-point sources. Specifically for TMDLs, enforcement comes when TMDLs are incorporated into Basin plans (water control plans). Controlling non-point source pollution is part of the effort to control water quality through TMDL programs, which rely on trade-offs between point and nonpoint pollutant control in order to achieve quality control (Cowan 2005). Best Management Practices (BMPs) and other conservation practices can help achieve TMDL 
goals in nonpoint source runoff water quality. BMPs can be applied to a watershed scale area, and their effectiveness can be projected or predicted through modeling.

BMP development is important for nitrate mitigation in the San Joaquin Valley.

For the San Joaquin River, fertilizer is the main source of nitrogen contribution, with manure being second (Jonas 2011). For other areas of intensively farmed and irrigated basins in central and southern California, a history of high nitrate concentration exists for the groundwater (Ritter, 2001). Over 200 municipal supply wells have been closed in Central Valley since 1980 because of nitrate levels exceeding the State's $45 \mathrm{mg} / \mathrm{l}$ drinking water standards (CVRWQCB, 2005). The San Joaquin Valley is the epicenter of the nitrate challenge, with $75 \%$ of nitrate exceedances in 2007 occuring in water systems located in the valley (Moore 2011). In a study on monitoring wells in the Modesto region, results indicated that if water practices and land use do not change, dispersion and continued downward movement of groundwater will continue to increase high concentrations of nitrates and uranium. The study also cited nitrate and uranium as the greatest threats to the long term sustainability of the groundwater resources of the study area and perhaps for other areas within the eastern San Joaquin Valley (Jurgens, 2008). A particular problem with nitrate contamination of groundwater is that the nitrate generally does not degrade. Nitrate contamination of groundwater is persistent. This water quality problem has solicited recent attention as a concern for small farming communities in Tulare County (Brown 2012).

\subsection{THE SOIL AND WATER ASSESSMENT TOOL (SWAT)}

The objective of this study is to develop a hydrologic computer model of the surface and ground waters of the San Joaquin Valley in order to be used for future studies 
that focus on water quality such as nitrate contamination. In order to properly model nutrient loading, a model must first be properly calibrated for streamflow and sediment loading.

The Soil and Water Assessment Tool (SWAT), an extension of the ArcGIS program, is a comprehensive continuous time based watershed scale computer model. The SWAT model is computationally efficient, representing modeling efforts under the direction of the United States Department of Agriculture (USDA) Agriculture Research Service (ARS). SWAT is used by the U.S. Environmental Protection Agency (U.S. EPA) in their Better Assessment Science Integrating Point and Nonpoint Sources (BASINS) software package, and has been assessed by over 250 peer-reviewed published articles (Gassman 2007). SWAT is capable of simulating weather, hydrology, soil processes, nutrient transport, and land management. Due to these comprehensive capabilities, the SWAT program was chosen as the modeling program to be used in this thesis research on the SJV.

The SWAT model has been developed for nearly 30 years from a collection of previous models in order to incorporate a pesticide component, a daily rainfall hydrology component, and a crop growth component into one model. Since the creation of the SWAT model in the early 1990's, it has continued to be developed through revisions, including the SWAT 2005 version and, recently, the SWAT 2009 edition. Model refinement is an ongoing process, however, and although SWAT has established its reliability, both nationally and internationally, there is still room for further model validations, recommendations, and improvements. This model evolution will continue as users incorporate advancements in scientific knowledge, provide new functionality that 
will expand the SWAT simulation domain, or enable more accurate simulations of currently supported processes (Gassman 2007). As SWAT is an open source code and encourages ongoing collaboration with scientists, it has developed through revisions and peer review and will continue to do so.

SWAT is especially well suited for agricultural watersheds. It is capable of evaluating land management practices within a watershed and performing an analysis of water, sediment, and agricultural chemical yields. Through these analyses, SWAT supports Total Maximum Daily Load (TDML) evaluations and has proven to be an effective method of evaluating alternative land use, Best Management Practices (BMPs), and other factors on pollutant losses (Gassman 2007). Continued investment in SWAT validation for these different management practices requires proper modeling analysis in a way that builds stakeholder trust in model validation.

Once stakeholder trust is established, the SWAT program can help decision makers form policies for the water community. This requires explicit involvement from interest groups and diverse expertise. Model reliability depends on the model's adherence to implicit modeling protocols and guidelines. Although many guidelines are 'implicit', meaning that they are intuitive, there are also general modeling standards, such as those suggested by public interest groups like the Central Valley Salinity Coalition (CVSC). Following these guidelines can help improve model legitimacy, model accuracy, and confidence placed in the model from stakeholders and technical staff (Quinn 2005). Basic steps include proper problem identification, well defined model objectives, model formulation, model calibration, model validation, and proper model documentation, as well as recorded model results. 
Proper problem identification is the natural first step; for my thesis, further validation for SWAT, particularly for nitrates and for a large area like the San Joaquin River basin, is important for research and for the future development of models to address nonpoint pollution analysis and Best Management Practice (BMP) implementation. The next step is to define model objectives; for this model, the basic objective of validating the model for SWAT is split into the three stages of calibration and validation for flow, sediment, and nutrients. Results depend on a comparison of model outputs to available information from existing studies on the San Joaquin River, particularly for flow and nutrients. A discussion of these results is necessary to draw conclusions based on the model, from which continued research or use of the study results can be used.

SWAT has already been studied as a method of modeling nitrate (Stewart et al. 2006, Chaplot et al. 2004, Bracmort et al. 2006, Gassman 2007), but not for the San Joaquin watershed. This study will focus on the validation of a model that is covering a vast area size and tries to include various processes and parameter optimizations provided in SWAT. Larger, more comprehensive models (like the San Joaquin) need to run in comprehensive models like SWAT in order to have evaluate TMDL's and BMPs in the watershed without generalizing the subbasin processes within that watershed. 


\section{CHAPTER 2 : BACKGROUND}

\subsection{THEORETICAL BACKGROUND OF SWAT}

The Soil and Water Assessment Tool (SWAT) model is a continuous time based river basin model extension of ArcGIS, which is able to conduct a comprehensive study of an entire watershed. The model is physically based, computationally efficient, and capable of continuous simulation over long time periods; it can project weather conditions over a long range of time and analyze seasonal effects while taking into account peak flows. The model is also capable of examining the interactions of several parameters at once, including topography, land use, soil type, bacteria and pathogens, land management, and various weather parameters. SWAT is also capable of being coupled with other models, or modified to better fit a region (Gassman 2007). The hydrologic and hydraulic components important for the San Joaquin River model include methods for a hydrologic water budget, hydraulic river routing, reservoir simulation, diversion simulation, and snow bank simulation.

Equation 1 Soil Water Content

$$
\begin{aligned}
& S W_{t}=S W_{0}+\sum_{i=1}^{t}\left(R_{\text {day }}-Q_{\text {surf }}-E_{a}-w_{\text {sepp }}-Q_{\text {gw }}\right) \\
& \text { where } \\
& \qquad \begin{aligned}
S W_{t} & =\text { soil water content at time } t ; \\
\mathrm{SW}_{0} & =\text { initial soil water content; } \\
t & =\text { time (in days); } \\
R_{d a y} & =\text { amount of precipitation on day } i ; \\
Q_{\text {staf }} & =\text { amount of surface runoff on day } i ; \\
E_{a}= & \text { amount of evapotranspiration on day } i ; \\
W_{\text {seep }} & =\text { water percolation to the bottom of the soil } \\
Q_{g w} & =\text { amount of water returning to the ground }
\end{aligned} \\
& \quad \text { water on day } i .
\end{aligned}
$$


A comprehensive water budget is important for an hydrologic analysis of a watershed which can accurately account for various processes of water. SWAT generates hydrology outputs for each subbasin by using Equation 1. SWAT accounts for several hydrologic processes including precipitation, surface runoff, evapotranspiration (ET), recharge, and soil water storage. Each hydrologic process is determined through the input of observed data and parameter calibration. SWAT uses the Soil Conservation Service (SCS) curve number (CN) equation for surface runoff, which is determined for each subbasin by the land use and soil layer. If the soil and land use properties are generalized over too large an area, the model may run the risk of inaccuracy due to overgeneralization.

Snow plays a crucial role in the hydrologic cycle when modeling a snowy mountainous region like the Sierra Nevada mountain range. Precipitation in these mountainous climates is typically greater than their neighboring plains and basins, accumulating as snow during the fall and winter and falling and contributing to runoff through snowmelt during the spring and summer. There are two methods normally applied in order to model snowmelt: the energy budget method and the temperature index method. SWAT snow modeling is based on the temperature index method, which uses readily available temperature values. Part of the method employed by SWAT to simulate snowfall includes elevation bands, up to ten per subbasin, which allows for a more orographic representation of the watershed. Based on the percentage of area within each elevation band, the precipitation gage and temperature gage data are adjusted per subbasin. Also, the accumulation, sublimation, and melting of snow is modeled separately for each elevation band (Neitsch 2005a). 


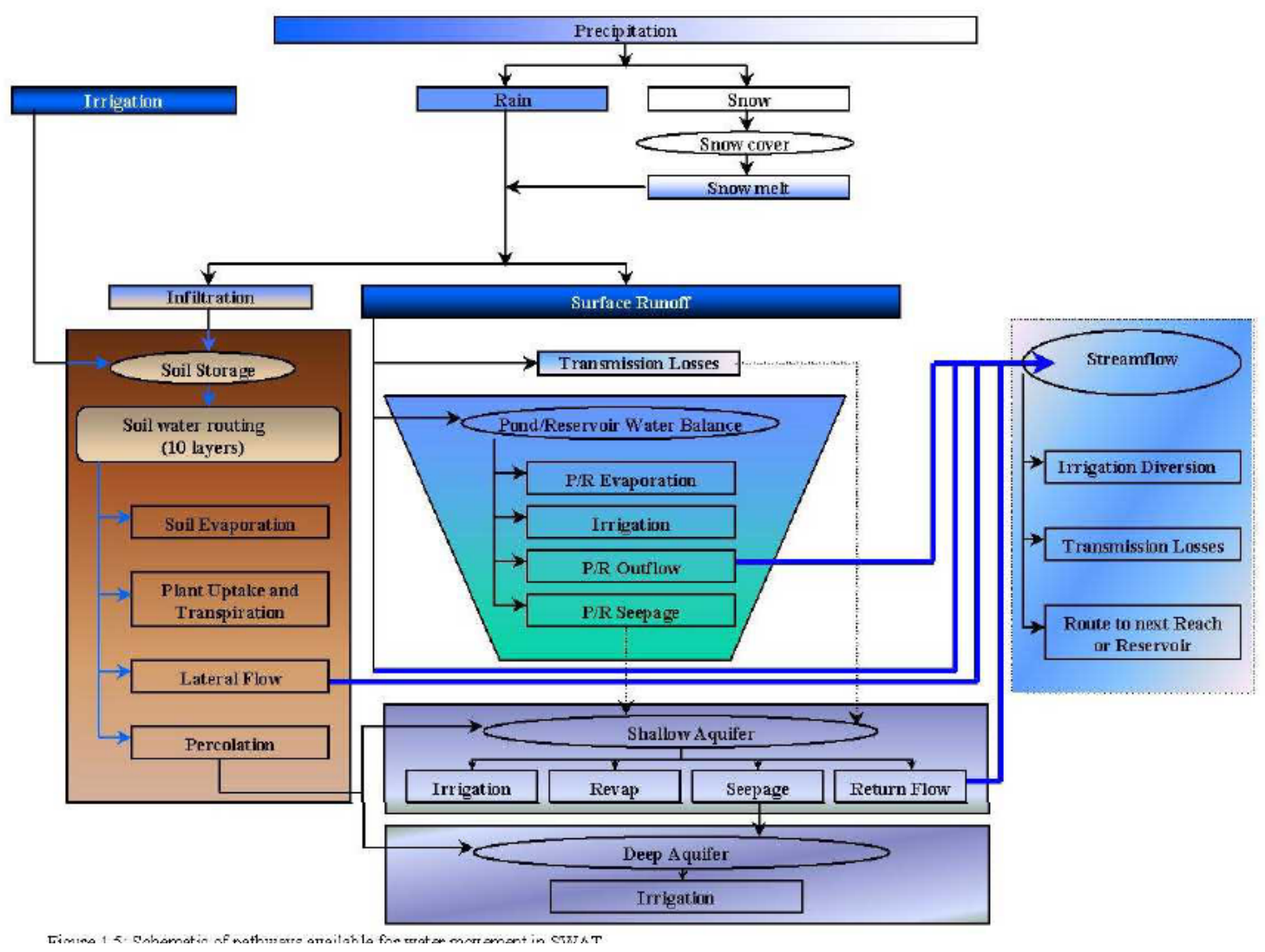

Figure 4 Schematic of Water Management in SWAT (Neitsch 2005a)

Figure 4 graphically represents the hydrologic balance equation, of which reservoirs play an important role. Reservoirs fall under one of the four categories of "impoundments" which SWAT models; the other three types of impoundments are ponds, wetlands, and depressions/potholes. Reservoirs are located on the main channel network, receive water from all subbasins upstream of the water body, and play an important role of water supply and flood control (Neitsch 2005a). In a spatial representation of the watershed, the reservoir would be located before the subbasin outlet, effectively retaining or routing streamflow. This suggests a flawed model representation if the reservoir location is not actually physically located near the outlet of the subbasin but further upstream. Nitrates in the simulation would potentially be retained by the 
reservoir instead of being routed to the outlet as surface runoff. The effects of Reservoirs on the San Joaquin model are further discussed in Section 6.1.

Water is routed using the variable storage routing method or the Muskingum river routing method, variations of the kinematic wave model. Channel characteristics include a trapezoidal shaped channel with a floodplain for when the volume of water exceeds the channel cross section area. Manning's equation is used in the Muskingum river routing method, and SWAT uses three parameters, the channel width at top of bank, depth of water in channel when filled to bank, and length of main channel.

SWAT simplifies and models the complexity of the nitrogen cycle in the water, atmosphere, and soil, including the soil profile and the shallow aquifer. Several components of nitrogen nutrient transport include nitrate movement, organic $\mathrm{N}$ in surface runoff, and nutrient lag in surface runoff and lateral flow (Neitsch 2005b). The nutrient transport processes determine the natural transport of nutrients from land areas into streams and water bodies due to soil erosion and weathering. Eventually, nutrient outflow including nitrates and nitrites are simulated at the outlets of each subbasin and the outlet of the entire watershed, which can then be compared with observed data.

There are two main conditions for nitrate leaching: appreciable levels of nitrate in the soil, and sufficient downward movement of water. Subsequently, the two main methods of nitrate mitigation include controlled nitrate application and uptake, and reduced irrigation. Many possible methods for model representation of these two methods of nitrate mitigation exist. Commonly, certain BMP's can be represented with different parameter changes; contour farming, for example, can be represented with variation of two SWAT parameters, the SCS Curve Number and the USLE practice factor. Other 
conservation practices, such as parallel terraces, crop rotation, cover crops, filter strips, etc., can be similarly analyzed by modifying SWAT parameters (Arabi 2008). These applications which effect irrigation runoff will also invariably affect nutrient runoff. For direct parameter changes to nitrate application, changing the SWAT crop database, which specifies the amount and time period of fertilizer application, is one option of directly controlling nitrate application in the program. Parameters such as the nitrogen percolation coefficient and the initial nitrate concentration are calibrated to produce accurate nitrate outflow values; changing these parameters after initial calibration is also a method of modeling nitrate mitigation.

\subsection{SAN JOAQUIN VALLEY WATERSHED}

The San Joaquin Valley is described as a gently sloping alluvial plain about 400 $\mathrm{km}$ long and an average of $74 \mathrm{~km}$ wide (Ritter 2001). The San Joaquin River drains a watershed approximately $35,000 \mathrm{~km}^{\wedge} 2$ (RDTC 1999), although the model in SWAT is measured at $34,323 \mathrm{~km}^{\wedge} 2$. This area is divided into the three physiographic provinces of central California; the valley region, the coastal mountain region, and the Sierra Nevada region. The land surface altitude of the valley rises from near sea level to about $300 \mathrm{~m}$ in the southeastern part of the basin. The study area lies within Latitude $36^{\circ} 30^{\prime} \mathrm{N}$ to $38^{\circ} 50^{\prime} \mathrm{N}$ and Longitude $119^{\circ} 45^{\prime} \mathrm{W}$ to $121^{\circ} 30^{\prime} \mathrm{W}$. The valley counties include San Joaquin, Stanislaus, Merced, Madera, and Fresno, while the mountainous counties include Amador, Calaveras, Tuolumne, and Mariposa. The largest cities are Fresno, Bakersfield, Modesto, and Stockton (CERES 2012).

The valley is lined on the East by the eastern Sierra Nevada ranges. The western costal valley is less rugged and lower in altitude and separates the Central Valley from 
the Pacific Ocean. The crest is generally less than 4,000 feet in elevation, except at the northern end (United States, 1949).

Much of the native grassland, woodland, and wetland in the SJV has been converted to farmland, to take advantage of the ample agricultural opportunities (CERES 2005). Since the San Joaquin is now one of the most important agricultural resources in the United States, the concern for agricultural sustainability has led to many studies. The San Joaquin Valley has been studied for nitrate concerns, sediment concerns, salinity concerns, as well as environmental effects on the delta. This includes dissolved oxygen and the effect on aquatic wildlife in the Delta.

The San Joaquin Valley has a typical Mediterranean climate, with warm and dry summers consisting of long sunny days and moderate winters consisting of moist and foggy days (CERES 2005, United States 1949). Traveling from the north to the south, temperature increases and the rainfall decreases. The mean annual rainfall throughout the central valley ranges from about 5 inches in the south to 15 inches in the north, with great variations from year to year. The growing season is typically long, with a frost free period from about the first of March to the middle of November. Sunshine during the summer months average about 95 percent of the possible.

Snow melt plays an enormous role in the watershed hydrology, more important than direct precipitation in the watershed's hydrologic budget. Summer droughts in the valley are caused by a subtropical high air pressure belt off of the coast which prevents summer rainfall. In the winter, this pressure belt moves southward, allowing storms which originate over the Pacific Ocean to move inward, depositing their water on the Sierra mountains and, to a lesser degree, the valley. A mean annual precipitation between 
50 and 90 inches of precipitation falls on the Sierra Nevadas, the greater part in the form of snow. These snow banks last long into the summer and their melt runoff contributes to the stream flow during the low-water season. The peak streamflow occurs in April, May, and June (United States 1949).

Soils also play an important role in the hydrologic simulation of a watershed.

Infiltration and percolation, where water seeps into the soil and becomes groundwater, is a fundamental part of the hydrologic water budget. Soils in the San Joaquin differ slightly from region to region, particularly between the west of the SJR and the east of the SJR, the differences of which are represented by the model through the STATSGO soil layer database. Overall, the sediments of the SJV consist of interlayered gravel, sand, silt, and clay, deposited in alluvial fans, flood plains, flood basins, and lacustrine and marsh environments. The contrast between the sediments on the eastern and western sides of the SJR and the mountain ranges they are derived from are an important part of the soil properties of the valley (Saleh 2007).

Soils on the east side of the valley are derived from the granitic, intrusive parent material of the Sierra Nevada Mountains and contain few soluble salts and trace elements. These soils are typically coarser-textured and have fewer water-restricting clay layers and low Total Organic Carbon (TOC) concentrations. (WSTB 1989, Ritter 2001, Saleh 2007). 
In contrast, the west side soils, derived from the layers of metasedimentary rocks and marine and continental sediments of the Coastal Range, contain salts and trace elements which are typically found in marine sediments. Confining clay layers underlie these east side soils, inhibiting deep infiltration of irrigation waters. Thus salt and trace element problems developed when outside irrigation was introduced and the water level rose, developing a high saline water table extending up into the root zone. 


\section{CHAPTER 3 : DATA AND METHODS}

\subsection{DATA}

\section{CLIMATE DATA}

Weather station data for the San Joaquin included daily data for precipitation, maximum and minimum temperature, relative humidity, and wind speed, as shown in Table 1. The California Irrigation Management Information Systems (CIMIS) website provided four weather stations extending along the Central Valley, shown in blue in figure 5. The California Data Exchange Center (CDEC) provided tables of data for the three temperature stations and three precipitation stations used for the snowy Sierra Nevada region, shown in green in figure 5. The stations used various weather collection devices for each gauge, including a Fenwall Thermistor/HUMICAP H-sensor (temperature, relative humidity), anemometer (wind speed), and tipping-bucket rain gauge (precipitation). Each of these tables was formatted using excel and access in order to be recognized by the SWAT program. Table 1 Weather Station Gage Data

WEATHER STATION GAGE DATA

\begin{tabular}{ccccccccl}
\hline \hline $\begin{array}{c}\text { Sta. } \\
\text { ID }\end{array}$ & Latitude & Longitude & $\begin{array}{c}\text { Elev } \\
\text { (ft) }\end{array}$ & Pcp & Temp & $\begin{array}{c}\text { Rel } \\
\text { Hum }\end{array}$ & $\begin{array}{c}\text { Wnd } \\
\text { Spd }\end{array}$ & Description \\
\hline 71 & $37^{\circ} 38^{\prime} 43^{\prime \prime}$ & $121^{\circ} 11^{\prime} 16^{\prime \prime}$ & 35 & $\mathrm{X}$ & $\mathrm{X}$ & $\mathrm{X}$ & $\mathrm{X}$ & Modesto \\
80 & $36^{\circ} 49^{\prime} 15^{\prime \prime}$ & $119^{\circ} 44^{\prime} 31^{\prime \prime}$ & 339 & $\mathrm{X}$ & $\mathrm{X}$ & $\mathrm{X}$ & $\mathrm{X}$ & Fresno State \\
92 & $37^{\circ} 13^{\prime} 55^{\prime \prime}$ & $120^{\circ} 52^{\prime} 5^{\prime \prime}$ & 75 & $\mathrm{X}$ & $\mathrm{X}$ & $\mathrm{X}$ & $\mathrm{X}$ & Kesterson \\
56 & $37^{\circ} 05^{\prime} 36^{\prime \prime}$ & $120^{\circ} 45^{\prime} 39^{\prime \prime}$ & 95 & $\mathrm{X}$ & $\mathrm{X}$ & $\mathrm{X}$ & $\mathrm{X}$ & Los Banos \\
MCF & $37^{\circ} 24^{\prime} 36^{\prime \prime}$ & $119^{\circ} 45^{\prime} 54^{\prime \prime}$ & 3300 & & $\mathrm{X}$ & & & Metcalf Gap \\
GRN & $37^{\circ} 49^{\prime} 59^{\prime \prime}$ & $120^{\circ} 30^{\prime} 00^{\prime \prime}$ & 1020 & & $\mathrm{X}$ & & & Green Springs \\
DAN & $37^{\circ} 53^{\prime} 49^{\prime \prime}$ & $119^{\circ} 15^{\prime} 25^{\prime \prime}$ & 9800 & & $\mathrm{X}$ & & & Dana Meadows \\
MCN & $37^{\circ} 49^{\prime} 12^{\prime \prime} \mathrm{N}$ & $120^{\circ} 18^{\prime} 00^{\prime \prime} \mathrm{W}$ & 938 & $\mathrm{X}$ & & & & Moccasin \\
& & & & & & & South Entrance \\
SEY & $37^{\circ} 30^{\prime} 0^{\prime \prime} \mathrm{N}$ & $119^{\circ} 38^{\prime} 00^{\prime \prime} \mathrm{W}$ & 5120 & $\mathrm{X}$ & & & & Yose. \\
& & & & & & & & Tuolumne \\
TUM & $37^{\circ} 52^{\prime} 23^{\prime \prime} \mathrm{N}$ & $119^{\circ} 21^{\prime} 00^{\prime \prime} \mathrm{W}$ & 8600 & $\mathrm{X}$ & & & & Meadows
\end{tabular}

Mountainous weather station daily maximum and minimum temperatures (from the CDEC) were calculated from hourly temperatures. For missing values, the average max/min 
values from days before and after were used. For longer periods of missing data, averages from years before and after for the same range were used so that each set of temperature ranges contained complete data. Similar methods were employed for precipitation stations from the CDEC. Database format for each weather station file followed the format given by Winchell 2009.

Figure 5 shows an outline of the San Joaquin River watershed with the stations labeled. The pink labels are the river gage locations, the yellow labels are the reservoir locations, the blue labels are the CIMIS weather stations, and the green labels are the CDEC weather stations. 


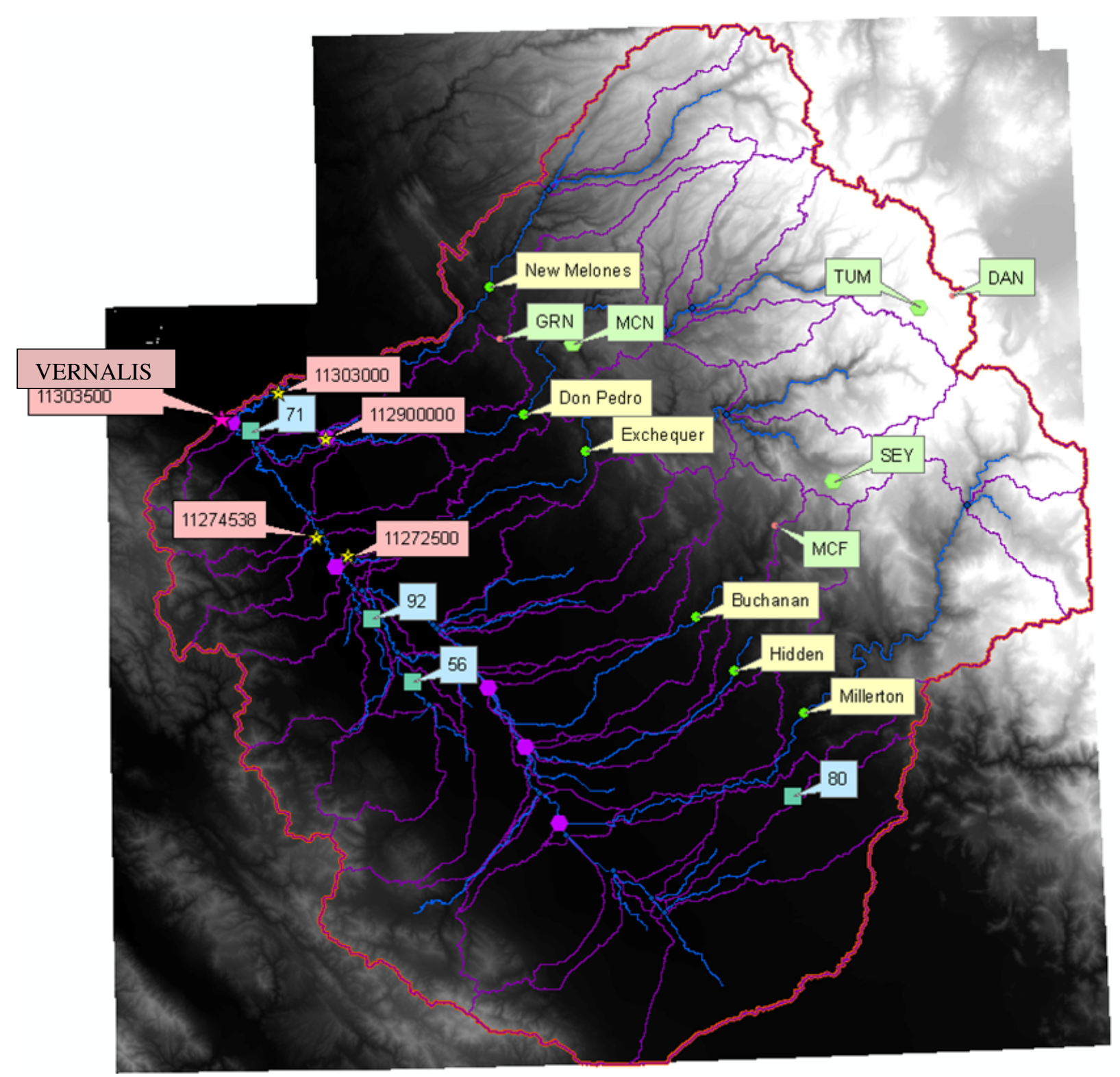

Figure 5 San Joaquin Watershed Station Data

\section{TOPOGRAPHY, SOIL, AND LAND COVER DATA}

Several mapping databases were necessary for the SWAT model to simulate hydrology. All mapping databases were downloaded and then edited to fit within latitude $38^{\circ} 20^{\prime} 00^{\prime \prime} \mathrm{N}$ and $36^{\circ} 15^{\prime} 00^{\prime \prime} \mathrm{N}$ and longitude $119^{\circ} 00^{\prime} 00^{\prime \prime} \mathrm{W}$ and $121^{\circ} 35^{\prime} 00^{\prime \prime}$ via the ArcGIS "clipping" tool. The ArcGIS transformation and projection tools were also used to project the databases and uniformly transform the horizontal data to NAD27. 
The USGS seamless viewer website provided the land use database used, labeled National Land Cover Dataset 2006 (NLCD 2006). Original horizontal datum format and projection were the NAD83 and Albers Conical Equal Area. The 21 classes of land cover in the NLCD represent the conterminous U.S., and included an agricultural layer "AGRR" which broadly represents agricultural land row crops. For more specific agricultural crop representation for the mainly agricultural San Joaquin valley floor, land use crop data was used to further subdivide the AGRR layer into more specific crop types which corresponded to the agricultural layers included in the SWAT land use database. These specific agricultural layers were downloaded for the San Joaquin (1996), Stanislaus (1996), Merced (1995), Fresno (2000), and Madera (1995) counties, from the Department of Water Resources (DWR), and were only for estimating a generic percentage of specific crop types for the AGRR layer over the entire model. The specific areas and percentages of these crop layers which were incorporated into the model are found in the Appendix, Figure 19. Table 2 shows the AGRR layer division by percentage. The eight generalized crop types included in the DWR system include G-grain and hay crops (6 types), R-rice, F-field crops (12 types), Ppasture (7 types), T-truck crops (25 types), D-deciduous fruits and nut crops (14 types), Ccitrus fruits crops (10 types), and V-vineyards (3 types), as well as I-Idle, as shown in the Appendix, Figure 20. 
Table 2 Agriculture Layer Subdivision

\begin{tabular}{ccc}
\multicolumn{3}{c}{ A G G R } \\
\hline \hline Layer & Percentage & S U B D I V I S I O N \\
\hline ORCD & 24 & Description \\
COTS & 16 & Orchard \\
SGBT & 1 & Cotton \\
CORN & 8 & Sugarbeet \\
GRBN & 3 & Corn \\
ALFA & 11 & Green Beans \\
PAST & 4 & Alfalfa \\
RICE & 1 & Pasture \\
ASPR & 1 & Rice \\
WMEL & 2 & Asparagus \\
ONIO & 1 & Watermelon \\
TOMA & 7 & Onion \\
AGRR & 4 & Tomato \\
GRAP & 16 & Agricultural Land-Row Crops \\
SPOT & 1 & Vineyards
\end{tabular}

The Digital Elevation Model (DEM) used for the SWAT model was downloaded from USGS as the National Elevation Dataset- 1/3 arc-second (approx. 10m resolution). The original horizontal datum was the North American Datum of 1983 (NAD83). The vertical datum for elevation was North American Vertical Datum 1988 (NAVD88), with vertical units of meters.

The soil layer used for the model originated from the State Soil Geographic (STATSGO) database, available from the Natural Resources Conservation Service (NRCS), part of the US Department of Agriculture (USDA). The spatial data includes a geo-referenced vector dataset, while the tabular digital data contains soil properties, chemical and physical. The spatial reference is the geographic North American Datum of 1983. A SSURGO soil layer, which represents a more detailed soil database, was not used for this model. A model set up including SSURGO soil database could produce more accurate results for another SJR watershed study, but would require more 
computational time and a SSURGO database conversion; therefore, the STATSGO database was used instead.

\section{RESERVOIR DATA}

Six major reservoirs were included in the SWAT model to simulate the largest reservoirs on the major tributaries in the study area. Although other reservoirs exist in the San Joaquin, only these six reservoirs were included in the model based on the inclusion in the category "Major California Reservoirs" from the CDEC website. Four out of these six can store over one million acre-feet of water (RTCD 1999). Release schedules and set rules operate the reservoirs which, in turn, regulate flows in the east side tributaries to the San Joaquin River. The flows are based on the combined demand for flood storage, fish migration pathways, irrigation supply, hydropower, water quality maintenance, and recreation (RTCD 1999).

Several reservoir parameters were necessary for the model to simulate the reservoir effects on the San Joaquin, most especially the daily reservoir release rate, as shown in yellow in figure 5. Also used by the model were the parameters of reservoir surface area and corresponding surface volume, which are shown in Table 4. Reservoir information, including measured outflow data and general statistics of the reservoirs like surface area and reservoir storage, were available from the USGS and CDEC websites. An excel table was developed for each Reservoir in order to correlate surface area and reservoir volume values, used in part to determine reservoir input values (Table 4). Reservoir release data was available from either the CDEC site or was estimated from gages downstream, as shown in Table 3 , as well as daily reservoir inflow and daily 
reservoir storage, for analysis purposes. Other surrounding stream gage data, not listed, were used to estimate initial nutrient values in the reservoir. The estimations were only necessary as an initial ballpark estimate, since the model assigns reservoir nutrient data once the simulation begins.

Table 3 Reservoir Data

RESERVOIR DATA

\begin{tabular}{|c|c|c|c|c|c|c|}
\hline Reservoir & $\begin{array}{c}\text { Reservoir } \\
\text { gage \# }\end{array}$ & $\begin{array}{c}\text { Discharge } \\
\text { gage \# }\end{array}$ & Lat & Long & $\begin{array}{c}\text { Ibbasi } \\
\#\end{array}$ & River \\
\hline \multicolumn{7}{|l|}{ New } \\
\hline Melones & 11299000 & 11299200 & $37^{\circ} 56^{\prime} 47^{\prime \prime}$ & $120^{\circ} 31^{\prime} 38^{\prime \prime}$ & 11 & Stanislaus \\
\hline Don Pedro & 11287500 & 11289650 & $37^{\circ} 3959$ & $120^{\circ} 2628$ & 13 & Toulumne \\
\hline Millerton & 11250100 & $*$ & $37^{\circ} 00^{\prime} 00^{\prime \prime}$ & $119^{\circ} 42^{\prime} 13^{\prime \prime}$ & 49 & Upper SJ \\
\hline Exchequer & 11269500 & 11269700 & $37^{\circ} 35^{\prime} 01^{\prime \prime}$ & $120^{\circ} 16^{\prime} 29^{\prime \prime}$ & 23 & Merced \\
\hline $\begin{array}{l}\text { Buchanan } \\
\text { Hidden }\end{array}$ & BUC & & & & 45 & Chowchilla \\
\hline Dam & HID & & & & 40 & Fresno \\
\hline
\end{tabular}

Table 4 Reservoir Input Values

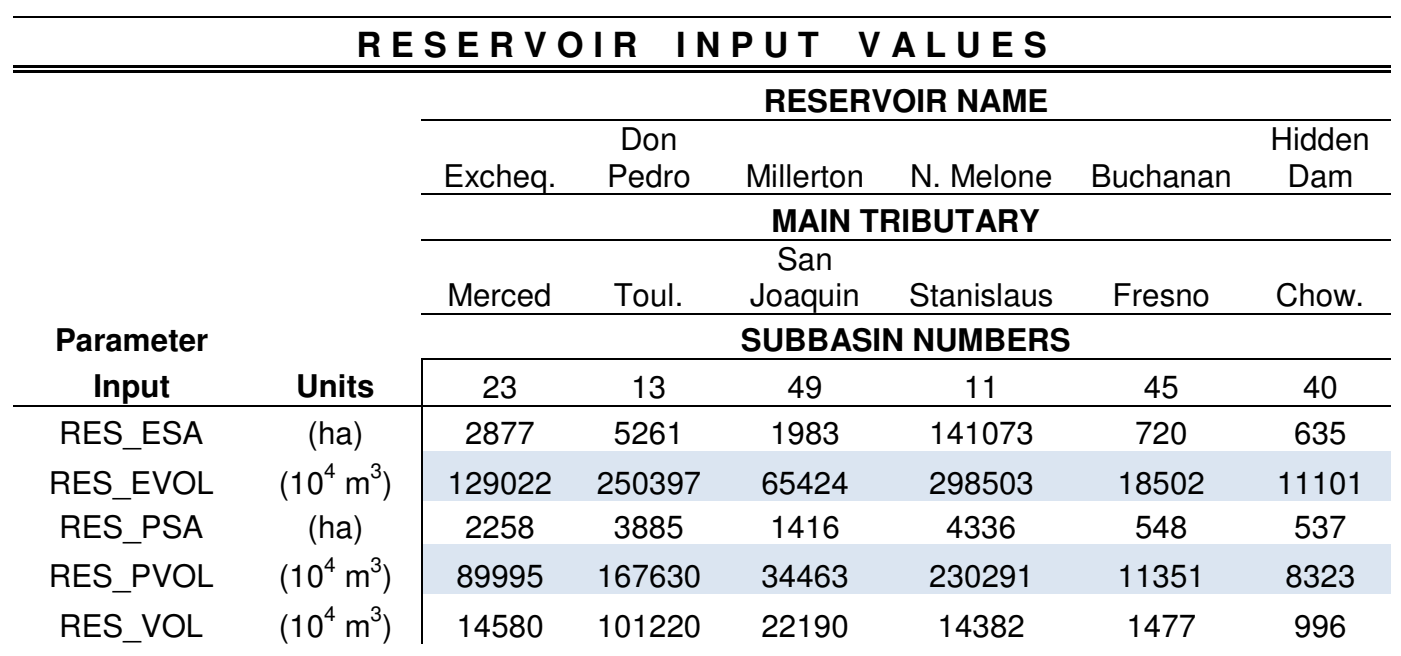




\section{WATER DIVERSIONS}

Four Eastern water use diversions and two Western water use diversions were included in the model to simulate agricultural and industrial water use, as shown in Table 5. For simplification, only these 6 water use diversions were included in the model, representing the most significant diversions from the San Joaquin River and its tributaries, as shown in the appendix, Table 18. Diversion data for the Eastern tributaries of the San Joaquin River were collected from canal stations based on water basin data from the water-data reports from the USGS website. Diversion data for the Western tributaries of the San Joaquin were established based on a publication from the CALFED Bay-Delta Program (Quinn 2002).

\section{Table 5 Diversions}

\section{DIVERSIONS}

\begin{tabular}{lcccc}
\hline \hline & & & & Subbasin \\
Diversion Label & Lat & Long & Parent River & $\#$ \\
\hline Madera Canal & $37^{\circ} 00^{\prime} 10^{\prime \prime}$ & $119^{\circ} 42^{\prime} 21^{\prime \prime}$ & San Joaquin & 46 \\
Friant-Kern Canal & $36^{\circ} 59^{\prime} 53^{\prime \prime}$ & $119^{\circ} 42^{\prime} 1 "$ & San Joaquin & 46 \\
Oakdale Canal & $37^{\circ} 51^{\prime} 32^{\prime \prime}$ & $120^{\circ} 37^{\prime} 56^{\prime \prime}$ & Stanislaus & 9 \\
Modesto Canal & $37^{\circ} 40^{\prime} 21^{\prime \prime}$ & $120^{\circ} 28^{\prime} 26^{\prime \prime}$ & Tuolumne & 11 \\
Turlock Canal & $37^{\circ} 39^{\prime} 57^{\prime \prime}$ & $120^{\circ} 26^{\prime} 24^{\prime \prime}$ & Tuolumne & 11 \\
Northside Canal & & & Merced & 19 \\
West Stanislaus District & & & & 13 \\
Patterson District & & & & 15
\end{tabular}

\section{STREAMFLOW, SEDIMENT, \& NUTRIENT DATA FOR MODEL CALIBRATION}

Several stream gages available from the USGS website were the crux for the calibration and validation of the model. Stream gages gave streamflow, sediment, and nutrient data, as shown in Table 6. The daily streamflow is the discharge of water from the natural streams, the accumulation of surface water at the watershed outlet, in cubic meters per second. The suspended sediment measured from the gages includes all solid 
material that is maintained in suspension by the upward components of turbulent currents or that exist in suspension as a colloid, in tons per day. Measured nutrients at the basin outflow included filtered nitrate as nitrogen, in milligrams per liter.

Table 6 USGS Gage Station

\begin{tabular}{ccccccc}
\hline \multicolumn{7}{c}{ U S G S G A G E S T A T I O N } \\
\hline \hline Gage ID & Gage name? & Lat & Long & Flow & Sediment & Nutrients \\
11272500 & Merced & $37^{\circ} 22^{\prime} 15^{\prime \prime}$ & $120^{\circ} 55^{\prime} 46^{\prime \prime}$ & $X$ & & \\
11274538 & Orestimba & $37^{\circ} 24^{\prime} 49^{\prime \prime}$ & $121^{\circ} 00^{\prime} 54^{\prime \prime}$ & $X$ & & \\
11290000 & Toulumne & $37^{\circ} 37^{\prime} 38^{\prime \prime}$ & $120^{\circ} 59^{\prime} 00^{\prime \prime}$ & $X$ & & \\
11303000 & Stanislaus & $37^{\circ} 43^{\prime} 47^{\prime \prime}$ & $121^{\circ} 06^{\prime} 34^{\prime \prime}$ & $X$ & & \\
11303500 & Vernalis & $37^{\circ} 40^{\prime} 34^{\prime \prime}$ & $121^{\circ} 15^{\prime} 55^{\prime \prime}$ & $X$ & $X$ & $X$
\end{tabular}

SNOW DATA

Snow data was obtained from the CDEC site for 15 gages as shown in yellow in figure 6. Input for the snow level in the model is snow water equivalent (SWE), which is the equivalent height of water for a measured height of snow. This is due to the fact that snow density typically ranges between 7 to 15 percent of water density (Muleta). An initial snow level for each elevation band in the SJ model (in mm H2O) was estimated from the CDEC snow depth (water content) stations using a gradient of SWE levels for the initial modeling date for each snow subbasin. The gradient was based on snow gage location, elevation, averages between stations, and best judgment, and produced the SWE values as shown in the appendix, figure 6. Only an initial SWE value was input into the model, as the SWE values for days following the SWE of the initial day are calculated by the model through a process which is described in Section 3.2. 


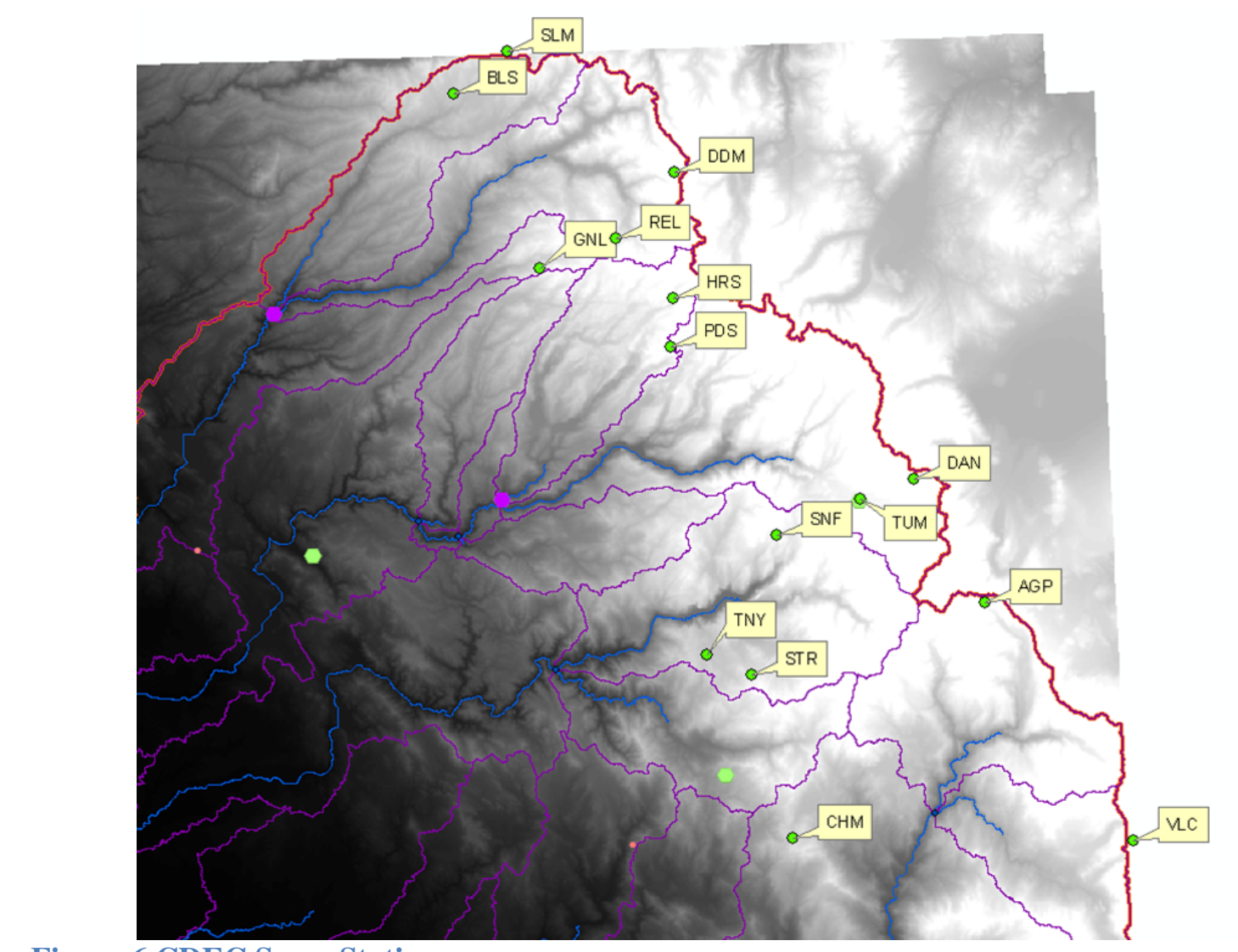

Figure 6 CDEC Snow Stations

\section{FERTILIZER DATA}

Fertilizer application is important for nutrient modeling, specifically nitrogen. This data was compiled primarily through two reports, (Potter 2001, King 2007). The fertilizer application was available as an average based on consultation with several expert sources (Potter 2001), and distinguished the San Joaquin Valley from other agricultural regions in the state. The typical months of fertilizer application were similarly estimated based on farmer interviews. Average fertilizer application amounts per crop type and per month are shown in Table 7. SWAT employs two methods of Nitrogen application, either through specified monthly/daily application or basing fertilizer application on a fraction of plant potential heat units (Nietsch 2005). The plant potential heat units method was used in the Vernalis model. 
Table 7 Fertilizer Application

\begin{tabular}{ccc}
\hline \multicolumn{2}{c}{ F E R T I L I Z E R } & \multicolumn{2}{c}{ A P P L I C A T I O N } \\
\hline \hline $\begin{array}{c}\text { SWAT LU } \\
\text { Code }\end{array}$ & $\begin{array}{c}\text { DWR LU } \\
\text { Code }\end{array}$ & $\begin{array}{c}\text { N application } \\
\text { rate (kg N/ha) }\end{array}$ \\
ORCD & D & 140 \\
COTS & F & 140 \\
SGBT & F & 140 \\
CORN & F & 140 \\
GRBN & F & 140 \\
ALFA & P & 100 \\
PAST & P & 100 \\
RICE & R & 100 \\
ASPR & T & 250 \\
WMEL & T & 250 \\
ONIO & T & 250 \\
TOMA & T & 250 \\
AGRR & P & 100 \\
GRAP & V & 70
\end{tabular}

\subsection{SENSITIVITY ANALYSIS AND MODEL CALIBRATION METHODS}

Since SWAT is a physically based model, databases (such as topography,

precipitation, soil, etc.) are uploaded into the program and used to solve the underlying theoretical equations for streamflow, sediment, and nutrient analysis. The parameters in these theoretical equations cannot be measured directly, and has to be determined through calibration exercise. The parameters are typically allowed to vary within a realistic range of values during the sensitivity and calibration process, essentially molding the watershed to best match actual observed outputs (Gassman 2007). When simulated outputs like streamflow are close to observed outputs, the model is said to be properly calibrated, one of the main goals of modeling. Of course, this is a simplification. Truly "accurate" or calibrated models depend on the initial objective functions of the model. For this thesis, the goal of the calibrated SJR model included an accurate hydrologic representation of 
the SJR watershed and of nutrient loading and runoff. These goals relied on additional minor objectives, including adequate snow cover representation and reservoir modeling. The overall purpose of the model plays an important role in how the calibrated model looks. For instance, in another model where the objective function may be climate change analysis instead of nutrient loading, the calibrated model may look different.

Besides calibration, uncertainty analysis may be needed. Uncertainty has been defined as "the estimated amount by which an observed or calculated value may depart from the true value" (Shirmohammadi et al. 2006). Uncertainty analysis is an important part of calibration. Uncertainty in the model may come from various sources within a model, including workable errors from erroneous or incomplete data (input uncertainty) or inherent modeling errors (structural uncertainty) due to physical processes not included in the model. Not only is it difficult if not impossible to capture all the physical processes in the watershed (structural uncertainty), but it is also likely that at least some parts of the input data are inaccurate or oversimplified (input uncertainty) (Abbaspour 2011). An uncertainty analysis can help identify sources of error in the model, in order to evaluate the model effectiveness (and maybe modeler effectiveness). No model will ever represent reality with precise accuracy, but as mentioned in the introduction (Section 1), models only need to represent reality sufficiently to use as a tool for policy implementation or experimentation, which uncertainty analysis helps evaluate.

Several statistical methods are employed to perform uncertainty analysis. Some methods available for SWAT from other developers include the methods of Sequential Uncertainty Fitting (SUFI-2), Particle Swarm Optimization (PSO), Generalized Likelihood Uncertainty Estimation (GLUE), ParaSol (Parameter Solutions), Parameter 
Estimation (PEST), and Markov Chain Monte-Carlo (MCMC) (Abbaspour 2011, Gassman 2007). For this SJR watershed model, the ParaSol process was used, outfitted with SCE-UA as available in SWAT. A brief overview is provided here, although more in depth statistical explanations can be found in Van Greinsven 2005 or Liew 2006. Before calibration, however, a sensitivity analysis is performed on the model to narrow down the list of calibration parameters.

Sensitivity analysis is the method through which parameters are weighed and ranked to determine which parameters are the most critical in effecting specific model outputs. The LH-OAT method was utilized for this model, which is a combination of the Latin Hypercube (LH) and One At a Time (OAT) processes, as developed by Van Griensven (2005). LH-OAT is a robust, efficient, and comprehensive analysis of all parameters. The options set for LH-OAT analysis are determined by the user through the Sensitivity Analysis box.

The LH method is "commonly applied in water quality modeling due to its efficiency and robustness" (Van Griensven 2005). The points sampled by the LH process using a stratified sampling approach are used in the OAT design (Gassman 2007, Van Griensven 2005). It subdivides each parameter into $\mathrm{N}$ ranges, each with an equal probability of occurrence. Its main drawback is its assumption on linearity.

OAT represents a global sensitivity method where a high number of parameters can be analyzed, as opposed to a local method. For each run, only one parameter is changed, so that output changes can be unambiguously attributed to the inputs, similar to a local method. But unlike a local method, the partial effects of each parameter are lumped together as an average of the partial effects of a set into the 'final effect'. The 
sensitivities of all the parameters can be analyzed in relation to each other, as opposed to each parameter by itself. This represents how local sensitivities are integrated into a global sensitivity, and is particularly useful for SWAT.

During the SWAT sensitivity analysis, SWAT runs $(\mathrm{p}+1)^{*} \mathrm{~m}$ cycles for sensitivity analysis; $\mathrm{p}$ is the \# of parameters being evaluated and $\mathrm{m}$ is the \# of LH loops. Both parameters are user defined. During each loop, a set of parameter values is chosen which represents a unique area of parameter space being sampled. After a baseline simulation, OAT chooses a parameter at random, and its value is changed from the previous simulation by a user defined percentage. Then OAT chooses another parameter, undergoing the same percentage change. After all the parameters have been changed, LH locates an entirely new sampling space with new parameters, and the process repeats. For each sensitivity analysis performed in the SJR model, the default values of $\mathrm{N}=10$ and \% change $=.05$ were used. Although the user can specify HRUs for each parameter, this option was also not used and parameter changes were applied over the entire basin.

Based off the sensitivity analysis, the user can select parameters for the model calibration. The SWAT interface includes several calibration options, which include PARASOL, SUNGLASSES, single or multi objective functions, and Uncertainty Analysis. The Uncertainty Analysis method here is an actual process programmed into SWAT, not to be confused with the process of uncertainty analysis, which is not capitalized for clarification. The details included here focus on the methods of calibration which were employed for the SJR model, including PARASOL and a Sum of the Square of the Residuals (SSQ) single objective function. For parameterization and optimization, 
SWAT uses an automated calibration procedure based on the Shuffled Complex Algorithm (SCE-UA).

The sampling accomplished by the SCE-UA first produces an initial population of feasible parameters based on random sampling. This initial population is proportioned into several communities with $2 \mathrm{p}+1$ points ( $\mathrm{p}$ represents \# of parameters being calibrated). Each community evolves based on a statistical reproduction process, the simplex method. During the evolution process, the entire population is periodically shuffled and points are assigned to communities. Through this process, the entire population tends to converge toward the neighborhood of global optimization. At this point, if the user opts to use the uncertainty analysis method, SWAT will further evaluate the simulations performed into 'good' and 'not good' simulations.

There are a few key user defined options, discussed briefly. SWAT includes a multi-objective function calibration which is based off of the single objective function. For the single objective function, SWAT uses either the Sum of the Square of the Residuals (SSQ) or the Sum of the Square Residuals Ranked (SSQR). The SSQ is the classic method of comparing the simulated series to the observed data and summing the square of the error, similar to the Mean Square Error method (MSE). SWAT also has options for lumped or distributed parameter change over the catchment basin, similar to the sensitivity analysis. The parameter changes occurring during calibration can also be set as either relative or absolute.

For the Vernalis model, several single objective functions were used in succession, as opposed to a multi-objective function model, simply for the purpose of being able to track and analyze individual sensitivity results. Research suggests that one 
method (single vs. multi objective function) may not necessarily be better than the other (Van Liew 2010). The SSQ method was used for all the calibration models, and the number of calibration cycles (MAXN) generally ranged from 1500 to 2200. This calibration number was based on calibration run time, which was generally between 2035 hours, and was also based on the Nash-Sutcliffe Efficiency (NSE) improvement between sets of a run, which were given in the parasolout.out file. For example, if the NSE improved only .1 between calibration sets, then the number of cycles was considered sufficient. The NSE is explained further in Section 4.2. 


\section{CHAPTER 4 : METHODOLOGY}

\subsection{MODELING PROCESS}

In order to create a working hydrology model, the SWAT model incorporates data from several sources, processes these data through watershed delineation and HRU overlay, from which a sensitivity analysis allows model calibration and validation. Data sources include topography, land use, soil layers, reservoirs, weather data, stream gage data, streamflow, sediment output, nutrient output, etc., which require preprocessing and formatting into tables recognized by SWAT in order to be used by the model. Afterwards, the process of watershed delineation divides the watershed into subbasins. Data layers such as soil and land use are applied to the subdivided watershed to create Hydrologic Response Units (HRUs). Other tabular data such as weather stations, reservoirs, and streamflow can be incorporated into the watershed after the HRU processing, after which sensitivity analysis and calibration can occur.

\section{WATERSHED DELINEATION AND INPUT DATA ASSIGNMENTS}

Watershed delineation is the process of taking a DEM and transforming it into a discretized watershed, capable of simulating runoff from several hydrologically connected sub-watersheds. The process of extracting hydrologic information from the DEM is known as terrain processing, which determines flow direction and flow accumulation, in order to form streams and calculate subwatershed properties.

An uploaded DEM is the first step of watershed delineation. Initially, the DEM datum (in ESRI grid format) was the North American Datum of 1983 (NAD 1983), but was converted into a geographic coordinate system of North American Datum 1927 (NAD27), which was then projected onto the Universal Transverse Mercator Zone 10 
coordinate system. "Masks" were sometimes used for proportioning off areas which corresponded to one tributary, as graphically shown in figures 7-12, Section 4.2. Model generated networks of streams were used for the model as opposed to importing a predefined digital stream network because pre-defined streams included manmade ditches and canals which would have been problematic for the model. A stream definition area of 40,000 Ha was used, which is a user input which determines the detail of the drainage network delineated by the interface; the smaller the number, the greater the detail. The area definition of 40,000 $\mathrm{Ha}$ is a large value for this input, signifying a greater generalization of the drainage network. The Vernalis gage location was selected for the watershed outlet site, as found in Table 6.

HRU ANALYSIS

After delineation, SWAT applies the land use (NLCD) and soil classification (STATSGO) datasets through a process called the HRU (Hydrologic Response Units) analysis. HRU overlay further subdivides the subbasins into HRUs in order to represent segments of subbasins which respond similarly during modeled hydrologic conditions. These HRUs are based on slope, soil class, and land use, which overlay the model according to user defined percentages which govern how many HRUs are produced. Lookup tables were used in order for the model to recognize and assign hydrological values to downloaded databases.

The HRU definition was primarily based on percentage definitions, changed by the user. The percentages define a threshold percentage; if the area of a layer category is less than the threshold percentage, then that layer category is not included in the final HRU distribution for that subbasin. An HRU definition of $10 \%, 10 \%$, and $15 \%$ was used 
for the datasets of land use, soil, and slope for the SJR model. During this HRU analysis process, the land use layer AGRR was further subdivided into several crop types, according to Table 2. The overall HRU results can be found in Section 5.2. DATA INPUT AND FILE EDITING

Weather input files were generated by the model from observed weather gage data (Section 3.1). Once the weather stations are input, SWAT allows the option of writing the input files, either individually or all at once, using a default Manning's $n$ value and heat index value. These files are written by SWAT for the use of SWAT, but are also available for editing once all of the files are written through the SWAT interface. Editing these files helps increase the accuracy of the model. The input files and their extensions are found in the SWAT user manual (Neitsch 2005). These input file editing options were utilized for several hydrologic components of the model, including the reservoirs, water use, elevation bands, snow levels, fertilizer application, and applying calibrated subbasin parameters to one or several subbasins or HRUs when appropriate.

The reservoir simulation is represented through a series of input files and can be edited if necessary. Reservoir simulation for the San Joaquin model was mainly based on daily reservoir release rate, but several other parameters were changed from their default values as well, as shown in Table 4. These edited input parameters included reservoir surface areas and volumes at the natural spillway and emergency spillway, and also included several nutrient and sediment parameters. Ultimately, the initial sediment and nutrient assignments are not expected to play a significant role in the reservoir modeling as a tune-up period of 12 months was used in the analysis to neutralize the effect of initial conditions (Section 3.1). 
Diversion data was similarly simulated through a series of water use files and edited for any individual subbasin effected by water use diversion. Specific values for water use input are shown in Table 5.

Snow elevation bands and initial snow levels for the mountainous regions were applied when snow was expected to play a significant role in the hydrologic runoff of the model. These snow parameters were included in the subbasin files, the values for which are shown in the Appendix, Table 22.

Fertilizer application was applied as per land use through the management files. Table 7 shows the amount of Nitrogen application in $\mathrm{kg} / \mathrm{ha}$ of $\mathrm{N}$ per land use.

SWAT allows editing of the default SWAT databases and the watershed database files containing the current inputs for the SWAT model (Winchell 2009). Whenever applicable, the calibrated parameter values were input into the model using this SWAT editing feature, which edited soil, reservoir, water use, HRU, subbasin, routing, or groundwater files. The calibration process is explained in Section 3.2.

The SWAT program interface always limited the values of parameter editing to an appropriate range of values, but at various times during the modeling process the parameter inputs were outside of this range of allowable values. Whenever this limitation occurred for a desired parameter change, another option of bypassing the interface was to edit the value in the file itself, a laborious process compared to using the SWAT interface. This process of editing parameter values through file editing was necessary whenever the SWAT program interface would not allow the desired parameter change. In Section 5.2, results show validation efficiency values before and after file editing, and Section 6.2 discusses the effectiveness of file editing for model accuracy. 


\subsection{MODEL EVALUATION METHODS}

The daily flow output calibration set-up progressed as shown in figures 7-12

below, which help illustrate the use of masks. A "mask" is a polygon drawn around a section of the watershed in order to isolate a subbasin and/or tributary. They are shown in Figures 7-11 below in various shades of green. 

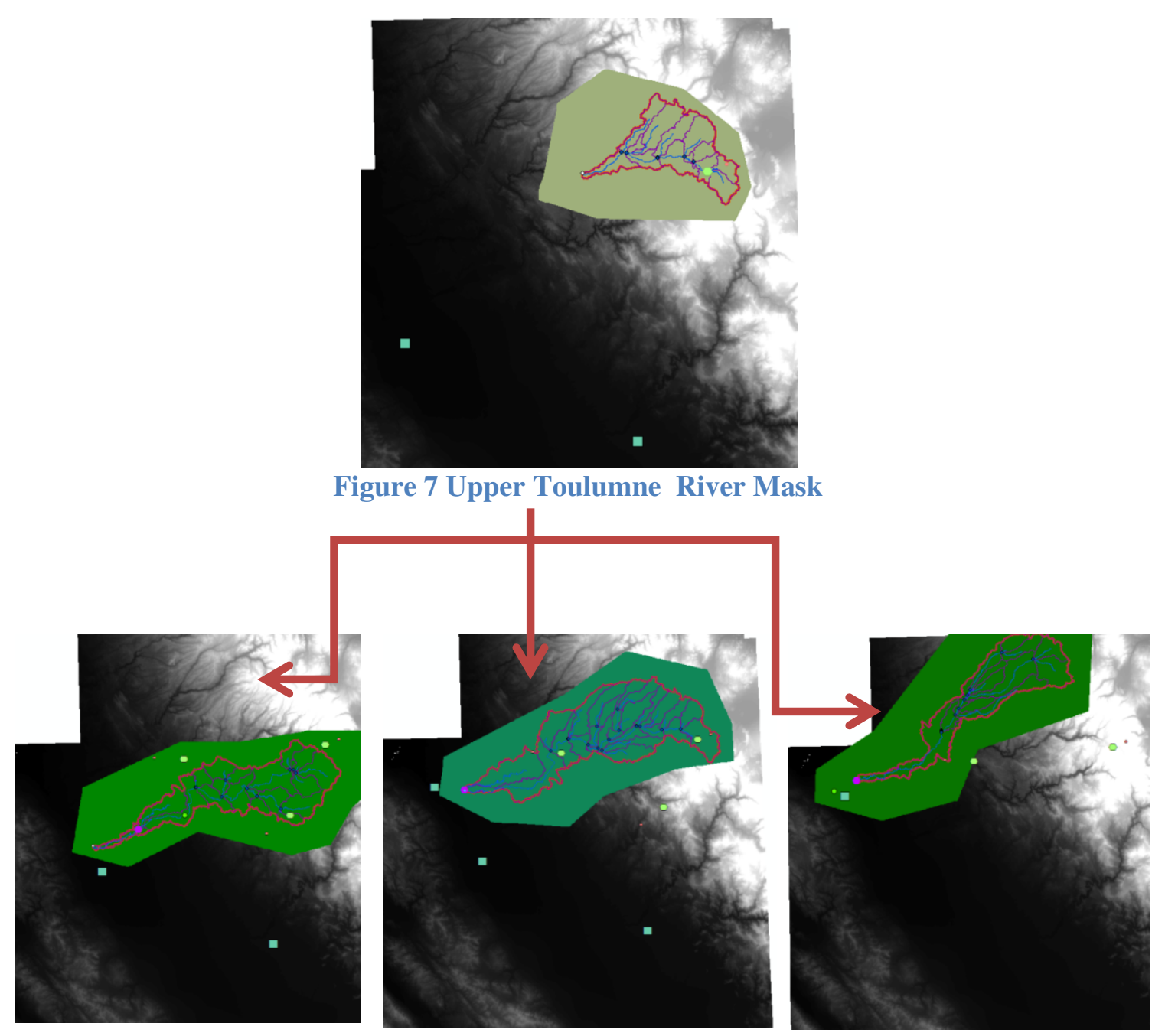

Figure 8 Merced River Mask Figure 9 Tuolumne River Mask Figure 10 Stanislaus River Mask

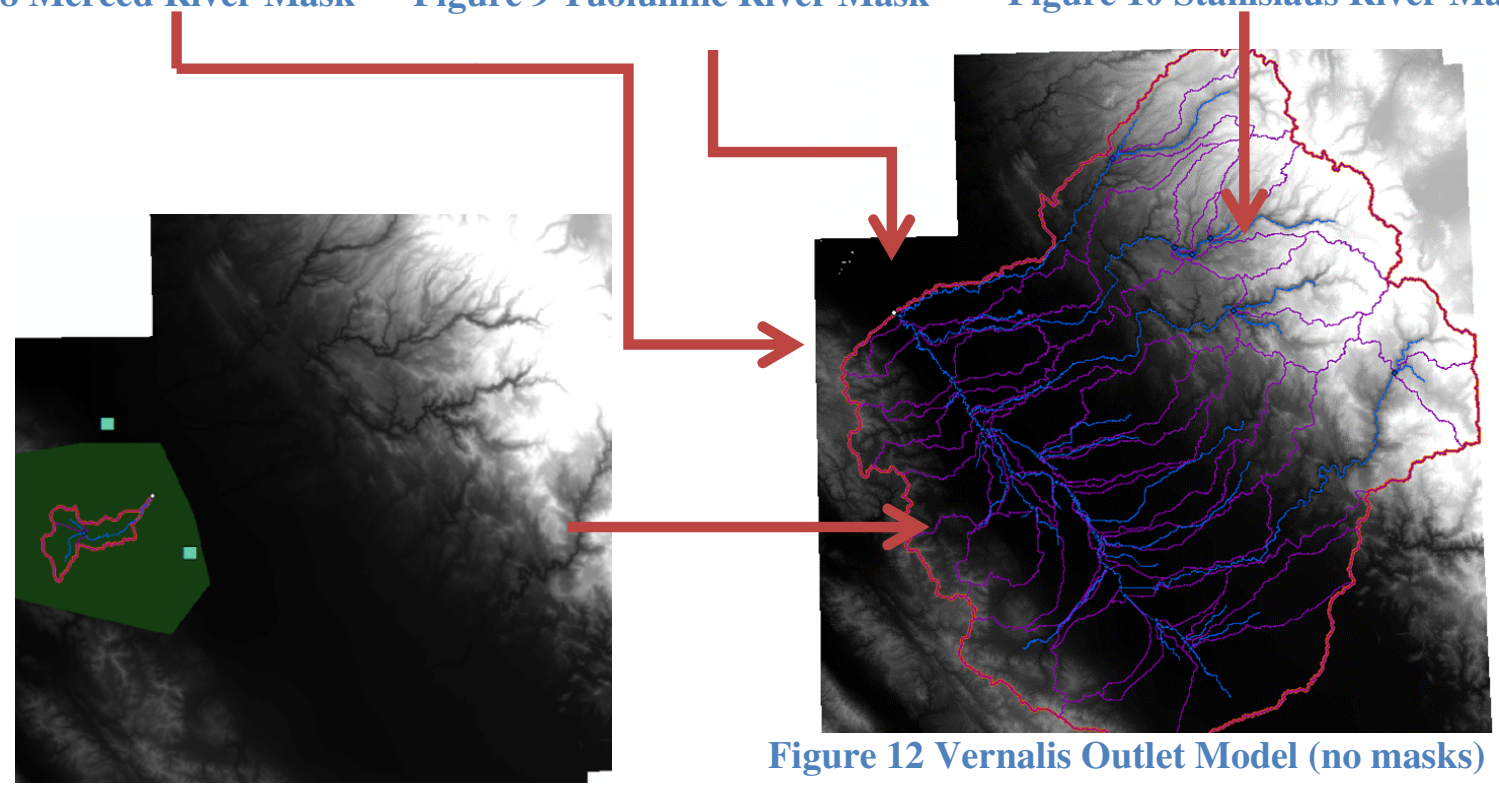

Figure 11 Orestimba River Mask 
The masks were an essential sectioning tool in order to isolate tributary watersheds, which increased computational efficiency and reduced simulation time. This “separate model” format also allowed easier and faster model input editing for pinpointing inaccuracies. The downside of using masks is that the delineated subbasins inside a mask may not necessarily represent the delineated subbasins for the entire watershed. This concern is addressed and discussed in Section 6.2.

An initial snow calibration for the upper Tuolumne River (Figure 7) was a necessary precursor to calibration of Tuolumne, Stanislaus, and Merced tributaries (Figures 8,9,10). Since the Orestimba River (Figure 11) did not produce adequate calibration efficiency values, the results were not used for the Vernalis calibration. Once the main tributaries were separately calibrated, the results were inserted into the Vernalis model, and the entire SJR watershed was calibrated for daily flow at the Vernalis outlet. No separate masks were used for the monthly suspended sediment output at the Vernalis outlet, which was performed after the daily flow calibration. Similarly, the monthly filtered nitrate output was calibrated at the Vernalis outlet only, without the use of masks and without calibrating the separate tributaries for nutrient loading.

A three-part evaluation of daily flow was performed for the tributaries of the Stanislaus, Merced, and Tuolumne river, as shown in Table 8, which consisted of a sensitivity analysis, a calibration run, and a validation run. The initial sensitivity analysis ranked the parameters for sensitivity, which guided the parameter selection for the calibration run. If the calibration run produced an acceptable NSE, then the calibrated parameters were input into the model. After this, a final validation run either validated or 
invalidated the calibrated parameter results. The results of all calibration and validation runs are found in Section 5.2.

The scheduling of the calibration/validation cycles were based on hydrologic theory. As a precursor to flow calibration, a hydrologic model must accurately simulate snow, as explained in Section 2.2, which is the first step in the calibration process. After calibrating parameters for subbasins with snow, daily flow calibration for tributaries and for the overall watershed is the next logical step to model calibration, since the basin water balance is the driving force behind everything that happens in a watershed. In order for the model to accurately predict movement of pesticides, sediments, or nutrients, the hydrologic cycle of the model must conform to what is happening in the watershed (SWAT theory 2005).

The next step, sediment calibration, is an important step before nutrient routing, since sediment erosion and transportation effect nutrient loading, and nutrients sorbed to sediments are a part of nutrient routing (Nietsch 2005a). For this model, the objective focus on flow and nutrient loading, so the sediment calibration step is only an intermediary step for nutrient modeling only. Following sediment output calibration, then, is nutrient output calibration, and these are the results of interest as discussed in Section 6.2.

Several statistical equations and graphical representations exist which typically help to evaluate model performance. Some of the common quantitative statistics used include the Nash-Sutcliffe Efficiency (NSE), Percent Bias (PBIAS), the ratio of root mean square error to the standard deviation of measured data (RSR), and the coefficient 
of determination $\left(\mathrm{R}^{2}\right)$, as well as typical statistical methods employed in determining goodness-of-fit, such as averages and standard deviations (Moriasi 2007, Green 2007).

For this model, however, the NSE quantitative statistic was mainly used with averages and graphs also giving an idea of the overall spread of the data as well as seasonal variation. The NSE came from a 1970 study from Nash and Sutcliffe and is commonly used in watershed models. It compares predicted values to the mean of the average observed values, where 1 indicates a perfect fit, although values can range from 1 to negative infinity (Green 2007). The NSE is calculated by SWAT during the calibration process, making it a logical choice for use for data computation. For model validation, the program does not give NSE values, so the NSE equation (Equation 2) was used for manually calculating the NSE value from SWAT output files. Guidelines for the NSE chosen for this model, as set forth in Moriasi 2007 and Green 2007, are as follows: NSE $>.5$ is generally regarded as satisfactory, while $>.65$ is considered very good. However, NSE >.4 are also regarded as satisfactory, as put forward in Green 2007 for their SWAT study.

\section{Equation 2 Nash-Sutcliffe Equation}

$$
\mathrm{NSE}=1-\left[\frac{\sum_{i=1}^{n}\left(Y_{i}^{\text {obs }}-Y_{i}^{\text {sim }}\right)^{2}}{\sum_{i=1}^{n}\left(Y_{i}^{\text {obs }}-Y^{\text {mean }}\right)^{2}}\right]
$$

Other methods of model evaluation which were more subjective included an analysis of snow fall, snow melt, and reservoir water balance. It was difficult to quantify the goals for these modes of evaluation, so arbitrary guidelines were assigned for each of these which compared calibration results with each other. Some comparative properties of each calibration which were used included average inches of snow fall over the snow subbasins, the total days out of the year which included snowmelt, and a spring/summer 
vs. fall/winter seasonal comparison of snowmelt. The water balance of the reservoirs was also evaluated to see if water storage was depleted, an indication of erroneous water balances.

The RMSE statistic was calculated by SWAT for each run in order to determine the calibration set which best accomplished the objective function (OF), as explained in Section 3.2. This statistical tool was also used as an intermediary model evaluator, in instances where 'good simulations' were used rather than the 'best simulation'. However, since the range of 'good fit' RMSE values change for different simulations, the RMSE was not used for overall model evaluation.

Table 8 Schedule of Sensitivity / Calibration / Validation

\begin{tabular}{|c|c|c|c|c|c|}
\hline $\begin{array}{l}\text { Simulation } \\
\text { Type }\end{array}$ & Location & $\begin{array}{c}\text { Subbasin } \\
\#\end{array}$ & Gage \# & $\begin{array}{l}\text { Time } \\
\text { Step }\end{array}$ & $\begin{array}{l}\text { Time } \\
\text { period }\end{array}$ \\
\hline \multicolumn{6}{|l|}{ SNOW } \\
\hline Sensitivity & Upper Tuolumne R. & 4 & 11276900 & Monthly & $1993-2000$ \\
\hline Calibration & Upper Tuolumne R. & 4 & 11276900 & Daily & 1993-1996 \\
\hline \multicolumn{6}{|l|}{ FLOW } \\
\hline Sensitivity & Stanislaus R. & 11 & 11303000 & Daily & 1993-1996 \\
\hline Calibration & Stanislaus R. & 11 & 11303000 & Daily & 1993-1996 \\
\hline Validation & Stanislaus R. & 11 & 11303000 & Daily & $1997-2000$ \\
\hline Sensitivity & Tuolumne R. & 16 & 11290000 & Daily & $1993-2000$ \\
\hline Calibration & Tuolumne R. & 16 & 11290000 & Daily & 1993-1996 \\
\hline Validation & Tuolumne R. & 16 & 11290000 & Daily & $1997-2000$ \\
\hline Sensitivity & Merced R. & 23 & 11272500 & Daily & 1993-1996 \\
\hline Calibration & Merced R. & 23 & 11272500 & Daily & 1993-1996 \\
\hline Validation & Merced R. & 23 & 11272500 & Daily & $1997-2000$ \\
\hline Sensitivity & Vernalis $\mathrm{R}$. & 10 & 11303500 & Daily & $1993-2000$ \\
\hline Calibration & Vernalis $\mathrm{R}$. & 10 & 11303500 & Daily & 1993-1996 \\
\hline Validation & Vernalis $\mathrm{R}$. & 10 & 11303500 & Daily & $1997-2000$ \\
\hline \multicolumn{6}{|l|}{ SEDIMENT } \\
\hline Sensitivity & Vernalis $\mathrm{R}$. & 10 & 11303500 & Monthly & 1993-1996 \\
\hline Calibration & Vernalis $\mathrm{R}$. & 10 & 11303500 & Monthly & 1993-1996 \\
\hline Validation & Vernalis R. & 10 & 11303500 & Monthly & $1997-2000$ \\
\hline \multicolumn{6}{|l|}{ NUTRIENTS } \\
\hline Sensitivity & Vernalis $\mathrm{R}$. & 10 & 11303500 & Monthly & $1993-2000$ \\
\hline Calibration & Vernalis $\mathrm{R}$. & 10 & 11303500 & Monthly & 1993-1996 \\
\hline Validation & Vernalis R. & 10 & 11303500 & Monthly & $1997-2000$ \\
\hline
\end{tabular}

NOTE: Only simulations with usable results are included in table; excluding additional simulations used for analysis purposes only. 


\section{CHAPTER 5 : RESULTS}

\subsection{SUBBASINS AND HYDROLOGIC RESPONSE UNITS (HRUs)}

For the comprehensive Vernalis outlet model, 59 subbasins, with an average size of $582 \mathrm{~km}^{2}$, were generated. Six subbasins contained reservoirs, which corresponded to the main tributaries leading into the SJR (Figure 5). 2246 Hydrologic Response Units (HRUs) were produced according to the land use, soil, and slope percentages of $10 \%$, $10 \%$, and $15 \%$, respectively, established during the HRU analysis process. For subbasins containing agriculture, more HRUs were generated as specific crop types were represented in the model (Table 2). These agricultural subbasins generally represented the valley region and resulted in an average of 50 HRUs per subbasin. Non-agricultural subbasins, which generally represented mountainous regions, had an average of 13 HRUs per subbasin.

Figure 13 shows a simplified land use distribution over the San Joaquin watershed according to the land use layer assigned in SWAT. Table 9 shows the land use definitions for the SWAT land use codes. The figure shows the general distribution of land use across the watershed, without the specific crop redistribution.

\section{Table 9 SWAT Land Use Definitions}

\begin{tabular}{ll}
\multicolumn{2}{c}{ S W A T } \\
\hline $\begin{array}{c}\text { SWAT Land } \\
\text { Use Code }\end{array}$ & \multicolumn{1}{c}{ SW S E E F I N I T I O N S } \\
\hline WATR & Water \\
URLD & Urban Residential Land Density \\
SWRN & Southwestern US (Arid) Range \\
FRSD & Forest-Deciduous \\
FRSE & Forest-Evergreen \\
FRST & Forest-Mixed \\
RNGB & Range-Brush \\
RNGE & Range-Grasses \\
HAY & Hay \\
AGRR & Agriculural Land-Row Crops \\
WETF & Wetlands-Forested \\
WETN & Wetlands-Non-Forested
\end{tabular}




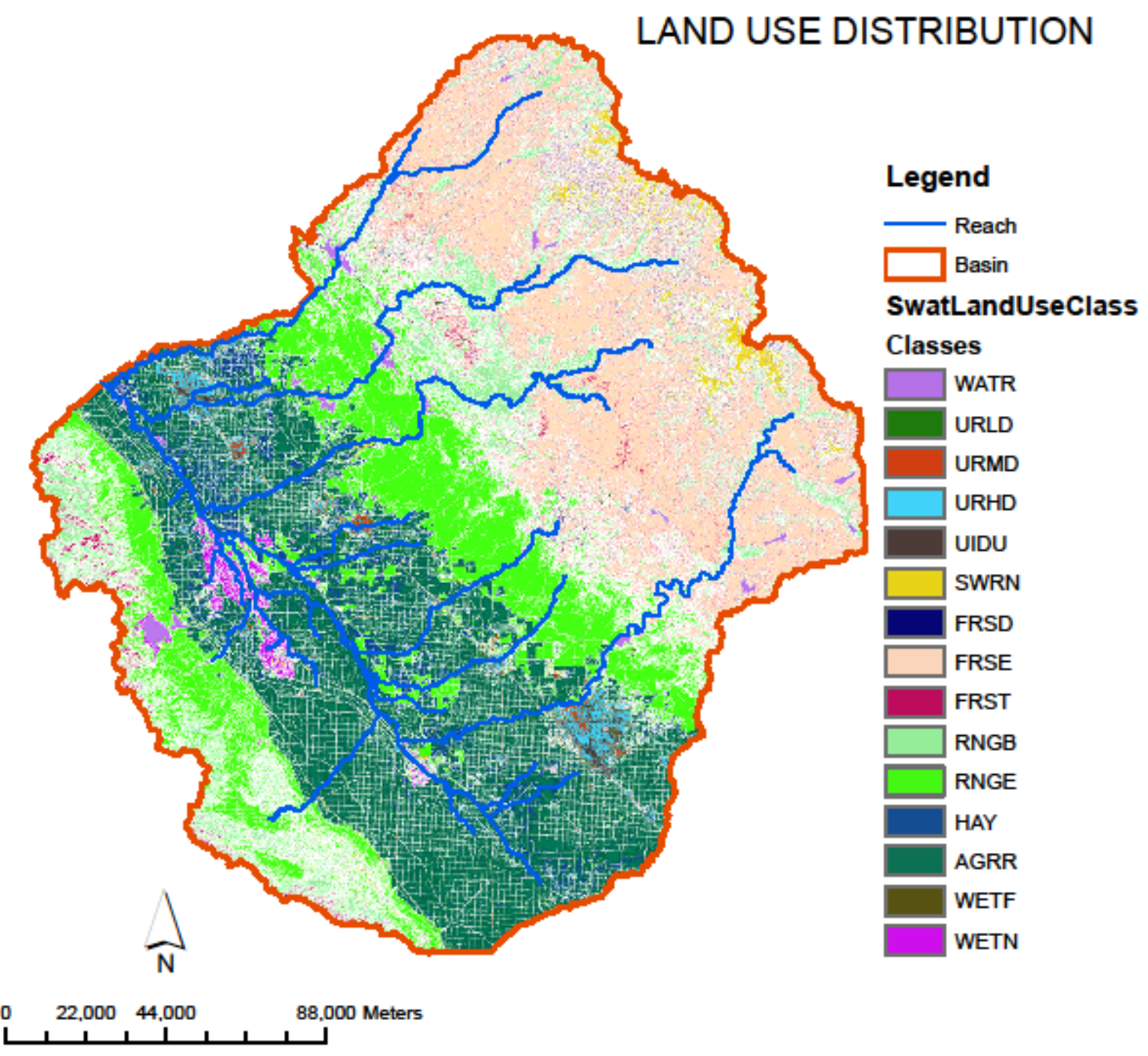

Figure 13 SWAT Land Use Distribution

Figure 14 shows the slope distribution after the creation of the HRUs, which limited the slope class of 5\%-20\% through the slope percentage threshold of $15 \%$. The majority of the valley region is shown in dark orange, which generally has a land slope less than 5\%. The mountainous regions shown in mixtures of white and blue generally have a land slope greater than $20 \%$. Over the entire watershed, the slope classification 
was divided as shown in Table 10, with a fairly even spread between the three slope classes, with the slope class $<20 \%$ being the least percentage of watershed area.

Table 10 SWAT Slope Distributions

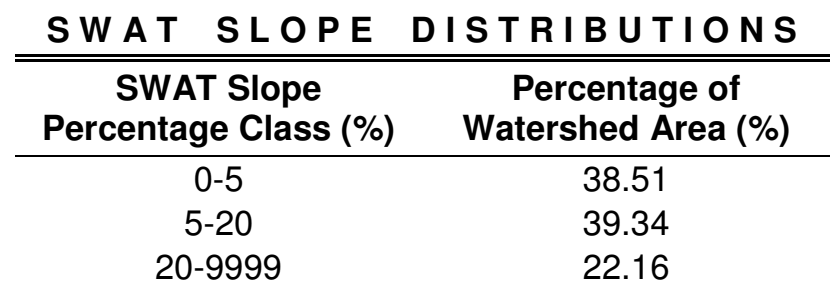

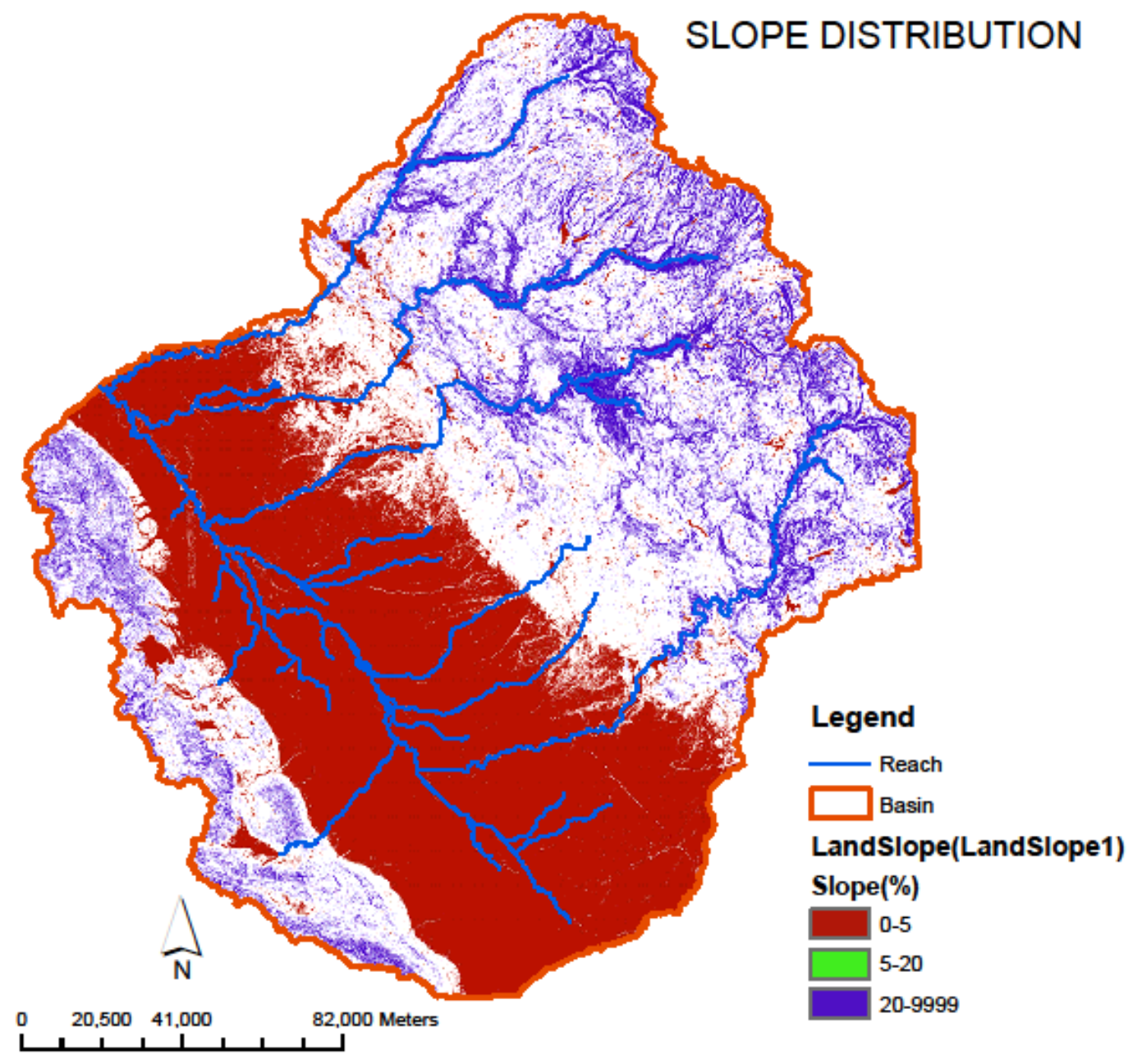

Figure 14 SWAT Slope Distribution 


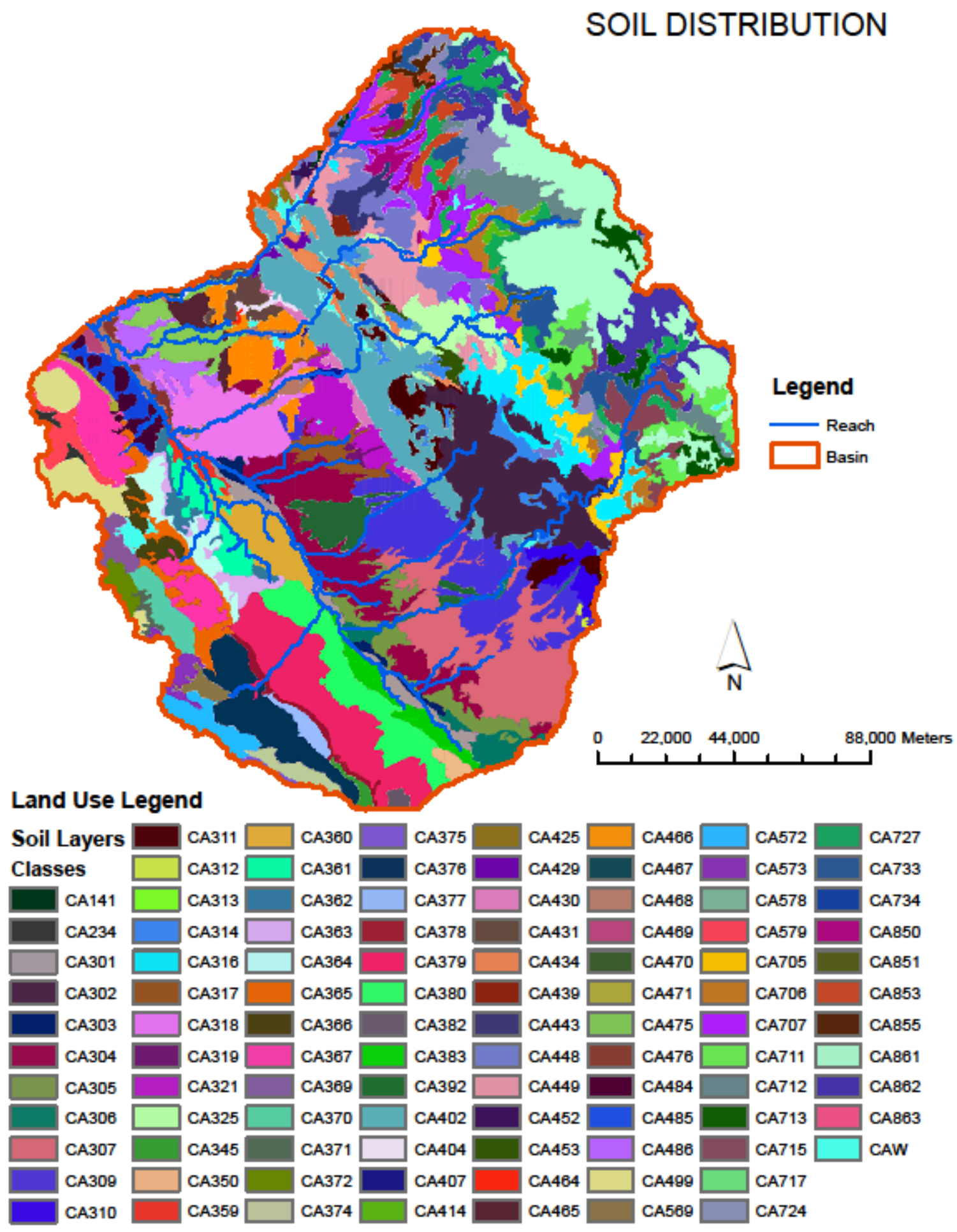

Figure 15 Soil Distribution 
Figure 15 shows the soil classifications produced by the soil layer input in SWAT. The 79 types of soil display the variety of soil properties over the entire watershed. SWAT soil types CA861 and CA302 each cover about 7\% of the watershed, which is the largest coverage by a single soil. This low percentage shows a fairly even spread of a variety of soil types within the watershed, without the domination of one particular soil type. The CA861 soil type was typically found in the mountains, a category of soil which is mostly rock volume ( $90 \%)$ and has a low available water capacity. Available water capacity (AWC), or the plant available water ( $\mathrm{mm} \mathrm{H} 2 \mathrm{O} / \mathrm{mm}$ soil), is the difference between the soil water capacity and the permanent wilting point; it is a measure of available water in the soil for plant uptake. Typically, rocky soils such as those found in the mountains have a low AWC compared with sandy or silty soils. For example, the soil type CA307 located predominantly in the valley area has a large percentage of sand and silt and therefore a higher AWC $(3-8 \mathrm{~mm} \mathrm{H} 2 \mathrm{O} / \mathrm{mmSoil})$ than the CA861 soil type ( $\sim \mathrm{mm}$ $\mathrm{H} 2 \mathrm{O} / \mathrm{mmSoil})$. This soil type represented $6.27 \%$ of the watershed area.

\subsection{SIMULATION RESULTS}

\section{SENSITIVITY ANALYSIS RESULTS}

Table 11 shows sensitivity analysis results for the Vernalis River watershed prior performing final calibration. The watershed analysis included all six reservoirs, all weather stations, snow subbasin elevation bands, and all diversion data. The rank of the parameter shows the degree of sensitivity. A ranking of one indicates that the parameter has the most influence on the flow output of the watershed. An unranked parameter had little or no influence on the watershed relative to the other parameters, with a ranking of

27. The Objective column represents the Observed vs. Simulated Sensitivity, which is the 
sensitivity of the parameters with the observed output compared with the simulated output. The Response column represents the Output Parameter Sensitivity, when the sensitivity analysis is applied to an error measure instead of an output variable (Van Griensven 2005). Both sensitivity results columns were taken into consideration for calibration parameter selection. Thirteen parameters were selected for the Vernalis outlet model calibration.

Table 11 Vernalis Sensitivity Results

\begin{tabular}{|c|c|c|}
\hline \multicolumn{3}{|c|}{ VER N A L IS } \\
\hline \multirow[t]{2}{*}{ RANKING } & \multicolumn{2}{|c|}{ PARAMETER NAME } \\
\hline & $\begin{array}{l}\text { Objective } \\
\text { (Objmet.dat) }\end{array}$ & $\begin{array}{c}\text { Response } \\
\text { (Responsmet.dat) }\end{array}$ \\
\hline 1 & Alpha_Bf & Alpha_Bf \\
\hline 2 & $\mathrm{Cn} 2$ & Cn2 \\
\hline 3 & Tlaps & Gwqmn \\
\hline 4 & Ch_N2 & Tlaps \\
\hline 5 & Ch_K2 & Timp \\
\hline 6 & Timp & Ch_K2 \\
\hline 7 & Gwqmn & Sol_Awc \\
\hline 8 & Sol_Z & Sō_Z \\
\hline 9 & Esco & Esco \\
\hline 10 & Sol_Awc & Blai \\
\hline 11 & Blai & Revapmn \\
\hline 12 & Surlag & Sol_K \\
\hline 13 & Gw_Delay & Surlag \\
\hline 14 & SölKK & Slope \\
\hline 15 & Epco & Epco \\
\hline 16 & Canmx & Gw_Delay \\
\hline 17 & Revapmn & Gw_Revap \\
\hline 18 & Slope & Canmx \\
\hline 19 & Gw_Revap & Ch_N2 \\
\hline 20 & Slsüubsn & Biomix \\
\hline 21 & Biomix & Slsubbsn \\
\hline 22 & Sol_Alb & Sol_Alb \\
\hline Unranked & Smfmn & Smfmn \\
\hline Unranked & Smfmx & Smfmx \\
\hline Unranked & Smtmp & Smtmp \\
\hline Unranked & Sftmp & Sftmp \\
\hline
\end{tabular}




\section{CALIBRATION AND VALIDATION RESULTS}

Table 12 shows the final sets of calibrated parameter values for each of the major calibration runs. The major calibration sets included parameter values for snow subbasins, the tributaries of Merced, Stanislaus, Tuolumne, and the overall San Joaquin watershed with the Vernalis outlet. The Vernalis model included results for sediments. Different values for the same parameter were often assigned to different subbasins. For the San Joaquin River flow calibration column, each parameter value was assigned to its own subbasin set. Approximately 40 calibration cycles were performed in order to obtain

these calibration numbers, with an average calibration cycle run time of 24 hours. At least 15 separate models were set up during the calibration process, including at least seven reproductions of the Vernalis models and the set-up of the masked SJ river tributaries. 
Table 12 Calibration Parameter Results

\begin{tabular}{|c|c|c|c|c|c|c|}
\hline \multirow[b]{3}{*}{ Parameter } & \multicolumn{2}{|c|}{ C ALIBRATION } & \multicolumn{2}{|c|}{ P A R A M E TER } & \multicolumn{2}{|c|}{ ES U L T S } \\
\hline & \multicolumn{6}{|c|}{ MAIN TRIBUTARY } \\
\hline & Snow & Stanislaus & Tuolumne & Merced & $\begin{array}{c}\text { SJR } \\
\text { (FLOW) } \\
\end{array}$ & $\begin{array}{c}\text { SJR } \\
\text { (SED) } \\
\end{array}$ \\
\hline ALPHA_BF & 0.31778 & 0.013864 & 0.010393 & 0.036379 & 0.43725 & --------- \\
\hline BIOMIX & ---------- & 0.48627 & ---------- & --------- & --------- & --------- \\
\hline BLAI & 7.6666 & --------- & --------- & --------- & --------- & --------- \\
\hline CANMX & 60.371 & 81.25 & 87.558 & 36.298 & 3.856 & 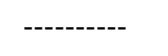 \\
\hline $\mathrm{CH} \_\mathrm{K} 2$ & 488.38 & 282.25 & 18.801 & 188.22 & 391.67 & --------- \\
\hline $\mathrm{CH} \_\mathrm{N} 2$ & 0.27737 & 0.13448 & 0.65205 & 0.14774 & 0.28637 & \\
\hline CN2 & ---------- & --------- & ---------- & --------- & 89.478 & -- \\
\hline EPCO & ---------- & 0.28284 & 0.73593 & 0.78171 & 0.54637 & --------- \\
\hline ESCO & 0.34307 & 0.39089 & 0.53084 & 0.32418 & 0.81163 & \\
\hline GW_DELAY & 5.2358 & 1.2932 & 6.7198 & 2.9168 & 2.6306 & \\
\hline GWNO3 & --------- & --------- & --------- & --------- & ---------- & ---- \\
\hline GW_REVAP & ---------- & 0.00611 & 0.032652 & 0.0019 & ---------- & \\
\hline QWQMN & 200.32 & 1000 & ---------- & 1000 & 16 & \\
\hline RCHRG_DP & --------- & ---------- & ----- & --------- & ----------- & \\
\hline REVAPMN & 33.533 & 3.6958 & ---------- & 21.867 & ---------- & --- \\
\hline SOL_AWC & 3.3232 & -0.036811 & 0.2432 & --------- & 0.76098 & ----- \\
\hline SOL_K & ---------- & 1.9823 & 2.4141 & ---------- & 1250.6 & ---------- \\
\hline SOL_Z & 7.6427 & 1.189 & 11.245 & 12.084 & 2.2939 & ---------- \\
\hline SURLAG & --------- & & & & ---------- & ---------- \\
\hline TLAPS & 27.108 & ---------- & ---------- & ----------- & 34.282 & ---------- \\
\hline USLE_P & --------- & ------ & ------ & ---------- & ---------- & 0.016747 \\
\hline SPCON & ------ & & & ---------- & ------ & 0.79323 \\
\hline SPEXP & ---------- & ------ & ------ & --------- & ---------- & 0.0070337 \\
\hline SMFMX & 5.56 & ----- & ---- & ---------- & ------ & ---------- \\
\hline SMFMN & 5.2504 & ---------- & ------- & ---------- & ---------- & ---------- \\
\hline SFTMP & 8.5 & ---- & ------ & ----------- & ----------- & --------- \\
\hline SMTMP & 12.5 & ---------- & --------- & ---------- & ---------- & ---------- \\
\hline TIMP & 0.42757 & ------ & ------ & ---------- & --------- & --------- \\
\hline CH_EROD & --------- & ---- & ----- & --------- & ---------- & 1.3873 \\
\hline CH_COV & ---------- & ---------- & ----------- & --------- & ---------- & 0.39656 \\
\hline
\end{tabular}


Table 14 shows the NSE values for the final calibration and validation results for flow and sediment for the various tributaries of the San Joaquin watershed. The time steps were either monthly or daily, depending on the data available. Calibration of snow subbasin \#4 was performed without conducting validation due to lack of proper data. Several of the tributaries included two validation values. The starred validation values represent the NSE values after file editing for certain calibration parameters, as explained in Section 4.1. Observed Merced daily flow values were not available from the USGS website after 1996 so substitute data was calculated from the CDEC hourly outflow. However, the unsuccessful NSE results (less than zero) were deemed unreliable and excluded from Table 14 but included in Figure 19 for reference. Merced Calibration results were used in the final Vernalis model. 
Table 13 Calibration/Validation Efficiency Values: Results

CALIBRATION / VALIDATION EFFICIENCY VALUES: RESU L T S

\begin{tabular}{|c|c|c|c|c|c|c|}
\hline $\begin{array}{c}\text { Simulation } \\
\text { Type }\end{array}$ & Location & $\begin{array}{l}\text { Subbasin } \\
\quad \#\end{array}$ & Gage \# & $\begin{array}{l}\text { Time } \\
\text { Step }\end{array}$ & $\begin{array}{l}\text { Time } \\
\text { period }\end{array}$ & $\begin{array}{c}\text { NSE } \\
\text { Results }\end{array}$ \\
\hline \multicolumn{7}{|l|}{ SNOW } \\
\hline $\begin{array}{l}\text { Calibration } \\
\text { FLOW }\end{array}$ & \multicolumn{5}{|c|}{ FLOW } & 0.34 \\
\hline Calibration & Stanislaus R. & 11 & 11303000 & Daily & 1993-1996 & 0.35 \\
\hline Validation & Stanislaus R. & 11 & 11303000 & Daily & $1997-2000$ & -2 \\
\hline Validation* & Stanislaus R. & 11 & 11303000 & Daily & $1997-2000$ & 0.2 \\
\hline Calibration & Tuolumne R. & 16 & 11290000 & Daily & $1993-2000$ & 0.94 \\
\hline Validation & Tuolumne R. & 16 & 11290000 & Daily & $1997-2000$ & 0.62 \\
\hline Validation* & Tuolumne R. & 16 & 1129000 & Daily & $1997-2000$ & 0.5 \\
\hline Calibration & Merced R. & 23 & 11272500 & Daily & 1993-1996 & 0.66 \\
\hline Validation & Merced R. & 23 & 11272500 & Daily & $1997-2000$ & $* * *$ \\
\hline Validation* & Merced R. & 23 & 11272500 & Daily & $1997-2000$ & $* * *$ \\
\hline Calibration & Vernalis $\mathrm{R}$. & 10 & 11303500 & Daily & 1993-1996 & 0.67 \\
\hline Validation & Vernalis R. & 10 & 11303500 & Daily & $1997-2000$ & 0.55 \\
\hline \multicolumn{7}{|l|}{ SEDIMENT } \\
\hline Calibration & Vernalis R. & 10 & 11303500 & Monthly & 1993-1996 & 0.77 \\
\hline \multicolumn{7}{|l|}{ NUTRIENTS } \\
\hline Calibration & Vernalis R. & 10 & 11303500 & Monthly & & --- \\
\hline Validation & Vernalis R. & 10 & 11303500 & Monthly & & --- \\
\hline \multicolumn{7}{|c|}{$\begin{array}{l}\text { NOTE: Only simulations with usable results are included in table; excluding } \\
\text { additional simulations used for analysis purposes only. }\end{array}$} \\
\hline
\end{tabular}

Figures 16-19 compare the simulated data against the observed data for the calibration of the Vernalis outlet, Tuolumne River, and Merced River, as well as Vernalis outlet validation. The simulated output values are shown in blue, and the observed data is shown in red. The graphs show the seasonal and yearly variations in data, as discussed in Section 6.2.

Figure 20 shows simulated data against the observed data for the sediment calibration for the Vernalis outlet model, with simulated output values in red and observed data shown in blue. 


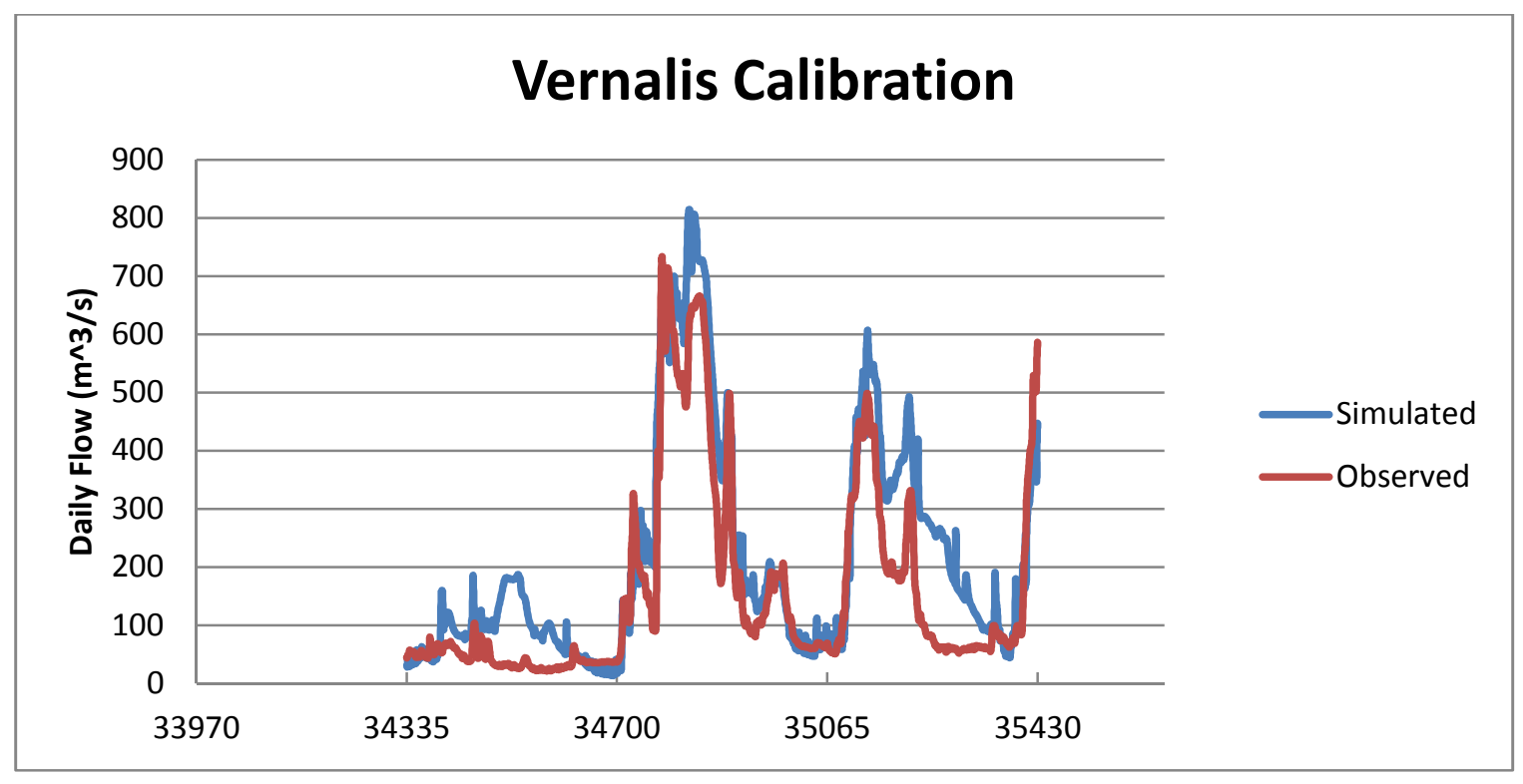

Figure 16 Vernalis Calibration

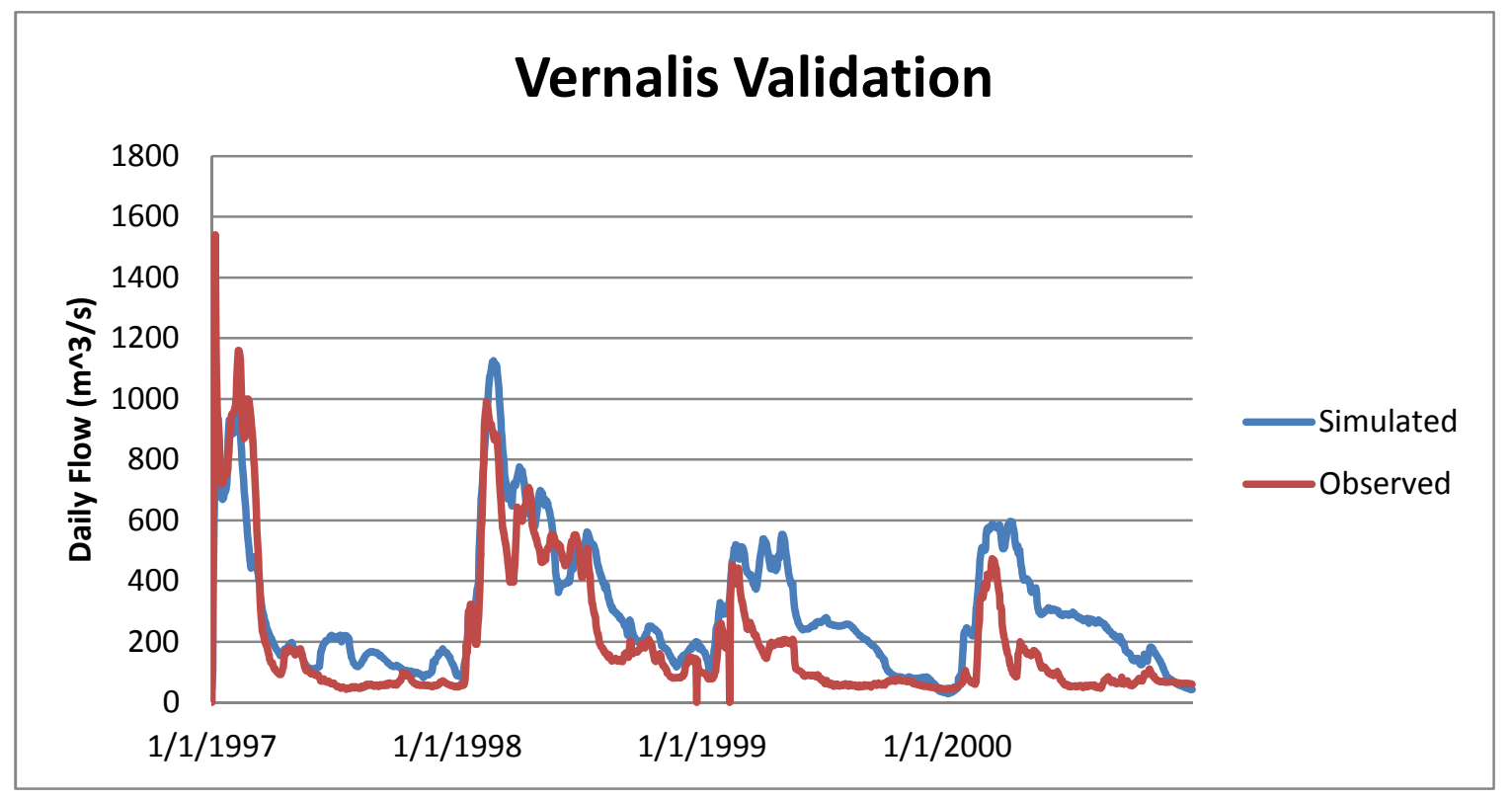

Figure 17 Vernalis Validation 


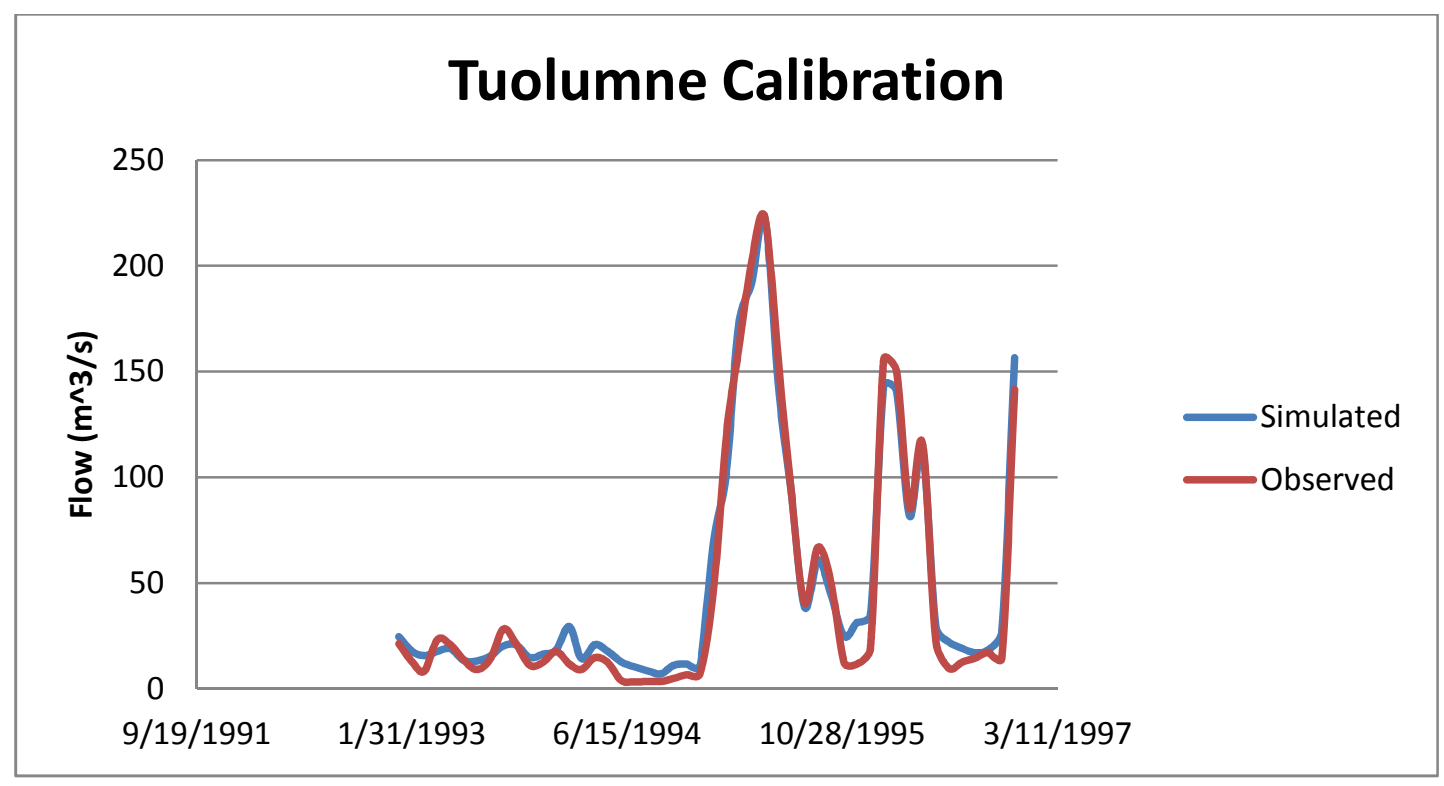

Figure 18 Tuolumne Calibration

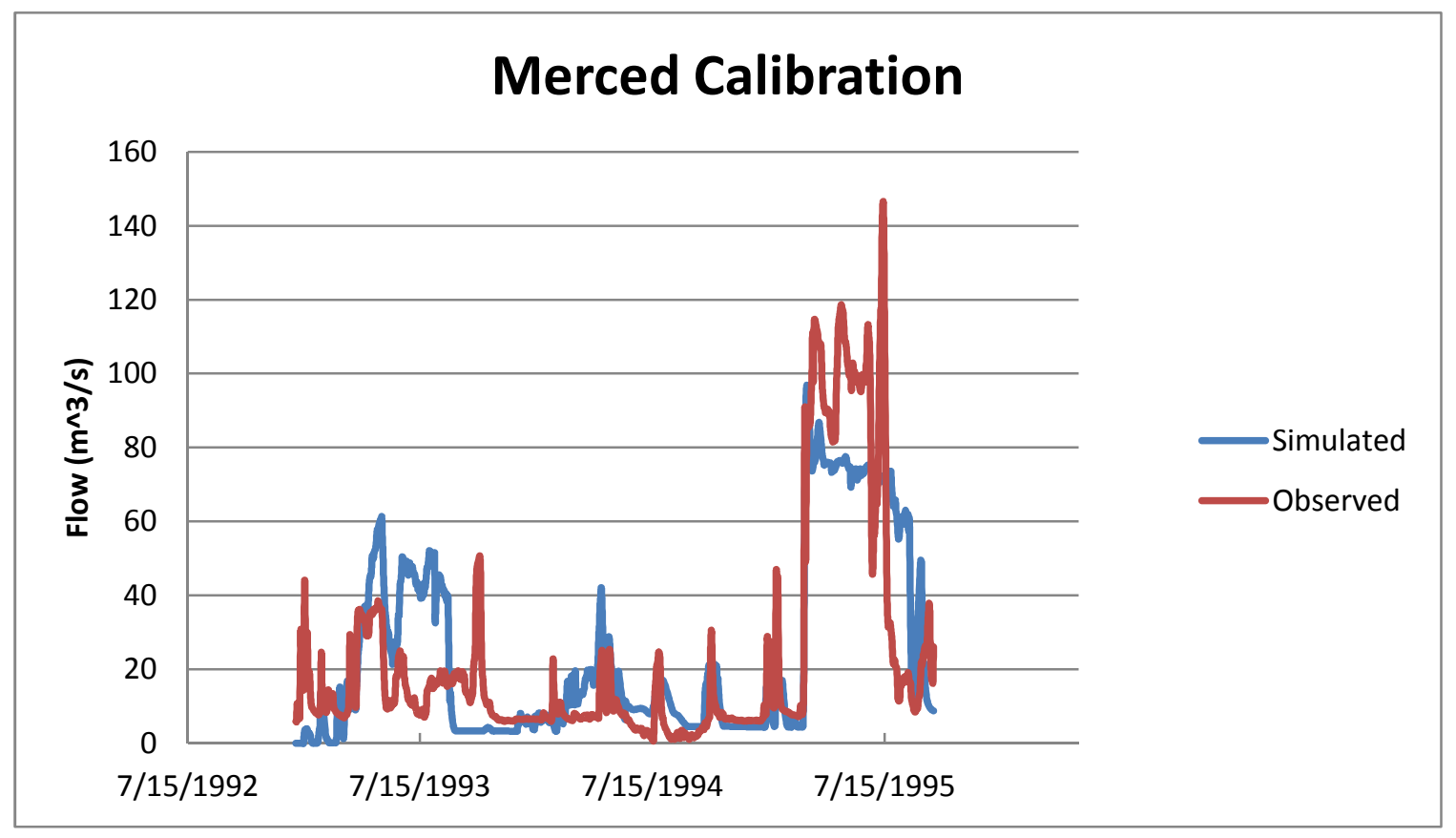

Figure 19 Merced Calibration 


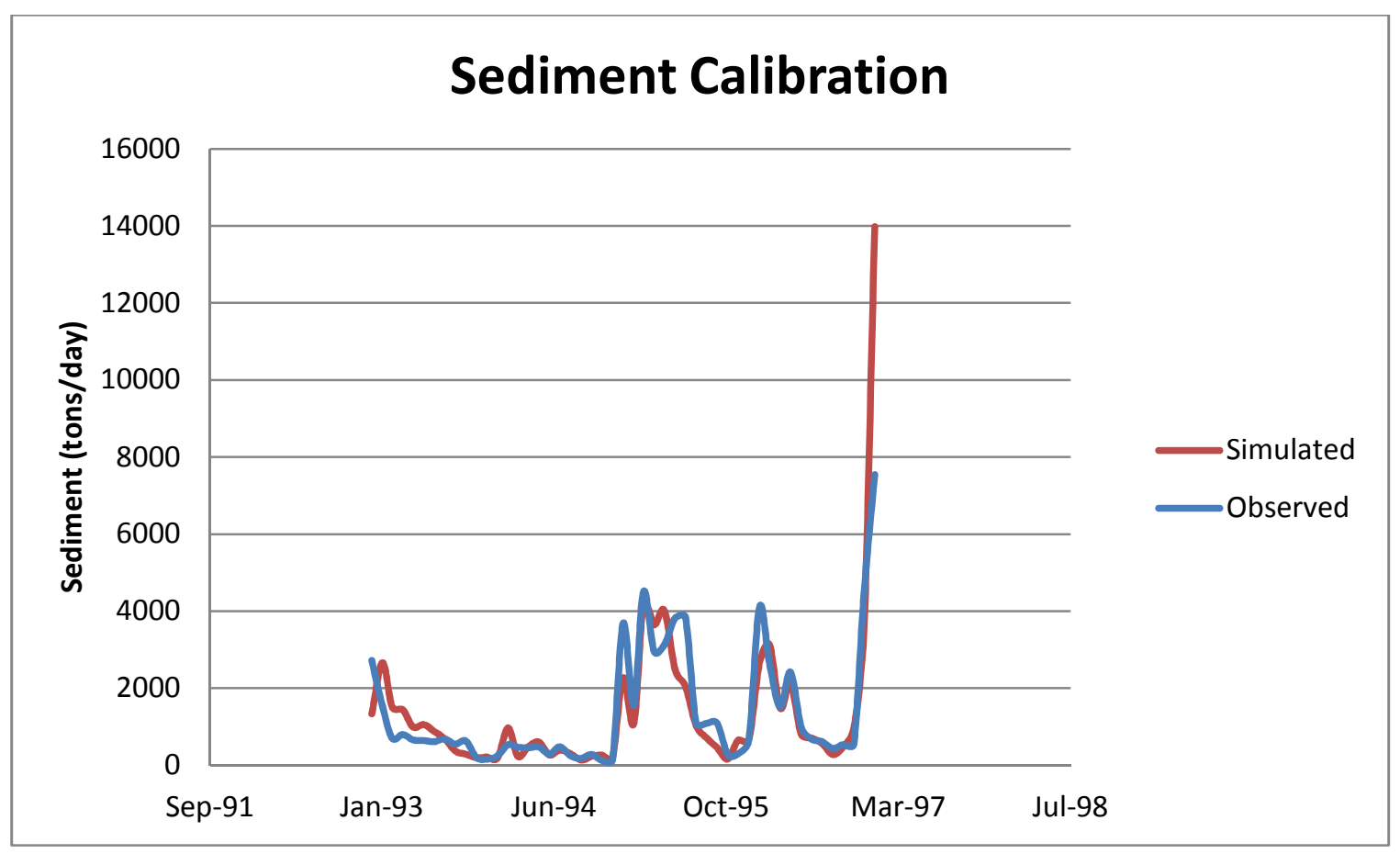

Figure 20 Sediment Calibration

Snow results such as snowfall and snowmelt are ordinarily shown in the HRU output file; however, snow results for the Vernalis model could not be obtained because the HRU file was too large for the program to process. Including the Elevation bands for the upper Tuolumne River model increased in model accuracy after successive model runs which excluded elevation bands at first and included them in later runs. Relevance of elevation bands for snow hydrology is explained in Section 2.2. 


\section{CHAPTER 6 : DISCUSSION OF RESULTS}

\subsection{WATERSHED CHARACTERISTICS}

The physical properties of the San Joaquin watershed represented by the San

Joaquin watershed model met spatial expectations. There were three main geographic regions; the coastal mountain range to the west were predominantly range brush land use with a slope greater than 5\% and soil types that range between sandy, silty, clayey, and rocky. The valley region typically has land slopes less than 5\%, soil types that are predominantly sandy and silty, and large portions of agricultural land use. The Sierra Nevada mountainous range was predominantly forested with land slopes greater than $5 \%$ and soil types that are typically rocky. There were also large areas of wetlands located in the western valley area, as shown in purple in Figure 13, typical of the Mud and Salt Sloughs as shown in Figure 21.

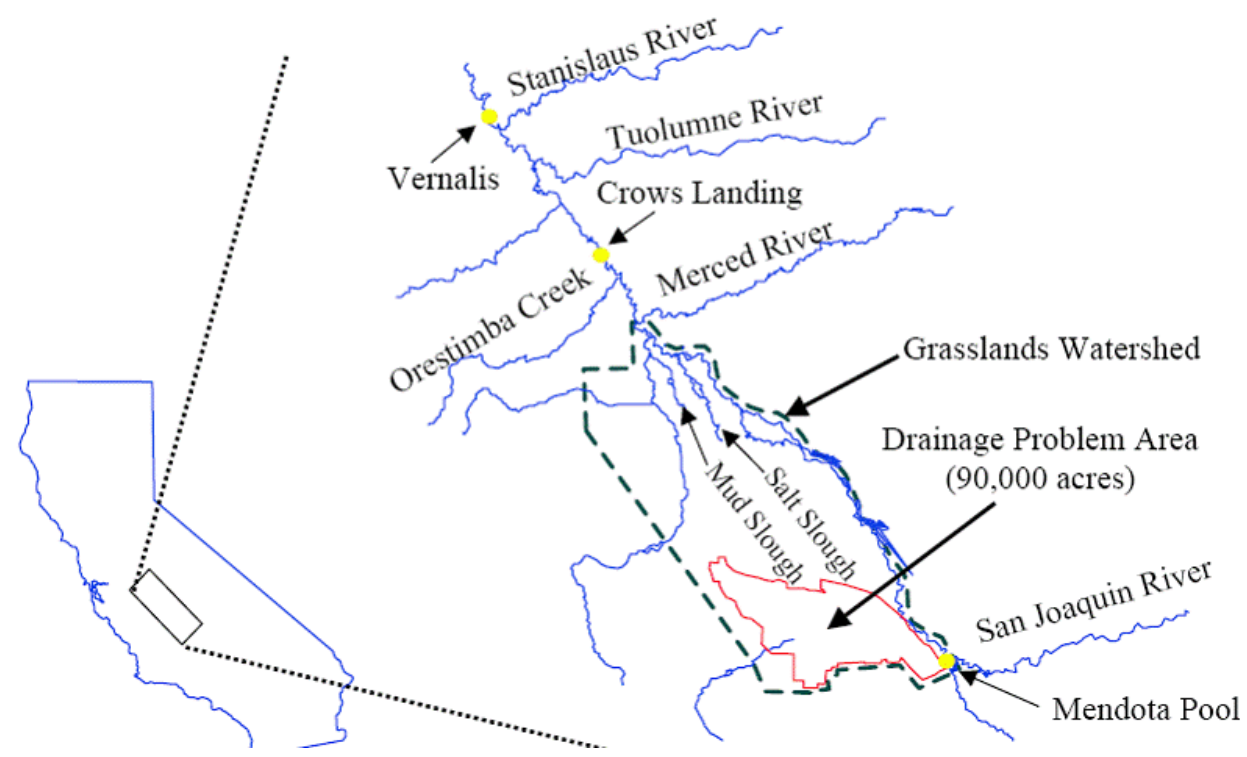

Figure 21 Mud and Salt Sloughs 
The flow averages for simulated validation runs and observed values for the same time frame are shown in table 15. The combined averages of the Merced, Tuolumne, and Stanislaus simulated daily flows were $66 \%$ of the total flow of the Vernalis outlet. This matched expected trends from an EPA study, which credits the Merced, Tuolumne, and Stanislaus Rivers for two-thirds of flow in the San Joaquin River. Mud and Salt Sloughs, other creeks that drain from the west, drainage canals that flow directly to the SJR, and the intermittent upstream SJR, contribute the remaining one-third of streamflow to the SJR (Selah 2007).

Table 14 Validation Averages

\begin{tabular}{lcc}
\multicolumn{2}{c}{ V A L I D A T I O N } & A V E R A G E S \\
\hline \hline River & Data Type & $\begin{array}{c}\text { Average Daily } \\
\text { Flow (m^3/s) }\end{array}$ \\
Stanislaus & Observed & 37.7 \\
& Simulated & 43.3 \\
Tuolumne & Observed & 51.2 \\
& Simulated & 56 \\
Merced & Observed & 59.65 \\
& Simulated & 28.97 \\
Vernalis (Flow) & Observed & 317.5 \\
& Simulated & 194.4
\end{tabular}

Table 16 shows comparison of simulated percentages of land use versus expected percentages of land use. The SWAT land use classification was obtained from the SWAT HRU soil/landuse report. The USEPA land use classification came from the 2007 EPA study (Selah 2007). The table shows that the land use classifications resulting from the SWAT HRU analysis generally corresponded with the land use classifications put forth by the USEPA study. 
Table 15 Land Use Comparison

LAND USE COMPARISON

\begin{tabular}{cccc}
\hline \hline SWAT & & \multicolumn{2}{c}{ USEPA REPORT } \\
\hline Land Use Classification & Percentage & Land Use Classification & Percentage \\
\hline Forest \& Range-Brush & 42 & Forest Land & 39 \\
Agricultural & 31 & Cropland and pasture & 32 \\
Range-grasses & 25.7 & Rangelands & 23 \\
Arid-Range & 2.3 & Barren Land & 3 \\
Wetlands & 0.52 & Wetlands & 1 \\
Residential-High Density & 0.25 & Urban Areas & 2
\end{tabular}

Table 17 shows the average reservoir inflows and outflows for the Vernalis model after a nitrate calibration run. The table shows the effect of nitrate retention of the six main reservoirs of the model. A possible source of nitrate inflow is from the spatial location of the reservoir in the model, as explained in Section 2.2 and discussed in Chapter 7.

Table 16 Reservoir Averages - Nitrate Calibration

\begin{tabular}{cccc}
\hline R E S E R V O I R & A V E R A G E S - N I T R A T E & C A L I B R A T I O N \\
\hline \hline RESERVOIR & $\begin{array}{c}\text { SIMULATED } \\
\text { AVERAGE DAILY } \\
\text { NITRATE INFLOW } \\
\text { (kg/day) }\end{array}$ & $\begin{array}{c}\text { SIMULATED DAILY } \\
\text { AVERAGE NITRATE } \\
\text { OUTFLOW } \\
\text { (kg/day) }\end{array}$ & $\begin{array}{c}\text { PERCENT } \\
\text { RETAINED }\end{array}$ \\
1 & 2785 & 2160 & $\%$ \\
2 & 658 & 516 & 22 \\
3 & 121726 & 61822 & 22 \\
4 & 1965 & 1642 & 49 \\
5 & 1340 & 111 & 16 \\
6 & 1396 & 142 & 92 \\
& & & 90
\end{tabular}

\subsection{DISCUSSION OF MODEL EVALUATION RESULTS SENSITIVITY ANALYSIS}

Sensitivity analysis revealed that generally the alpha_bf value was the most sensitive parameter (Table 11). The alpha_bf constant is a groundwater parameter, $\boldsymbol{\alpha}_{\mathrm{gw}}$, combining the terms of hydraulic conductivity of the aquifer ( $\mathrm{mm} /$ day), the specific yield of the shallow aquifer $(\mathrm{m} / \mathrm{m})$, and distance from the ridge or subbasin divide for the 
groundwater system to the main channel (m). A high alpha_bf value indicates that groundwater recharge has a large influence on groundwater baseflow, whereas a low value indicates that groundwater recharge has little to no groundwater influence (Nietsch 2005). The high sensitivity ranking of the alpha_bf parameter reveals the important role groundwater plays in watershed hydrology, specifically how the change in groundwater flow to the main channel over time plays an important role.

The ranking of the other parameters were usually a mixture of parameters for groundwater (alpha_bf, gw_delay, gw_revap, qwqmn), soil (sol_k, sol_z, Sol_awc) topography (slope, slsubbsn) and routing (Cn2, Surlag, Cn_K2, Ch_N2), as well as plant growth (Esco, epco, and Canmx) (Table 11). The mixture of parameter sensitivities to various hydrologic processes (groundwater, soil, topography, etc.) indicates a watershed which is sensitive to all the hydrologic processes, and therefore balanced.

Snow parameters (SMFMX, SMFMN, SFTMP, SMTMP, TIMP) were surprisingly insensitive, generally ranking the lowest, 27 . The lower sensitivities were most likely due to the effect of reservoirs on the San Joaquin watershed model, absorbing the effect of snowmelt and releasing water based on operating rules. Therefore, in spite of their insensitivity, the snow parameters were an important part of the snowmelt and snowfall calibration.

\section{DISCUSSION OF CALIBRATION RESULTS}

A concern in using the "separate model" format with the use of the masks was that the delineated subbasins of the SJ watershed tributaries may not necessarily represent the conditions of the separately delineated masked area, as explained in Section 4.2. The calibrated NSE numbers of the tributaries are with masks, while the validated 
NSE numbers of the tributaries are without masks; therefore, a comparison of validation versus calibration NSE results shows the effectiveness of the "separate model" format and the use of masks. In general, the validation NSE results were less than calibration NSE results (as expected) but not significantly, as discussed with each tributary.

The Tuolumne River calibration gave a NSE of .94. This value was very good according to the guidelines set in Section 4.2, where a NSE of .5 or greater is considered satisfactory and a NSE of .65 or greater is considered very good. The validation NSE results gave .62 and .5 , before and after file editing, both considered good. The difference between the Calibration NSE results and the Validation NSE results shows that the use of masks most likely reduced accuracy in the Vernalis model. The reduced NSE value after file editing for the Tuolumne River, from a NSE of .62 to a NSE of .5 was not expected, since the file editing was expected to increase the accuracy of the model.

The Merced River calibration gave a NSE of .66, considered very good. Observed data from the USGS website for Merced daily outflow were not available after 1996, as discussed in Section 5.2, so no NSE results are available for the validation of the Merced River watershed. The results of the Merced River calibration were used in the final Vernalis River model.

The Stanislaus River calibration gave a NSE of .35, considered unsatisfactory. The second validation NSE value of .2 was also unsatisfactory but close in value to the calibrated NSE of .35 , which shows consistency between the masked river tributary model and the SJ watershed model. The NSE results of -2 and .2 show the change in model accuracy before and after file editing of two parameters (GW_REVAP, 
SOL_AWC), showing the sensitivity of the model to parameter change. This margin of difference is much greater than anticipated, so that other errors with that particular Stanislaus model are suspected. The results were still deemed useable and were input into the final Vernalis model.

The Vernalis outlet San Joaquin River watershed, which included the entire area of the San Joaquin watershed, gave a calibration NSE of .66, considered very good. The Vernalis validation NSE results yielded a lower value of .55, still considered good, and therefore useable for sediment and nutrient calibration and validation. There was no use of masks or file editing between the calibration and validation models of the Vernalis outlet model.

The simulated Vernalis flow was less varied and lower in total average than the observed Vernalis flow but was able to follow the observed seasonal variation, important for an analysis of seasonal fertilizer application. According to Table 15, the Vernalis observed average was approximately $150 \%$ of the simulated average, and the graph in Figure 16 shows a close seasonal correlation between the simulated and the observed.

Overall, the observed data tended to be more sporadic than the simulated data, as shown in Figures 16-19. There are several sources of water use and diversions which could count for this difference, including irrigation and manmade waterways, which are difficult to account for in SWAT, but the NSE values dictated the utility of the model.

For snow calibration, an initial sensitivity and calibration set was performed for the snow parameters for two different Sierra Nevada sites; upper Stanislaus River and upper Tuolumne River. The upper Stanislaus River results gave erroneous results, most 
likely due to erroneous flow data complicated by several existing reservoirs, so only the upper Tuolumne River results are analyzed and discussed here.

The main objective of the snow parameterization was to represent snow fall and snow melt accurately and establish the five snow parameters (Sftmp, Smfmn, Smfmx, Smtmp, Timp) over the entire SJ basin. The snow parameterization objective also included parameter calibration for hydrologic parameters for several upstream subbasins. Snow parameterization was accomplished by running several calibration cycles, limited by several difficulties. One difficulty was that the measured snowfall and snowmelt data available from the CDEC website were not comparable to the simulated snowfall and snowmelt. Subjective and manual analysis of the HRU output file (snow fall and snow melt for each HRU, per day) guided the process; parameter sets which yielded little to no snowfall and snowmelt were considered bad (although these sets may have had a higher NS efficiency), while parameters sets were considered good if the model yielded higher amounts of snowfall and modeled snowmelt which lasted into the spring and summer months.

The parameter outputs also had to make logical sense. For instance, a parameter set was considered bad if the model gave a negative value for a parameter which should have only been positive. These negative values were difficult to adjust for in some cases of parameter calibration. Modeled flow output accuracy for snow parameter calibration was based on these constraints, as well as the Nash-Sutcliffe efficiency (NSE) given for each run.

The final results of snow parameter calibration of the upper Tuolumne River are shown in Section 5.2. The snow parameter set included two snow parameters which were 
set at a specific value instead of being calibrated: a snow fall temperature of $8.5^{\circ} \mathrm{C}$ and a snowmelt temperature $12.5^{\circ} \mathrm{C}$. These two parameters were set after several calibration cycles in order to force the model to simulate more snowfall and a longer snowmelt period. The final NS efficiency of the upper Tuolumne River was .34, which was not acceptable by the modeling guidelines set forth in Section 4.2. However, as these were the most accurate results after numerous calibration runs (more than ten), and as the snow calibration was not the main objective of the model, the snow parameter results were used for the rest of the calibration cycles, with moderate success.

The optimization of Orestimba River gave an initial NSE below 0.5. The model had difficulty modeling the high water table and lack of proper drainage, physical properties typical of SJ farmland west of the SJ River. The parameter values reflected this difficulty. The runoff curve number $(\mathrm{CN})$ parameter is a measure of surface water runoff, and is a function of soil permeability, land use, and antecedent soil water conditions (Nietsch 2005). A high CN indicates high surface water runoff; a low CN indicates low surface water runoff. The initial negative values for the $\mathrm{CN}$, which are not within the range of possible $\mathrm{CN}$ values, indicate the model's efforts to retain surface water runoff to reflect the lack of proper drainage in areas like the Mud and Salt Sloughs. Because of the low NSE results of the Orestimba River and negative CN values, the Orestimba calibration results were not included in the final Vernalis model and not shown in Section 5.2 .

Although groundwater parameters were an essential part of the calibration for the San Joaquin River watershed model, the role of nitrates in groundwater needs further analysis which is beyond the scope of this study. The San Joaquin river watershed needs 
a special approach in SWAT which involves the interactions between irrigation, drainage, and base flow separation, etc., which would be essential for an understanding of irrigation runoff contribution to nitrate concentrations in groundwater.

\section{SEDIMENT RESULTS}

Sediment calibration gave a NSE of .77, considered very good, and the sediment validation was similarly considered very good. However, after sediment validation, a problem with the Vernalis model arose as a result of the file editing, which made the sediment parameter calibration and validation values unusable.

In most cases the file editing improved validation accuracy, but problems arose when trying to calibrate for parameters within the same files that had been manually edited. For instance, the basin file (.bsn) was manually edited for the snow parameters (SMFMX, SMFMN, SFTMP, SMTMP) which were outside the allowable range given by the SWAT interface. These parameters were unaltered throughout the calibration/validation process until the sediment calibration, since the Spcon and Spexp parameters are part of the (.bsn) file. Due to this parameter conflict, the snow parameters reverted back to default values when performing the sediment calibration. So although the results of the Sediment calibration and validation showed the potential of the Vernalis model to model sediment, the Vernalis sediment calibration rendered the model unusable for a Vernalis nitrate calibration.

\section{NUTRIENT RESULTS}

Despite the inaccuracies of the Vernalis sediment model, a test run for the calibration of nitrates for the Vernalis outlet model was performed in order to determine the potential of the model for nitrate calibration. Only a few conclusions were gleaned 
from this calibration run. Fertilizer application was successfully applied via the SWAT interface for each land use according to Table 7, which increased nutrient loading of the model. Reservoir retention was as low as $20 \%$ and as great as $90 \%$ for some of the reservoirs in the Vernalis model, which shows a potential of error in too much or too little nutrient retention.

Future studies on the SJR for nutrients would need to be compared to measured results which show that the eastside tributaries of the Merced, Tuolumne, and Stanislaus Rivers account for only 17 to 25 percent of the nitrite and nitrate load at the Vernalis site, while the Mud and Salt Sloughs contribute 25 to 51 percent (Selah 2007).

\section{PROGRAM EFFECTIVENESS}

One poignant weakness of the SWAT model was in the input editing interface. Unless the calibration sets were properly restrained at the outset of the calibration run, calibration results would give parameters that were well outside the allowable range of the interface. For instance, several calibration cycles were performed for the Vernalis sediment model, which finally yielded satisfactory results. However, the $\mathrm{CH}$ EErod parameter was outside the range of allowable values that could be input into the model. This discrepancy between calibrated values and allowable parameter input values occurred several times during the calibration and prolonged the process. A temporary solution to this problem was to manually edit input files (Section 4.2), but as previously mentioned, the method of manually editing input files created problems during sediment calibration, which rendered the final calibrated sediment model unusable. 


\section{CHAPTER 7 : CONCLUSIONS \& RECOMMENDATIONS}

\section{SUMMARY OF RESULTS}

The success of the model depended on the ability of the model to simulate hydrology and hydraulics in the San Joaquin watershed adequately enough for potential future studies on fertilizer application and nitrate loading. This objective depended on the ability of the model to account for major tributary flow from the eastern tributaries (Stanislaus River, Merced River, Tuolumne River, upper San Joaquin River) as well as tributary flow from the area west of the San Joaquin River (Orestimba River, Mud and Salt Sloughs). The eastern tributaries gave satisfactory results, while the area west of the San Joaquin needs further study, particularly for nutrient loading. Ideally, the model had to represent all areas of the watershed accurately so that future fertilizer application studies could focus on specific areas within the watershed, such as an individual river tributary or a specific land use, as a study of nitrate loading within that particular area and its effect on the entire watershed. Based on this objective, the model is a successful base for future studies with many areas of recommended application and further development.

The snow cover components of the SJR model proved the most difficult to model in terms of seasonal accuracy and an adequate representation of a snowpack. A snowpack typically stores snow in the winter and releases water during the spring and early months of summer. The model had difficulty in retaining snow cover; heavy rains and snow were often converted into runoff within the same month of occurrence, a source of error. The model would then try to compensate for the insufficient lag time of water through other runoff coefficients, the surface lag time or the groundwater delay parameters (SURLAG and GW_DELAY). These erroneous snow cover results were compounded by the 
presence of reservoirs and water diversions in the mountains which were excluded from the model.

The inclusion of the six major reservoirs on each of the major tributaries feeding into the San Joaquin River greatly tempered the inaccuracies of the Sierra Nevada snow cover. Since reservoir outflow was a reliable measured daily output which was downloaded and included in the model, overall model accuracy was obtained at streamflow outlets downstream of the major reservoirs.

However, reservoirs were also a possible source of inaccuracy of the nutrient and sediment outputs due to sediment and nitrate retention. The reservoirs are geographically located at the base of the mountains, which would retain much of the sediments and nutrients of the mountains but would not effect the majority of fertilizer application on the land uses downstream. However, as discussed in Section 2.2, the SWAT program modeled reservoirs at the outlet of the subbasin, which could potentially retain much of the sediment and nutrient outputs downstream of agricultural land use area in the model.

The water diversions were successfully incorporated into the model, representing some of the major diversions in the San Joaquin watershed. The inclusion of water diversions in the model shows the versatility of the SWAT model in incorporating several hydrology components into one model.

The use of masks proved to be an effective method for speeding up the calibration process without decreasing the accuracy by appreciable amounts. In future studies for similar watersheds the use of a mask for a tributary calibration may be advantageous but should be evaluated on a case by case basis. The upper Tuolumne River watershed, the Stanislaus River, and the Tuolumne River demonstrated the usefulness and success of the 
masks. The method of bypassing the SWAT interface by editing the files for parameters outside the allowable range was a successful method for calibration and validation until the Vernalis sediment calibration. Future studies will need to be conducted in order to calibrate the Vernalis model for sediment without changing the parameters of the Vernalis flow calibration.

The Tuolumne River watershed and Merced River watershed calibrations gave very good NSE results, while the Stanislaus River watershed calibration gave unsatisfactory results. Overall, these results were input successfully into the Vernalis model so that smaller operations of the model (tributary flow, snow cover, etc.) were accurately accounted for in the larger model. The tributary calibration helped prevent inaccuracy in the model that might have resulted from oversight of the smaller components.

The Orestimba River calibration gave unsatisfactory NSE results, and the CN values were consistently negative or close to zero. Although this may have adequately represented the poor drainage in various parts of the western San Joaquin watershed, it was not useable for results in the Vernalis outlet model. Further study is needed to represent the western area of the San Joaquin Valley and to model nitrate loading within that area.

The final calibrated Vernalis watershed model is acceptable to use for a study on the SJR watershed and to analyze various physical properties of the watershed. The NSE results of the Vernalis model validation were considered good according to the standards set in Section 4.2. Various properties of the modeled and actual watershed closely resemble each other as shown in Section 5.1, such as topography, soil classification, and 
land use, and the expected flow contribution from the eastern tributaries matched expected values. However, further study and analysis is required prior to sediment and nitrate calibration and validation in order to work around the input file problem discussed in Section 6.2. Studying the various effects of soil, land use, snowmelt, and reservoir retention on nitrates will require additional time and consideration.

\section{RECOMMENDATIONS/FURTHER STUDY}

Another delineation of the watershed is suggested where an outlet table is added which contains the watershed outlet plus 6 additional outlets below each of the major reservoirs. These added outlets should reconstruct the subbasins so that each reservoir is spatially near a subbasin outlet. An analysis of this reconstructed watershed might prove useful for future studies which involve the use of major reservoirs. Along the same idea, a future delineation of the watershed which includes outlets located more spatially near known river gages could improve model accuracy.

Ultimately, several useful modeling conclusions can be drawn from the effectiveness of the San Joaquin River watershed model, but further research is needed in order to analyze the watershed for nitrate accuracy and apply those results to policies and fertilizer use in the San Joaquin Valley. Following the preliminary steps outlined in Section 4.2, future studies based on the validated Vernalis model would need to adequately validate the model for sediment output (tons/day), then calibrate and validate the model for nutrient output ( $\mathrm{kg} / \mathrm{day})$. Analyzing the subbasin output file would show trends in the Nitrate runoff for comparison with expected results, as explained in Section 
6.2. After this, a study in the effects of fertilizer use on Nitrate runoff would be theoretically possible (Arabi 2008).

Developing a large-scale model in which the computation time required may sometimes span several days inevitably requires some comments about the user interface ability of the modeling program. Although the SWAT model was shown to have the capabilities of successfully incorporating several hydrologic and hydraulic components over a large area, the time intensive file formatting and extensive model setup called into question the practicality of such a model. The SWAT model was shown to be a powerful and versatile tool capable of simulating a watershed approximately $35,000 \mathrm{~km}^{2}$ in size, but may be better suited for smaller watersheds of study due to time and resource constraints. 


\section{CHAPTER 8 : BIBLIOGRAPHY \& ACKNOWLEDGEMENTS}

Abbaspour, Karim C. "SWAT-CUP4." N.d. MS. EAWAG Aquatic Research, 2011 n.p.

Arabi, Mazdak, Jane R. Frankenberger, Bernie A. Engel, and Jeff G. Arnold. "Representation of Agricultural Conservation Practices with SWAT." Hydrological Processes 22.16 (2008): 3042-055. Print.

Baker, Andrea, Michael Carroll, and Gary Freeman. Assessing the Region via Indicators, The Economy 1999-2004. Rep. Modesto: Great Valley Center, 2005. Print.

Bay-Delta Modeling Forum. Protocols for Water and Environmental Modeling. Publication. California Water and Environmental Modeling Forum, 21 Jan. 2000. Web. <http://www.cwemf.org/>.

Bracmort, K. S., M. Arabi, J. R. Frankenberger, B. A. Engel, and J. G. Arnold. 2006. Modeling long term water quality impact of structural BMPs. Trans. ASABE 49(2): 367-374.

Brown, Todd R. "Much of Valley's Water Not Safe to Drink." Healthy Cal. N.p., 17 July 2012. Web. 02 Nov. 2012. <http://www.healthycal.org/archives/9220>.

Burton, Carmen, and Belitz, Kenneth. Ground-Water Quality Data in the Southeast San Joaquin Valley, 2005-2006-Results from the California GAMA Program. Rep. N.p.: U.S. Department of the Interior, 2008. Print. Ser. 351.

California Environmental Resources Evaluation System (CERES). "The San Joaquin Valley Bioregion -- An Overview." California Natural Resources Agency. 2005. Web. 04 Nov. 2012. $<$ http://ceres.ca.gov/geo_area/bioregions/San_Joaquin_Valley/index.html>.

California Water and Environmental Modeling Forum. A Strategic Analysis Framework for Managing Water in California. Publication. California Water and Environmental Modeling Forum, Sept. 2005. Web. <http://www.cwemf.org/>.

Canter, Larry W. Nitrates in Groundwater. Boca Raton, FL: Lewis, 1996. Print.

Central Valley Regional Water Quality Control Board (CVRWQCB). Basin Planning Program. Rep. State Water Control Board, 5 Aug. 2005. Web. 25 Oct. 2012. $<$ http://www.waterboards.ca.gov/centralvalley/water_issues/basin_plans/planning _overview.pdf>.

Chaplot, V., A. Saleh, D. B. Jaynes, and J. Arnold. 2004. Predicting water, sediment, and NO3-N loads under scenarios of land use and management practices in a flat watershed Water Air Soil Pollut. 154(1-4): 271-293.

Committee on Irrigation-Induced Water Quality Problems, Water Science and Technology Board (WSTB), Commission on Physical Sciences, Mathematics, and Resources, and National Research Council, comps. Irrigation Induced Water Quality Problems: What Can Be Learned from the San Joaquin Valley Experience. Washington, DC: National Acad., 1989. Print. 
Cowan, Tadlock. California's San Joaquin Valley: A Region in Transition. Washington D.C., USA. UNT Digital Library. http://digital.library.unt.edu/ark:/67531/metacrs8225/.

Creedon, Pamela. The State of the Central Valley Region Address. Rep. Regional Water Quality Control Board, 1 Dec. 2011. Web. 25 Oct. 2012.

$<$ http://www.waterboards.ca.gov/centralvalley/board_info/exec_officer_reports/st ate_of_cvrwqcb_dec_2011.pdf>.

Department of Water Resources. Standard Land Use Legend. Rep. N.p.: Statewide Planning Branch Division of Planning, 1993. Print.

Domagalski, Joseph L., and Neil M. Dubrovsky. "Pesticide residues in ground water of the San Joaquin Valley, California." Journal of Hydrology 130.1-4 (1992): 299338. Web. 3 Jan. 2012.

Eldridge, Audrey, and Neil Dubrovsky. Nitrogen and Phosphorus Pollution Series Nitrate in Ground Water. Comp. Jill Jonas. EPA, 29 Mar. 2011. Web. 26 Oct. 2012. <http://water.epa.gov/learn/training/wacademy/upload/2011_03_29_slides.pdf>.

Ficklin, Darren L., Yuzhou Luo, Eike Luedeling, and Minghua Zhang. "Climate Change Sensitivity Assessment of a Highly Agricultural Watershed." Journal of Hydrology 374 (2009): 16-29. Print.

Ficklin, Darren L., Yuzhou Luo, Eike Luedeling, Sarah E. Gatzke, and Minghua Zhang. "Sensitivity of Agricultural Runoff Loads to Rising Levels of $\mathrm{CO} 2$ and Climate Change in the San Joaquin Valley Watershed of California." Environmental Pollution 158.1 (2010): 223-34. Print.

Gassman, P. W., M. R. Reyes, C. H. Green, and J. G. Arnold. "The Soil and Water Assessment Tool: Historical Development, Applications, and Future Research Directions." American Society of Agricultural and Biological Engineers 50.4 (2007): 1211-250. Print.

Germon, J. C., and S. Dupain. Management Systems to Reduce Impact of Nitrates. London: Elsevier Applied Science, 1989. Print.

Green, C., and A. Vangriensven. "Autocalibration in Hydrologic Modeling: Using SWAT2005 in Small-scale Watersheds." Environmental Modelling \& Software 23.4 (2008): 422-34. Print.

Harter, T. and J. R. Lund. 2012. Project and Technical Report Outline. Technical Report 1 in: Addressing Nitrate in California's Drinking Water with A Focus on Tulare Lake Basin and Salinas Valley Groundwater. Report for the StateWater Resources Control Board Report to the Legislature. Center for Watershed Sciences, University of California, Davis.

Jonas, Jill, Audrey Eldridge, and Neil Dubrovsky. Nitrogen and Phosphorus Pollution Series: Nitrate in Ground Water. EPA, 29 Mar. 2011. PPT. 
Jurgens, Bryant C., Burow, Karen R., Dalgish, Barbara A., and Shelton, Jennifer L. 2008. Hydrogeology, Water Chemistry, and Factors Affecting the Transport of Contaminants in the Zone of Contribution of a Public-Supply Well in Modesto, Eastern San Joaquin Valley, California Scientific Investigations Report 5156

King, Jack, Jr. Air Quality and Fertilization Practices: Establishing a Calendar of Nitrogen Fertilizer Application Timing Practices for Major Crops in the San Joaquin Valley. Tech. Fertilizer Research and Education Program, 8 August, 2007. Web. 30 Oct. 2012.

Luo, Yuzhou, Xuyang Zhang, Xingmei Liu, Darren Ficklin, and Minghua Zhang. "Dynamic Modeling of Organophosphate Pesticide Load in Surface Water in the Northern San Joaquin Valley Watershed of California." Environmental Pollution 156.3 (2008): 1171-181. Print.

Moore, Eli, and Eyal Matalon. The Human Costs of Nitrate-contaminated Drinking Water in the San Joaquin Valley. Rep. no. ISBN: 1-893790-31-2. Oakland: Pacific Institution, 2011. Print.

Muleta, Misgana. Snow Hydrology. N.p.: n.d. PPT.

Neitsch, S.L., J.G. Arnold, J.R. Kiniry, J.R. Williams. Soil and Water Assessment Tool Theoretical Documentation. 2005a. MS. Texas A\&M University, Temple. Soil and Water Assessment Tool. Blackland Research Center, Jan, 2005. Web. $<$ http://swatmodel.tamu.edu/software/arcswat/>.

Neitsch, S.L., J.G. Arnold, J.R. Kiniry, R. Srinivasan, J.R. Williams. Soil and Water Assessment Tool Input/Output File Documentation.. 2005b. MS. Texas A\&M University, Temple. Soil and Water Assessment Tool. Blackland Research Center, Sept. 2004. Web. <http://swatmodel.tamu.edu/software/arcswat/>.

$\mathrm{Ng}, \mathrm{H} . \mathrm{Y} . \mathrm{F}$ et al. "Modeling and testing of the effect of tillage, cropping and water management practices on nitrate leaching in clay loam soil." Agricultural Water Management 43.1 (2000): 111-131. Web. 17 Jan. 2012.

Potter, Christopher, Charles Krauter, and Steven Klooster. Statewide Inventory Estimates of Ammonia Emmisions from Native Soils and Chemical Fertilizers in California. Rep. California Air Resources Board, 30 June 2001. Web. 30 Oct. 2012.

Quinn N.W.T. , C.W. Chen and W.T. Stringfellow. 2000. A Decision Support System for Real-Time Management of Dissolved Oxygen in the Stockton Deep Water Ship Channel. Environmental Software Systems. Environmental Information and Decision Support. IFIP TC5 WG5.11, 5th International Symposium on Environmental Software Systems (ISESS'2000), May 28-June 2, 2000 Austria. Quinn, N.W.T., Tulloch, Alice. 2002. San Joaquin River Diversion Data Assimilation, Drainage Estimation and Installation of Diversion Monitoring Stations. CALFED Bay-Delta Program. 
Quinn, N.W.T. et al. 2005. "Elements of a decision support system for real-time management of dissolved oxygen in the San Joaquin River Deep Water Ship Channel." Environmental Modelling \& Software 20.12: 1495-1504. Web. 3 Jan. 2012.

Ritter, William F., and Adel Shirmohammadi. Agricultural Nonpoint Source Pollution: Watershed Management and Hydrology. Boca Raton, FL: Lewis, 2001. Print.

River Discharge Technical Committee (RDTC). River Discharge Report. Rep. San Joaquin Valley Drainage Implementation Program, 13 Jan. 1999. Web. $<$ http://www.water.ca.gov/>.

Saleh, D.K., Domagalski, J.L., Kratzer, C.R., and Knifong, D.L., 2007, Organic carbon trends, loads, and yields to the Sacramento-San Joaquin delta, California, water years 1980-2000, second edition: U.S. Geological Survey Water-Resources Investigations Report 03-4070, 77. p

Saleh, D.K., Kratzer, C.R., Green, C.H., and Evans, D.G., 2009, Using the Soil and Water Assessment Tool (SWAT) to simulate runoff in Mustang Creek Basin, California: U.S. Geological Survey Scientific Investigations Report 2009-5031, $28 \mathrm{p}$.

Shirmohammadi, A., I. Chaubey, R. D. Harmel, D. D. Bosch, R. Munoz-Carpena, C. Dharmasri, A. Sexton, M. Arabi, M. L.Wolfe, J. Frankenberger, C. Graff, and T. M. Sohrabi. 2006. Uncertainty in TMDL models. Trans. ASABE 49(4): 10331049.

Smith, Josh E. "Merced Irrigation District Could Reverse Limits." Merced Sun Star. N.p., 21 Mar. 2012. Web. 19 Apr. 2012. $<$ http://www.mercedsunstar.com/2012/03/21/2277720/water-fight-under-waymerced-irrigation.html>.

State Water Resources Control Board. "Total Maximum Daily Load Program." California Environmental Protection Agency, n.d. Web. 27 Oct. 2012. $<$ http://www.waterboards.ca.gov/water_issues/programs/tmdl/background.shtml>.

State Water Resources Control Board (SWRCB) "Report on San Joaquin Valley Agricultursal Drainage." Report on San Joaquin Valley Agricultursal Drainage. 4 Aug. 1999. Web. 25 Oct. 2012. <http://www.waterboards.ca.gov/board_info/agendas/1999/august/0804-08.htm>.

Stewart, G. R., C. L. Munster, D. M. Vietor, J. G. Arnold, A. M. S. McFarland, R. White, and T. Provin. 2006. Simulating water quality improvements in the upper North Bosque River watershed due to phosphorus export through turfgrass sod. Trans. ASABE 49(2): 357-366.

Stringfellow, William T. et al. "Comparison of wetland and agriculture drainage as sources of biochemical oxygen demand to the San Joaquin River, California." Agricultural Water Management 95.5 (2008): 527-538. Web. 17 Jan. 2012. 
Umbach, Kenneth W. San Joaquin Valley: Selected Statistics on Population, Economy, and Environment. Sacramento: California Research Bureau, California State Library, 2002; www.library.ca.gov/crb/02/10/02-010.pdf.

United States. Bureau of Reclamation. Central Valley Basin; a Comprehensive Report on the Development of the Water and Related Resources of the Central Valley Basin for Irrigation, Power Production and Other Beneficial Uses in California, and Comments by the State of California and Federal Agencies. Washington: U.S. Govt. Print. Off., 1949. Print.

Van Griensven, A. 2005. Sensitivity, auto-calibration, uncertainty and model evaluation in SWAT2005. Unpublished report.

Van Liew, Michael W., and Tamie L. Veith. Guidelines for Using the Sensitivity Analysis and Auto-calibration Tools for Multi-gage or Multi-step Calibration in SWAT. Department of Biological Systems Engineering. 2010. University of NebraskaLincoln.

Winchell, M., R. Srinivasan, M. Di Luzio, and J. Arnold. ArcSWAT 2.3.4 Interface For SWAT2005: User's Guide. 2009. MS. Texas A\&M University, Temple. Soil and Water Assessment Tool. Blackland Research Center, Sept. 2009. Web. $<$ http://swatmodel.tamu.edu/software/arcswat/>. 


\section{APPENDIX}

Table 17 Monthly Diversion Values

MONTHLY DIVERSION VALUES (cfs \& $10^{4} \mathrm{~m}^{3} /$ day)

\begin{tabular}{cccccccccccc}
\hline \hline & \multicolumn{3}{c}{ Oakdale Canal (Stanislaus River) } & \multicolumn{8}{c}{ Subbasin 11} \\
Jan & Feb & Mar & Apr & May & Jun & Jul & Aug & Sep & Oct & Nov & Dec \\
\hline 1.46 & 1.9 & 48.6 & 224 & 354 & 374 & 379 & 348 & 261 & 99 & 4.32 & 0.9 \\
0.4 & 0.5 & 11.9 & 54.8 & 86.6 & 91.5 & 92.7 & 85.1 & 63.9 & 24.2 & 1.1 & 0.2
\end{tabular}

Modesto Canal (Tuolumne River)

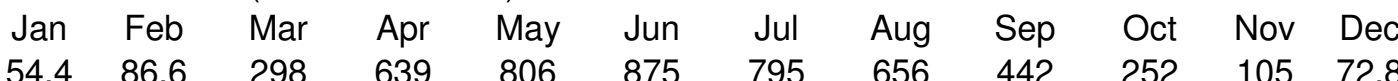

Turlock Canal (Tuolumne River)

Jan Feb Mar Apr May Jun Jul Aug Sep Oct Nov Dec

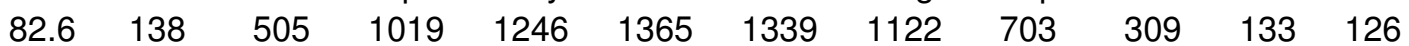

\begin{tabular}{cccccccccccc} 
& \multicolumn{4}{c}{ Total Tuolumne River } & \multicolumn{1}{c}{ Subbasin 13 } \\
Jan & Feb & Mar & Apr & May & Jun & Jul & Aug & Sep & Oct & Nov & Dec \\
\hline 137 & 225 & 803 & 1658 & 2052 & 2240 & 2134 & 1778 & 1145 & 561 & 238 & 199 \\
33.5 & 55.0 & 196.5 & 405.6 & 502.0 & 548.0 & 522.1 & 435.0 & 280.1 & 137.3 & 58.2 & 48.6
\end{tabular}

\section{Northside Canal discharge (Merced River) Subbasin 23}

\begin{tabular}{cccccccccccc}
\hline Jan & Feb & Mar & Apr & May & Jun & Jul & Aug & Sep & Oct & Nov & Dec \\
\hline 2.5 & 2 & 8.7 & 34 & 51 & 55 & 61 & 54 & 31 & 13 & 4.4 & 4 \\
0.6 & 0.5 & 2.1 & 8.3 & 12.5 & 13.5 & 14.9 & 13.2 & 7.6 & 3.2 & 1.1 & 1.0
\end{tabular}

Friant-Kern Canal (San Joaquin)

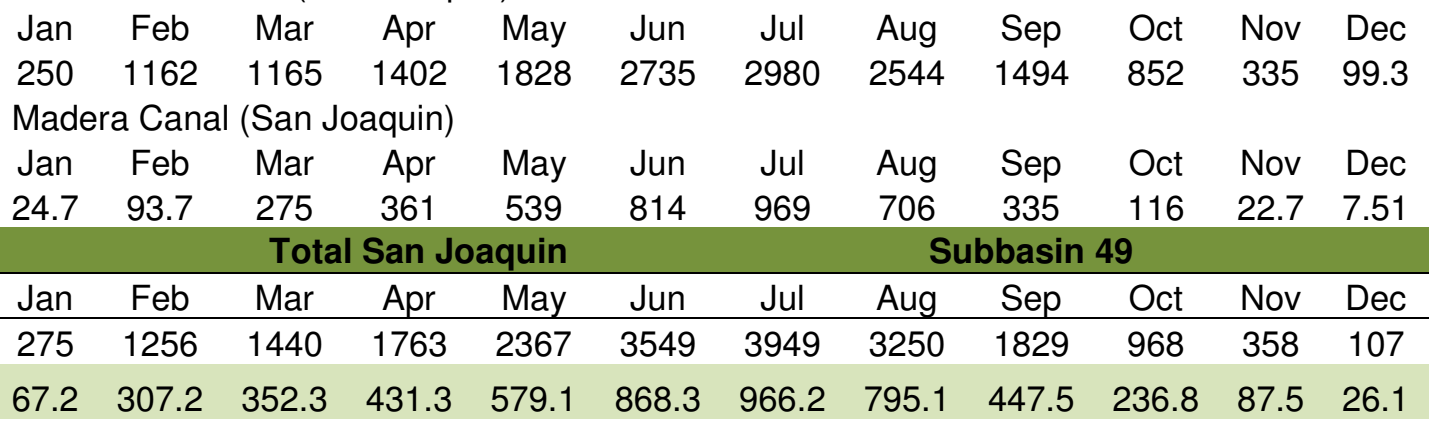

\begin{tabular}{cccccccccccc}
\multicolumn{4}{c}{ Patterson Irrigation District } & \multicolumn{1}{c}{ Subbasin 18 } \\
Jan & Feb & Mar & Apr & May & Jun & Jul & Aug & Sep & Oct & Nov & Dec \\
\hline 0 & 0 & 12 & 90 & 140 & 135 & 141 & 129 & 64 & 10 & 0 & 0 \\
0.0 & 0.0 & 2.9 & 22.0 & 34.3 & 33.0 & 34.5 & 31.6 & 15.7 & 2.4 & 0.0 & 0.0
\end{tabular}

\begin{tabular}{cccccccccccc}
\multicolumn{1}{c}{ West Stanislaus Irrigation District } & \multicolumn{1}{c}{ Subbasin 15 } \\
\hline Jan & Feb & Mar & Apr & May & Jun & Jul & Aug & Sep & Oct & Nov & Dec \\
\hline 14 & 3 & 24 & 98 & 155 & 150 & 170 & 128 & 59 & 14 & 12 & 16 \\
3.4 & 0.7 & 5.9 & 24.0 & 37.9 & 36.7 & 41.6 & 31.3 & 14.4 & 3.4 & 2.9 & 3.9
\end{tabular}


Table 18 Land Use Diversion :: Area Per County

LAND USE DIVISION:: AREA PER COUNTY

\begin{tabular}{|c|c|c|c|c|c|c|c|c|c|}
\hline \multicolumn{2}{|c|}{ Stanislaus } & \multicolumn{2}{|c|}{ Merced } & \multicolumn{2}{|c|}{ Madera } & \multicolumn{2}{|c|}{ Fresno } & \multicolumn{2}{|c|}{ San Joaquin } \\
\hline TOTAL & 309799 & TOTAL & 493092 & TOTAL & 309749 & TOTAL & 1227851 & TOTAL & 484630 \\
\hline C & 666 & C & 360 & C & 6644 & C & 36241 & C & 263 \\
\hline $\mathrm{D}$ & 137954 & $\mathrm{D}$ & 115434 & $\mathrm{D}$ & 90563 & $D$ & 180504 & $\mathrm{D}$ & 105298 \\
\hline F6 & 52767 & F1 & 88288 & F1 & 46389 & $\mathrm{~F} 1$ & 303505 & $\mathrm{~F} 2$ & 18629 \\
\hline F8 & 1303 & $\mathrm{~F} 2$ & 2130 & F6 & 15189 & $\mathrm{~F} 2$ & 3368 & F5 & 6503 \\
\hline F10 & 37618 & F5 & 8292 & F10 & 9345 & F5 & 18674 & F6 & 72547 \\
\hline $\mathrm{P} 1$ & 34564 & F6 & 57412 & $\mathrm{P} 1$ & 35186 & F6 & 32073 & F7 & 596 \\
\hline $\mathrm{R}$ & 2946 & F8 & 3496 & P3 & 11529 & F7 & 202 & F8 & 1126 \\
\hline T9 & 5341 & F10 & 14196 & $\mathrm{R}$ & 427 & F8 & 5539 & F10 & 16633 \\
\hline T13 & 1561 & P1 & 81428 & T9 & 1355 & F10 & 7134 & F12 & 1570 \\
\hline T15 & 15442 & P3 & 59682 & T10 & 1999 & $\mathrm{~F} 2$ & 66192 & $\mathrm{~F} 2$ & 2550 \\
\hline T16 & 1248 & $\mathrm{R}$ & 5623 & $\mathrm{~T} 18$ & 101 & $\mathrm{P} 1$ & 98942 & $\mathrm{P} 1$ & 61224 \\
\hline T18 & 1100 & T9 & 10824 & V & 91020 & P3 & 13729 & P3 & 32640 \\
\hline $\mathrm{T} 21$ & 589 & $\mathrm{~T} 13$ & 6409 & & & $\mathrm{R}$ & 6522 & $\mathrm{R}$ & 5990 \\
\hline T24 & 955 & T15 & 19680 & & & T2 & 2811 & T2 & 22774 \\
\hline \multirow[t]{11}{*}{ V } & 15744 & T20 & 1046 & & & T8 & 1225 & T9 & 8721 \\
\hline & & V & 18795 & & & T9 & 36010 & T10 & 1356 \\
\hline & & & & & & T10 & 28308 & T12 & 3602 \\
\hline & & & & & & T15 & 114940 & T15 & 38845 \\
\hline & & & & & & T16 & 1279 & T16 & 1319 \\
\hline & & & & & & T17 & 6319 & T17 & 773 \\
\hline & & & & & & T18 & 3177 & T18 & 745 \\
\hline & & & & & & T21 & 2775 & T20 & 283 \\
\hline & & & & & & V & 258382 & $\mathrm{~T} 21$ & 2878 \\
\hline & & & & & & & & AGGR & 898 \\
\hline & & & & & & & & V & 76866 \\
\hline
\end{tabular}

**Land Use definitions are available from (DWR 1993). 
Table 19 Combined Division of Area

\begin{tabular}{|c|c|c|c|}
\hline \multirow[b]{2}{*}{ CDEC ID } & \multicolumn{2}{|c|}{ DIVISIONO } & A RE A \\
\hline & Total Area & $\begin{array}{c}\text { SWAT } \\
\text { Equivalent }\end{array}$ & Percentage \\
\hline$C \& D$ & 673927.228 & ORCD & 24 \\
\hline $\mathrm{F} 1$ & 438181.348 & COTS & 16 \\
\hline F5 & 33469.443 & SGBT & 1 \\
\hline F6 & 229988.571 & CORN & 8 \\
\hline F7 & 798.041 & GRSG & 0 \\
\hline F8/F9/F10 & 96389.49 & GRBN & 3 \\
\hline F12 & 1570.204 & SUNF & 0 \\
\hline P1 & 311344.44 & ALFA & 11 \\
\hline P3/P4 & 117580.38 & PAST & 4 \\
\hline $\mathrm{R}$ & 21508.158 & RICE & 1 \\
\hline $\mathrm{T} 2$ & 25584.994 & ASPR & 1 \\
\hline T8 & 1224.522 & LETT & 0 \\
\hline T9 & 62250.868 & WMEL & 2 \\
\hline T10 & 31662.154 & ONIO & 1 \\
\hline $\mathrm{T} 12$ & 3601.559 & POTA & 0 \\
\hline T13 & 7970.012 & SPOT & 0 \\
\hline T15 & 188907.045 & TOMA & 7 \\
\hline T16 & 3845.646 & FRST & 0 \\
\hline T20 & 1328.41 & STRW & 0 \\
\hline T21 & 6242.44 & PEPR & 0 \\
\hline T24 & 954.928 & CAUF & 0 \\
\hline T17/T18/F2/V & 102615.18 & AGRR & 4 \\
\hline $\mathrm{V}$ & 460807.538 & VINE & 16 \\
\hline T17 & 7092.469 & AGRR & \\
\hline T18 & 5123.617 & AGRR & \\
\hline & 898.41 & AGRR & \\
\hline F2 & 89500.684 & AGRR & \\
\hline
\end{tabular}


Table 20 SWAT Parameter Definitions

SWAT PARAMETER DEFINITIONS

\begin{tabular}{|c|c|c|}
\hline Parameter & $\begin{array}{l}\text { File } \\
\text { Name }\end{array}$ & Explanation \\
\hline ALPHA_BF &.$g w$ & Baseflow alpha factor [days] \\
\hline BIOMIX & .mgt & Biological mixing efficiency \\
\hline BLAI & crop.dat & Maximum potential leaf area index crop \\
\hline CANMX &.$h r u$ & Maximum canopy storage $[\mathrm{mm}$ \\
\hline $\mathrm{CH}$-K2 & rte & Channel effective hydraulic conductivity [mm/hr] \\
\hline $\mathrm{CH}_{-} \mathrm{N} 2$ & rte & Manning's n-value for main channel \\
\hline CN2 & .mgt & Initial SCS CN II value \\
\hline EPCO & hru & Plant uptake compensation factor \\
\hline ESCO &.$h r u$ & Soil evaporation compensation factor \\
\hline GW_DELAY &.$g w$ & Groundwater delay [days] \\
\hline GWNOH &.$g w$ & Concentration of nitrate in groundwater contribution [mg N/l] \\
\hline GW_REVAP &.$g w$ & Groundwater "revap" coefficient \\
\hline QWQMN &.$g w$ & Threshold water depth in the shallow aquifer for flow [mm] \\
\hline RCHRG_DP &.$g w$ & Deep aquifer percolation fraction \\
\hline REVAPMN &.$g w$ & Threshold water depth in the shallow aquifer for "revap" [mm] \\
\hline SLOPE &. hru & Average slope steepness $[\mathrm{m} / \mathrm{m}]$ \\
\hline SLSUBBSN & .hru & Average slope length $[\mathrm{m}]$ \\
\hline SOL_ALB & sol & Moist soil albedo \\
\hline SOL_AWC & sol & Available water capacity [mm H20/mm soil] \\
\hline SOL_K & sol & Saturated hydraulic conductivity $[\mathrm{mm} / \mathrm{hr}]$ \\
\hline SOL_LABP &.$c h m$ & Initial labile P concentration [mg/kg] \\
\hline SOL_ORGN &.$c h m$ & Initial organic $\mathrm{N}$ concentration $[\mathrm{mg} / \mathrm{kg}]$ \\
\hline SOL_ORGP &.$c h m$ & Initial organic $P$ concentration $[\mathrm{mg} / \mathrm{kg}]$ \\
\hline SOL_NO3 &.$c h m$ & Initial $\mathrm{N}_{3}$ concentration $[\mathrm{mg} / \mathrm{kg}]$ \\
\hline SOL_Z & sol & Soil depth $[\mathrm{mm}]$ \\
\hline SURLAG & .bsn & Surface runoff lag time [days] \\
\hline TLAPS & sub & Temperature lapse rate $\left[{ }^{\circ} \mathrm{C} / \mathrm{km}\right]$ \\
\hline USLE_P & mgt & USLE support practice factor \\
\hline SPCON &.$b s n$ & Lin. re-entrainment parameter for channel sediment routing \\
\hline SPEXP &.$b s n$ & Exp. re-entrainment parameter for channel sediment routing \\
\hline SMFMX &.$b s n$ & Melt factor for snow on June 21 [mm H2O/ㅇ-day] \\
\hline SMFMN &.$b s n$ & Melt factor for snow on December 21 [mm H2O/ㅇ-day] \\
\hline SFTMP &.$b s n$ & Snowfall temperature $\left[{ }^{\circ} \mathrm{C}\right]$ \\
\hline SMTMP & bsn & Snow melt base temperature $\left[{ }^{\circ} \mathrm{C}\right]$ \\
\hline TIMP & .bsn & Snow pack temperature lag \\
\hline NPERCO &.$b s n$ & Nitrogen percolation coefficient \\
\hline PPERCO & .bsn & Phosphorus percolation coefficient \\
\hline PHOSKD & .bsn & Phosphorus soil partitioning coefficient \\
\hline CH_EROD & .rte & Channel erodibility factor \\
\hline $\mathrm{CH}_{-} \mathrm{COOV}$ & .rte & Channel cover factor \\
\hline USLEE_C & crop.dat & Minimum USLE cover factor crop \\
\hline
\end{tabular}


Table 21 Snow Elevation Subbasins

\begin{tabular}{|c|c|c|c|c|c|c|c|}
\hline \multicolumn{8}{|c|}{ SNOW } \\
\hline \multicolumn{4}{|c|}{ Subbasin 1} & \multicolumn{4}{|c|}{ Subbasin 2} \\
\hline \multicolumn{2}{|c|}{ Elevation } & \multicolumn{2}{|c|}{ SWE } & \multicolumn{2}{|c|}{ Elevation } & \multicolumn{2}{|c|}{ SWE } \\
\hline $\mathbf{m}$ & $\mathbf{f t}$ & inches & $\mathrm{mm}$ & $\mathbf{m}$ & $\mathbf{f t}$ & inches & $\mathbf{m m}$ \\
\hline 2869 & 9411 & 22 & 551 & 528 & 1731 & 5 & 134 \\
\hline 2606 & 8548 & 20 & 507 & 843 & 2764 & 7 & 181 \\
\hline 2343 & 7685 & 18 & 463 & 1158 & 3798 & 9 & 229 \\
\hline 2080 & 6823 & 16 & 419 & 1473 & 4831 & 11 & 276 \\
\hline 1817 & 5960 & 15 & 375 & 1788 & 5865 & 13 & 323 \\
\hline 1554 & 5097 & 13 & 331 & 2103 & 6898 & 15 & 370 \\
\hline 1291 & 4234 & 11 & 288 & 2418 & 7931 & 16 & 418 \\
\hline 1028 & 3371 & 10 & 244 & 2733 & 8965 & 18 & 465 \\
\hline 765 & 2508 & 8 & 200 & 3048 & 9998 & 20 & 512 \\
\hline 502 & 1645 & 6 & 156 & 3363 & 11032 & 22 & 559 \\
\hline \multicolumn{4}{|c|}{ Subbasin 3} & \multicolumn{4}{|c|}{ Subbasin 4} \\
\hline \multicolumn{2}{|c|}{ Elevation } & \multicolumn{2}{|c|}{ SWE } & \multicolumn{2}{|c|}{ Elevation } & \multicolumn{2}{|c|}{ SWE } \\
\hline $\mathbf{m}$ & $\mathbf{f t}$ & inches & $\mathrm{mm}$ & $\mathbf{m}$ & $\mathrm{ft}$ & inches & $\mathrm{mm}$ \\
\hline 786 & 2579 & 7 & 174 & 810 & 2658 & 4 & 98 \\
\hline 1049 & 3440 & 9 & 233 & 1154 & 3785 & 6 & 141 \\
\hline 1311 & 4301 & 12 & 292 & 1488 & 4880 & 7 & 183 \\
\hline 1573 & 5162 & 14 & 351 & 1821 & 5975 & 9 & 225 \\
\hline 1836 & 6023 & 16 & 410 & 2155 & 7071 & 10 & 266 \\
\hline 2098 & 6884 & 18 & 470 & 2489 & 8166 & 12 & 308 \\
\hline 2361 & 7745 & 21 & 529 & 2823 & 9261 & 14 & 350 \\
\hline 2623 & 8606 & 23 & 588 & 3157 & 10356 & 15 & 392 \\
\hline 2885 & 9467 & 25 & 647 & 3490 & 11451 & 17 & 433 \\
\hline 3148 & 10327 & 28 & 706 & 3824 & 12546 & 19 & 475 \\
\hline \multicolumn{4}{|c|}{ Subbasin 5} & \multicolumn{4}{|c|}{ Subbasin 6} \\
\hline \multicolumn{2}{|c|}{ Elevation } & \multicolumn{2}{|c|}{ SWE } & \multicolumn{2}{|c|}{ Elevation } & \multicolumn{2}{|c|}{ SWE } \\
\hline $\mathbf{m}$ & $\mathbf{f t}$ & inches & $\mathrm{mm}$ & $\mathbf{m}$ & $\mathbf{f t}$ & inches & $\mathrm{mm}$ \\
\hline 477 & 1565 & 4 & 105 & 517 & 1697 & 4 & 114 \\
\hline 725 & 2378 & 6 & 160 & 684 & 2243 & 6 & 151 \\
\hline 973 & 3191 & 9 & 216 & 850 & 2790 & 7 & 189 \\
\hline 1220 & 4004 & 11 & 272 & 1017 & 3336 & 9 & 226 \\
\hline 1468 & 4817 & 13 & 328 & 1183 & 3882 & 10 & 264 \\
\hline 1716 & 5630 & 15 & 383 & 1350 & 4428 & 12 & 301 \\
\hline 1964 & 6443 & 17 & 439 & 1516 & 4975 & 13 & 339 \\
\hline 2212 & 7256 & 19 & 495 & 1683 & 5521 & 15 & 376 \\
\hline 2459 & 8069 & 22 & 551 & 1849 & 6067 & 16 & 413 \\
\hline 2707 & 8882 & 24 & 607 & 2016 & 6613 & 18 & 451 \\
\hline \multicolumn{4}{|c|}{ Subbasin 7} & \multicolumn{4}{|c|}{ Subbasin 8} \\
\hline \multicolumn{2}{|c|}{ Elevation } & sW & & & tion & SW & \\
\hline $\mathbf{m}$ & $\mathbf{f t}$ & inches & $\mathrm{mm}$ & $\mathbf{m}$ & $\mathbf{f t}$ & inches & $\mathrm{mm}$ \\
\hline 388 & 1273 & 3 & 85 & 559 & 1835 & 0 & 12 \\
\hline 460 & 1510 & 4 & 101 & 810 & 2657 & 1 & 32 \\
\hline 533 & 1747 & 5 & 117 & 1061 & 3479 & 2 & 61 \\
\hline
\end{tabular}




$\begin{array}{cccccccc}605 & 1984 & 5 & 133 & 1311 & 4302 & 4 & 99 \\ 677 & 2221 & 6 & 150 & 1562 & 5124 & 6 & 147 \\ 749 & 2458 & 7 & 166 & 1812 & 5946 & 8 & 203 \\ 821 & 2695 & 7 & 182 & 2063 & 6768 & 11 & 268 \\ 894 & 2931 & 8 & 198 & 2314 & 7590 & 13 & 343 \\ 966 & 3168 & 8 & 215 & 2564 & 8412 & 17 & 426 \\ 1038 & 3405 & 9 & 231 & 2815 & 9235 & 20 & 519\end{array}$

Subbasin 9

\begin{tabular}{ccccc}
\hline \multicolumn{2}{c}{ Elevation } & & \multicolumn{2}{c}{ SWE } \\
\cline { 1 - 2 } \cline { 5 - 5 } $\mathbf{m}$ & $\mathbf{f t}$ & & inches & $\mathbf{m m}$ \\
\hline 601 & 1973 & & 1 & 15 \\
958 & 3144 & & 2 & 48 \\
1315 & 4315 & & 4 & 100 \\
1672 & 5486 & & 7 & 170 \\
2029 & 6657 & & 10 & 259 \\
2386 & 7828 & & 14 & 366 \\
2743 & 8999 & & 19 & 491 \\
3100 & 10170 & & 25 & 635 \\
3457 & 11341 & & 31 & 797 \\
3814 & 12512 & & 39 & 978
\end{tabular}

Subbasin 17

\begin{tabular}{|c|c|c|c|c|c|c|c|}
\hline \multicolumn{2}{|c|}{ Elevation } & \multicolumn{2}{|c|}{ SWE } & \multicolumn{2}{|c|}{ Elevation } & \multicolumn{2}{|c|}{ SWE } \\
\hline $\mathbf{m}$ & $\mathbf{f t}$ & inches & $\mathrm{mm}$ & $\mathbf{m}$ & $\mathbf{f t}$ & inches & $\mathrm{mm}$ \\
\hline 1272 & 4173 & 2 & 40 & 1249 & 4097 & 6 & 162 \\
\hline 1560 & 5118 & 4 & 106 & 1490 & 4889 & 9 & 217 \\
\hline 1848 & 6063 & 7 & 173 & 1732 & 5682 & 11 & 273 \\
\hline 2136 & 7008 & 9 & 240 & 1973 & 6474 & 13 & 329 \\
\hline 2424 & 7953 & 12 & 306 & 2215 & 7266 & 15 & 385 \\
\hline 2712 & 8898 & 15 & 373 & 2456 & 8059 & 17 & 441 \\
\hline 3000 & 9843 & 17 & 439 & 2698 & 8851 & 20 & 496 \\
\hline 3288 & 10787 & 20 & 506 & 2939 & 9643 & 22 & 552 \\
\hline 3576 & 11732 & 23 & 572 & 3181 & 10436 & 24 & 608 \\
\hline 3864 & 12677 & 25 & 639 & 3422 & 11228 & 26 & 664 \\
\hline
\end{tabular}

Subbasin 49

\begin{tabular}{ccccc}
\hline \multicolumn{2}{c}{ Elevation } & & \multicolumn{2}{c}{ SWE } \\
\cline { 1 - 2 } \cline { 5 - 5 } $\mathbf{m}$ & $\mathbf{f t}$ & & inches & $\mathbf{m m}$ \\
\hline 208 & 682 & & 0 & 0 \\
528 & 1731 & & 0 & 0 \\
848 & 2781 & & 0 & 0 \\
1167 & 3830 & & 1 & 16 \\
1487 & 4879 & & 4 & 90 \\
1807 & 5928 & & 6 & 164 \\
2127 & 6977 & & 9 & 237 \\
2447 & 8027 & & 12 & 311 \\
2766 & 9076 & & 15 & 385 \\
3086 & 10125 & & 18 & 459
\end{tabular}

